\title{
حصر وتقييم مشروعات التنمية بمنطقة هضبة الجلالة البحرية - مصر باستخدام نظم المعلومات الجغرافية.
}

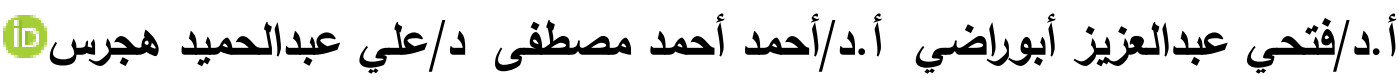

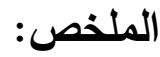

تعد المشاريع التتموية أحد وسائل تطوير المجتمعات ، وفي ظل ندرة الموارد فقد أصبح دور المشاريع التتموية أكثر أهمية وتحويل الأفكار إلي واقع علمي يعزز من تفعيل استخدام الموارد الاستخدام الأمثل ، حيث استهدف

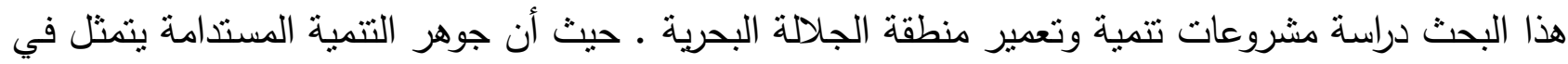
توفير احتياجات الأجيال الحالية دون التعدي علي إمكانية حصول الأجيال المقبلة علي منطلباتهم في المستقبل ، وتلك التتمية تحمل بين طياتها نحقيق الأهداف الاقتصادية والاجتماعية على أن تتسم موارد البيئة المتاحة بالاستخدام الرشيد لضمان استمرارية الاتنفاع بها مستقبلاً.

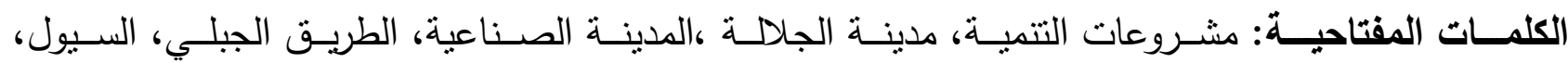
منطقة الجلالة البحرية ، نظم المعلومات الجغرافية .

\section{Monitoring and Evaluating Development Projects in the EI Galala EI}

Bahrya Plateau - Egypt Using Geographical Information Systems.

\section{Abstract:}

Development projects are considered one of the means of developing societies, In light of the scarcity of resources, the role of development projects has become more important and the transformation of ideas into a scientific reality that enhances the optimization of the use of resources, this research aims to study reconstruction projects of the El Galala El Bahrya area. Whereas the core of sustainable development is to provide the needs of the current generation without infringing on the possibility of future generations obtaining their requirements in the future, this development carries with it the achievement of economic and social goals, provided that the available environmental resources are characterized by rational use to ensure their continued use in the future.

Keywords: Development projects, El Galala city, Industrial city, Mountain road, Flash Flood, El Galala El Bahrya Area, Gis.

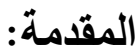

لأثكال السطح تأثيراً كبيراً على مشاريع التتمية المختلفة بمنطقة هضبة الجلالمة البحرية ، فقد تكون عاملاً

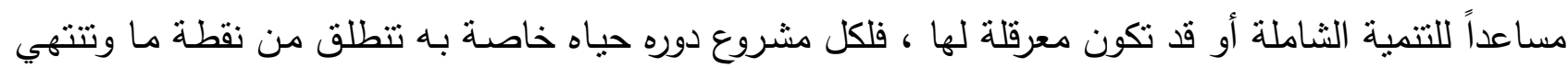

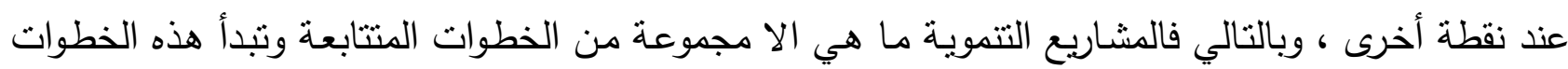

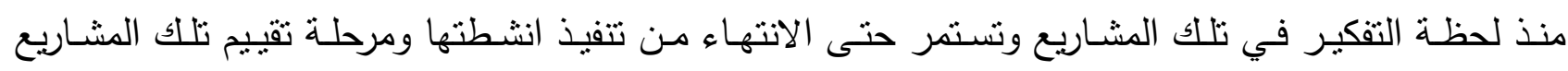
التتموية. ويعد مشروع تعمير منطقة الدراسة من المشاريع القومية للدولة ، هذا المشروع تشرف على تتفيذه الهيئة 


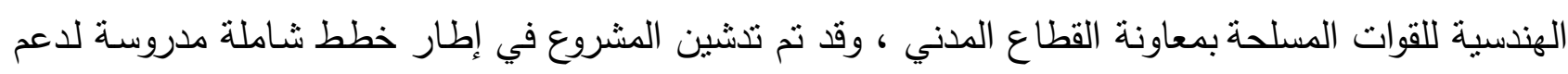

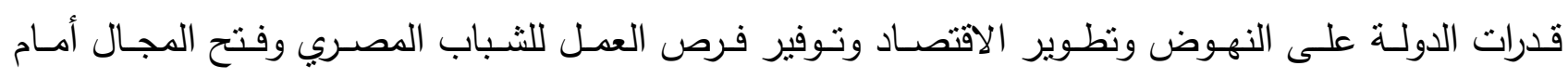

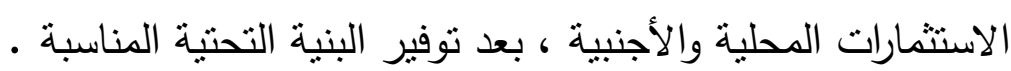

\section{موقع وحدود منطقة الدراسة:}

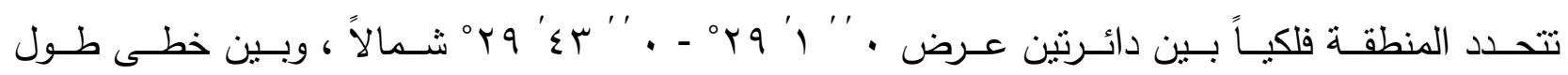

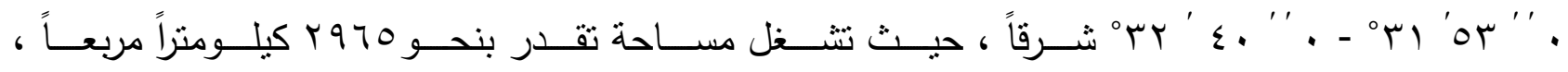

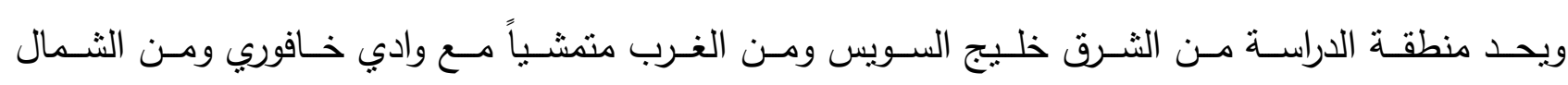

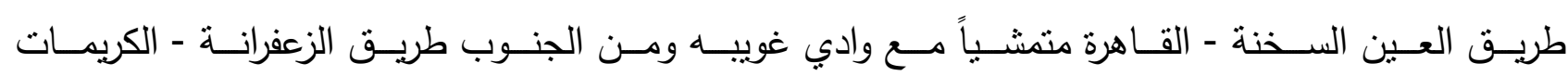

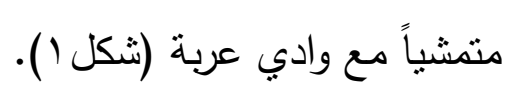
مشكلة الدراسة:

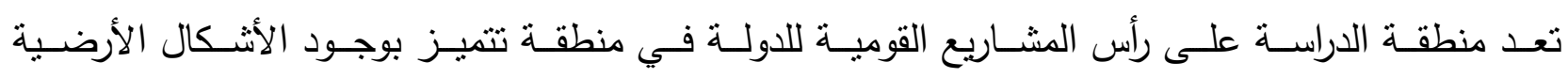

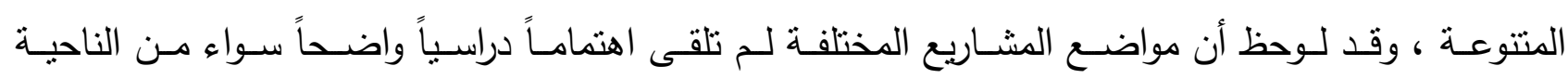

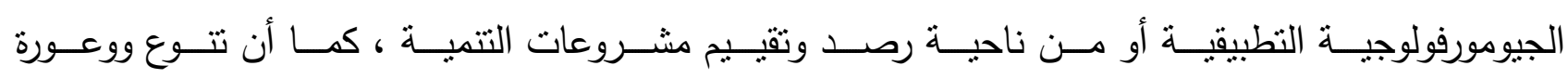

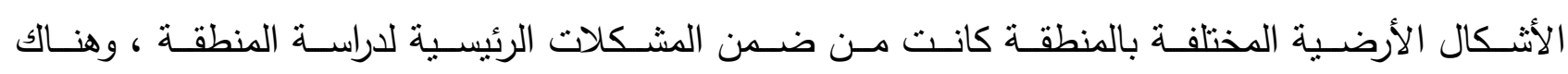

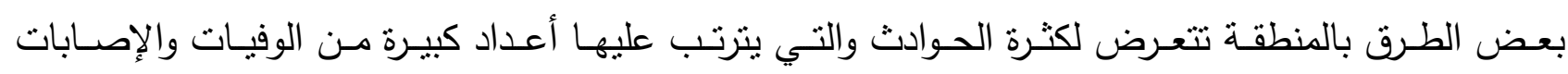

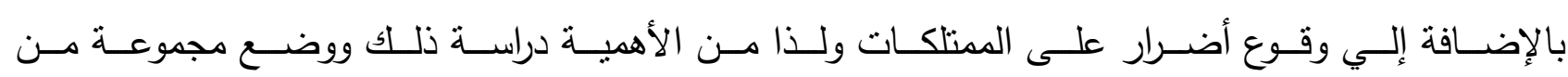
المقترحات لتفادي أخطارها.

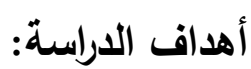

حيث أن لكل دراسة هدف يسعي الباحث إلي تحقيقه ، ومن أهم أهداف الدراسة : ا - دراسة الخصائص الطبيعية وتأثيرها على مشروعات التتمية بمنطقة هضبة الجلاهلة البلة البحرية. r - حصر وتقييم مشروعات التتمية بمنطقة الدراسة. r- توظيف واستخدام نظم المعلومات الجغرافية في حصر وتقييج مشروعات التتمية بمنطقة الدراسة. ع- محاولة الوصول إلى حلول يمكن تنفيذها لتجنب المخاطر المتكررة بمنطقة الدراسة. 


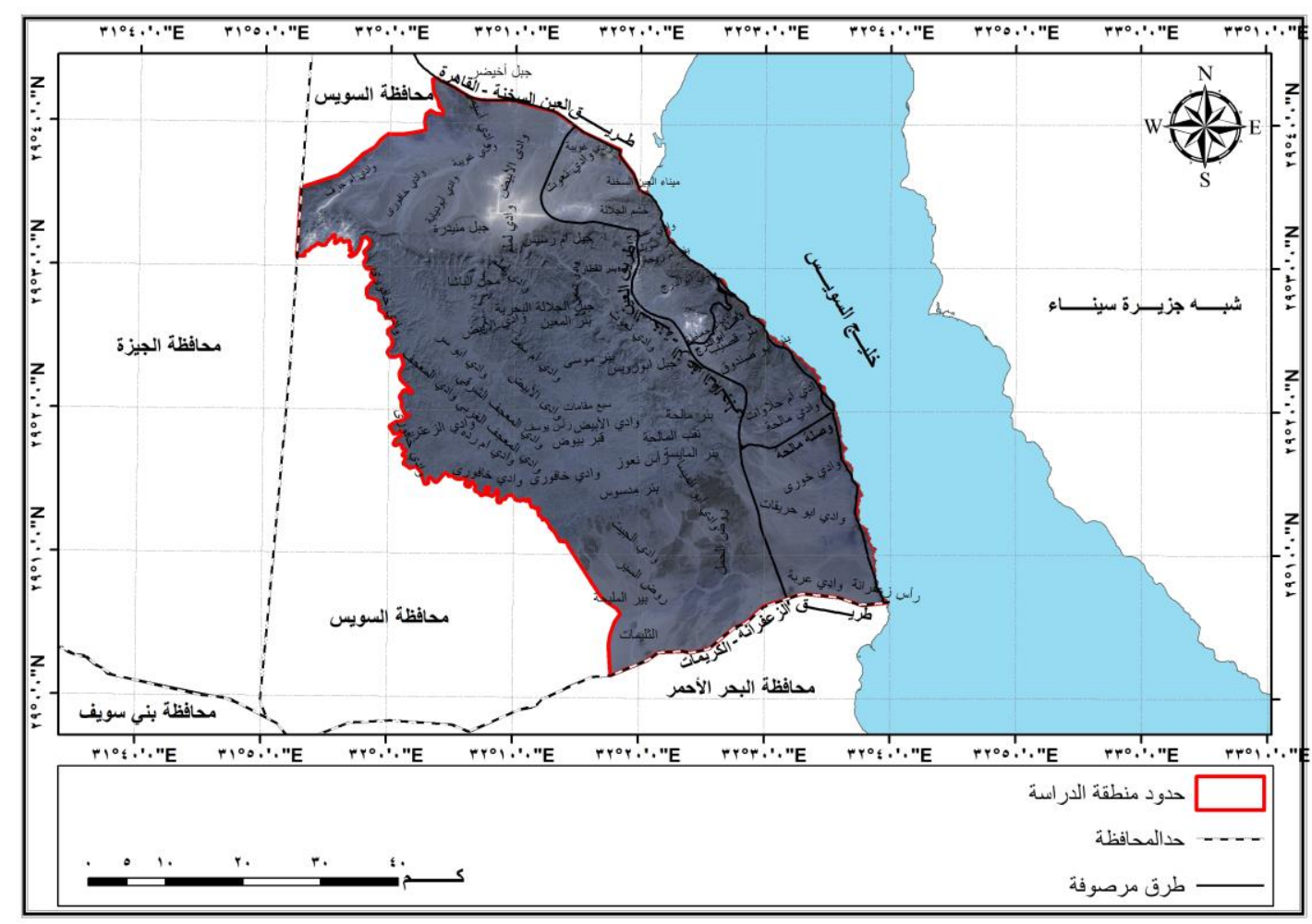

(شكل رقم ا ) موقع وحدود منطقة الاراسة على صورة فضائية للقمر الصناعي 8 Land Sat

مناهج الدراسة وأساليبها:

اعتمدت الدراسة على عدة مناهج أهمها : الدنهج التطبيقي والمنهج الوظيفي وقد تم استخدام عدة أساليب منها أسلوب التحليل الكارتوجرافي وأسلوب التحليل الكمي وأسلوب نظم المعلومات الجغرافية.

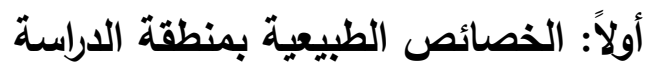
أ- الخصائص الجيولوجية الخئية

تجدر الإثارة إلي أنه كلما كان النسيج الحبيبي للصخر أثند صلابة وأقل مسامية وتأثيراً بالثقوق والفواصل

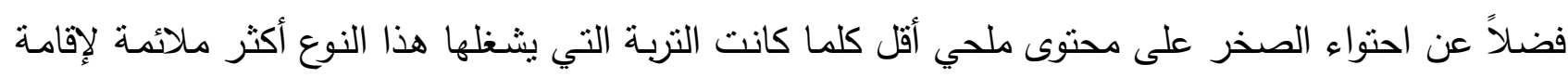

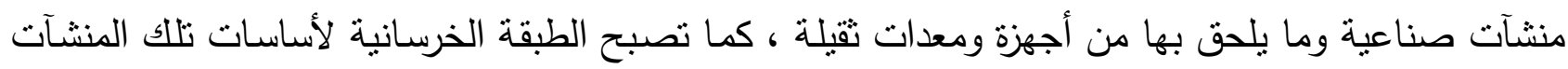

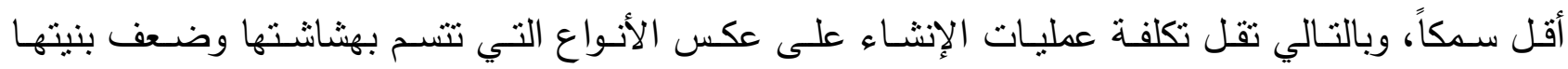

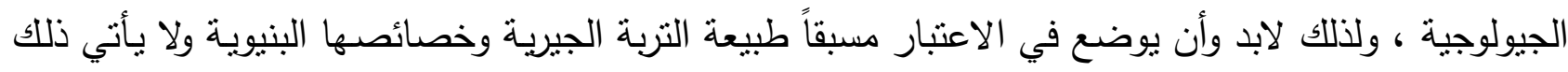

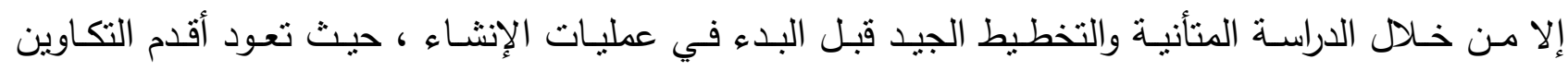

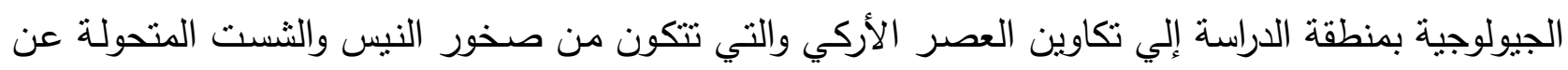

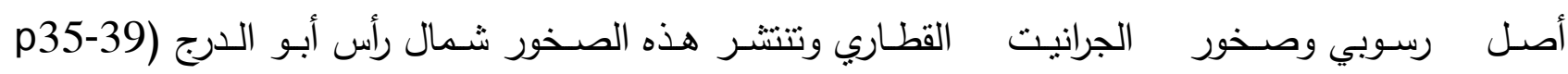
(Shurmann,1955,

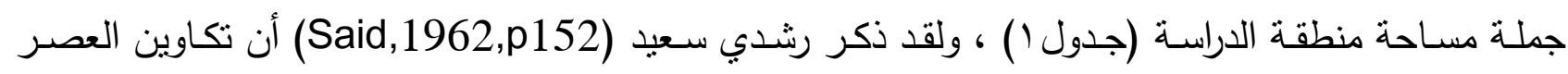
الكربوني تتكون من الحجر الرملي الغني بالحفريات ، وتظهر تكاوين الحجر الرملي الكربوني إلي الجنوب من 
العين السخنة بنحو خمسة كيلومتر علي الحافة الثرقية من منطقة خشم الجلالة وهي بذلك تمثل الركن الثمالي الثرقي من هضبة الجلالمة البحرية وتمتد هذه التكاوين على طول حضيض الحافية الثرقية لهضبة الجلالـة

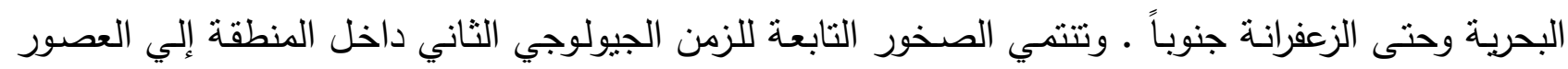

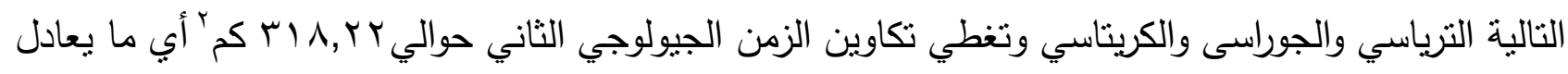

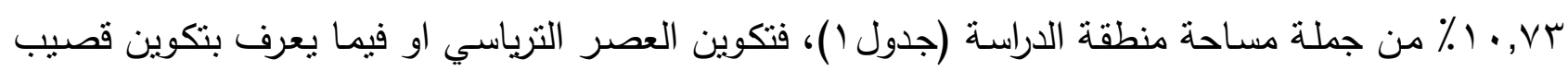

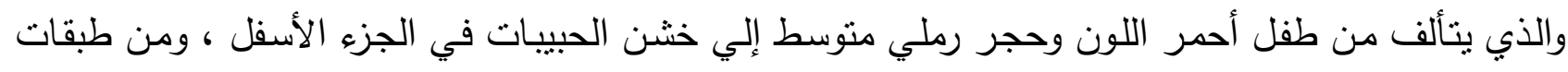

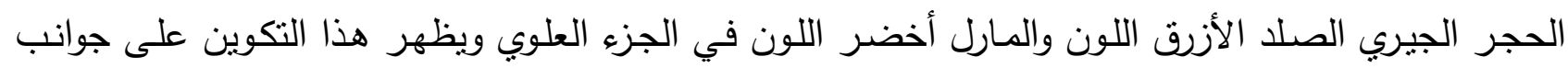

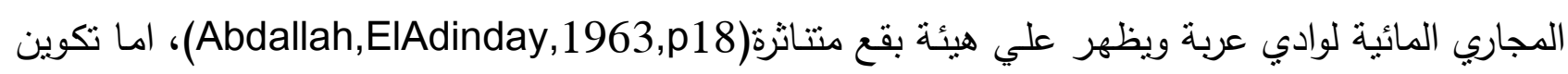

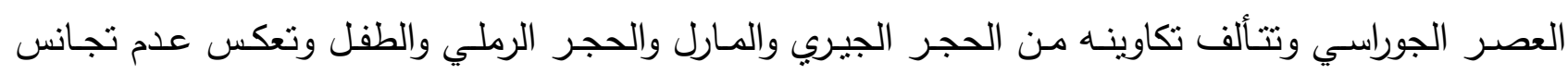

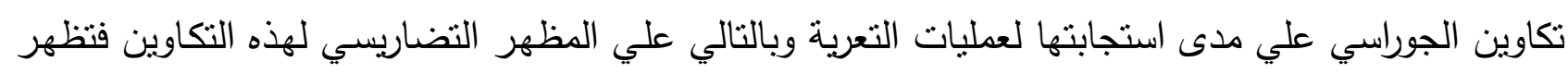

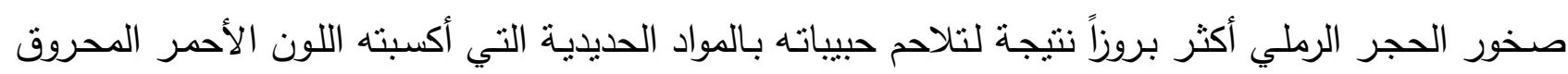

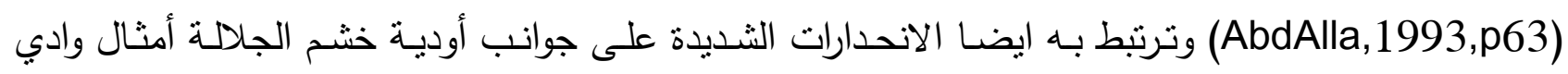

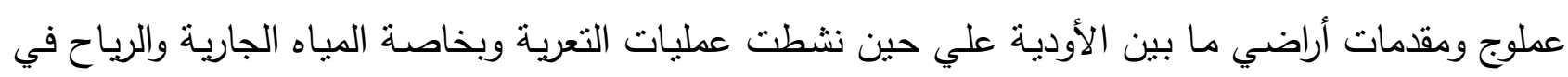

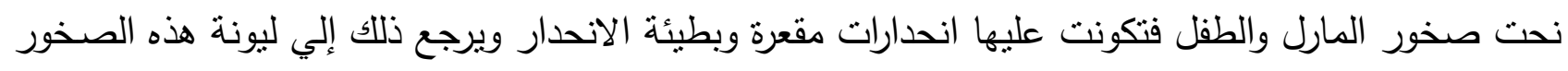

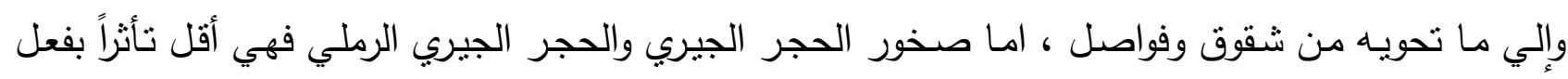

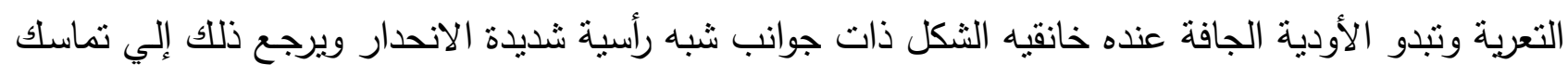

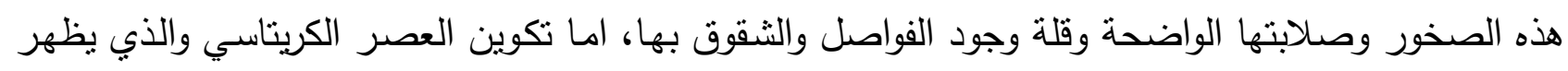

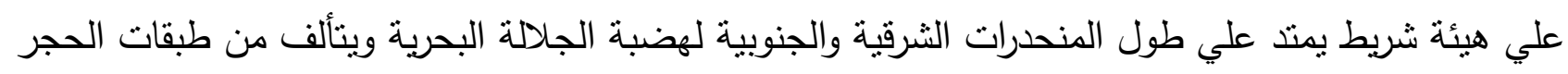
الرملي الأبيض الناعم الحبيبات والحجر الرملي الدولوميتي والحجر الرملي الحديدي مـع تبادلات من الطفل الرملي والكاولين والمارل ويحتوي علي بعض الطفل الغني بمكونات كربونية والذي ينتشر بالمنحدرات الجنوبية

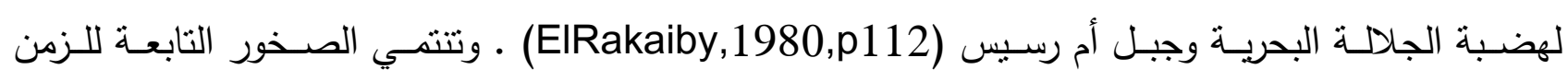

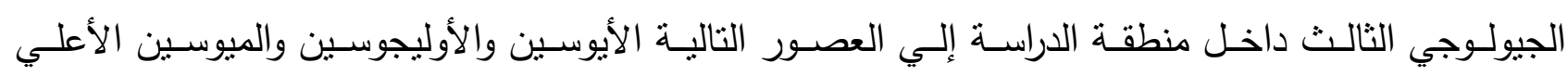

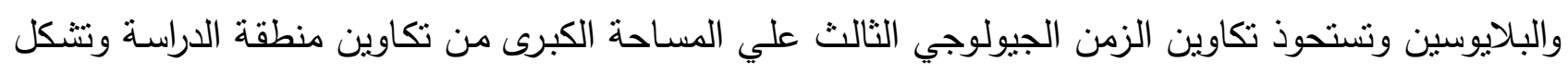

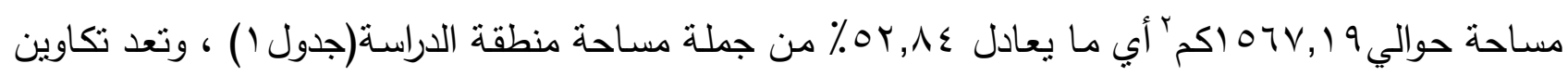

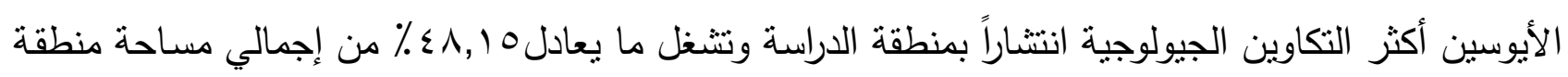

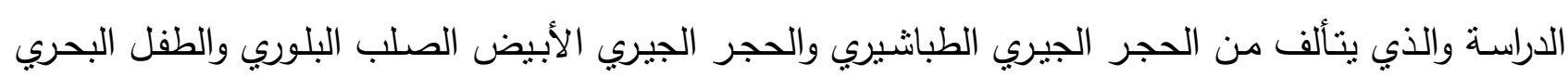

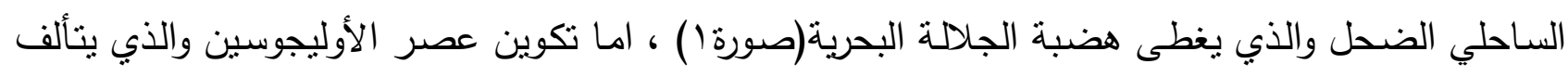

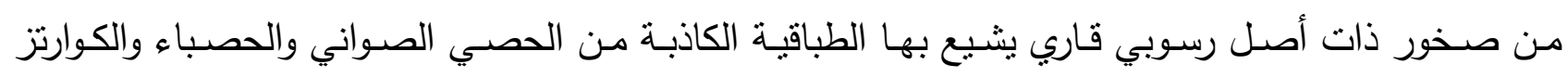

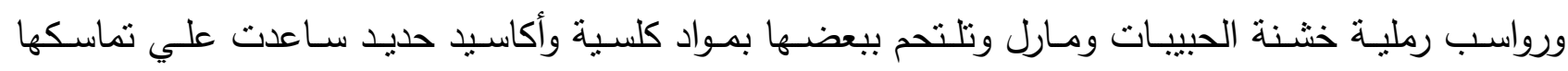

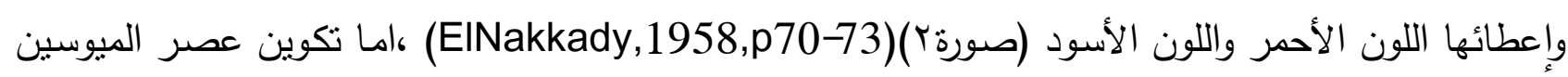


والذي يتألف من صخور الحجر الرملي والحجر الرملي الطباشيري الناصع البياض أو الوردي اللون وذلك تبعاً

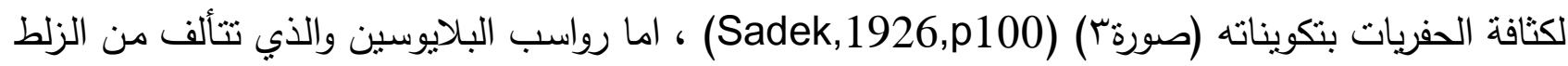

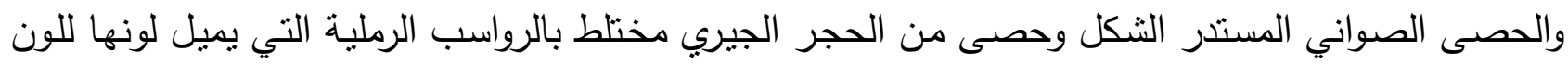

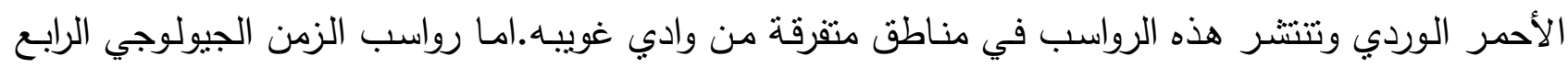

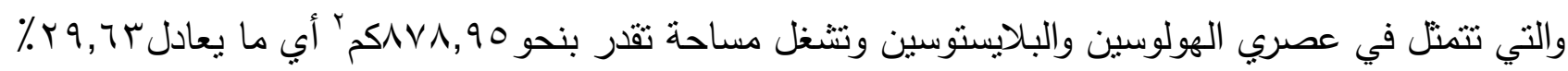

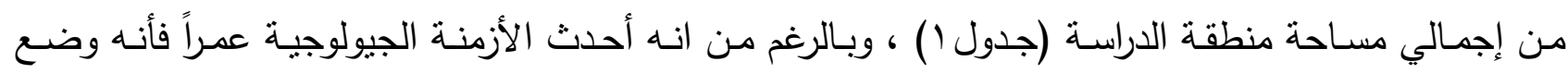

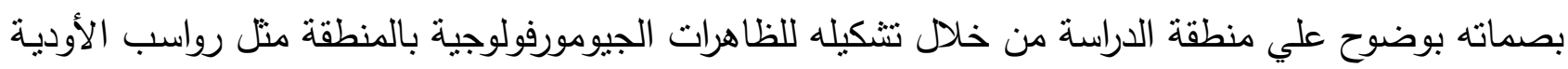

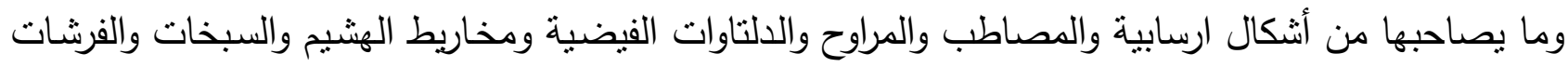

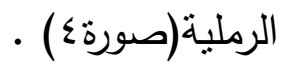
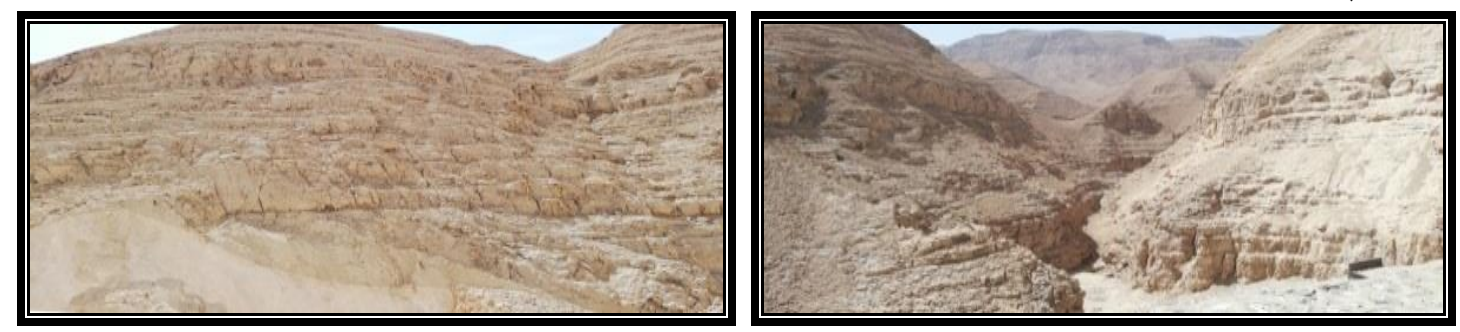

(صورة رقم ا ) التتابع الصخري لعصر الأيوسين الأوسط بمنطقة وادي أم رسيس

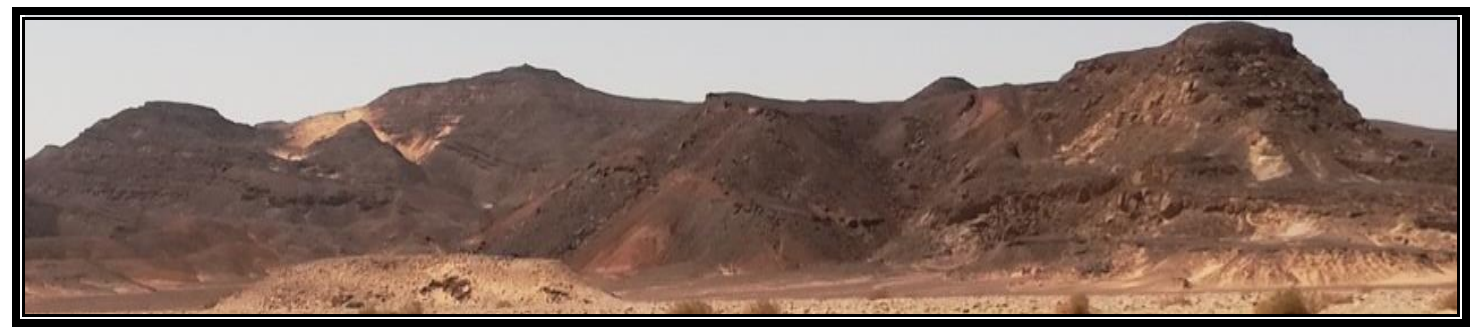

(صورة رقم r) التتابع الصخري لعصر الأوليجوسين شمال وادي الثونه أحد روافد وادي غويبه

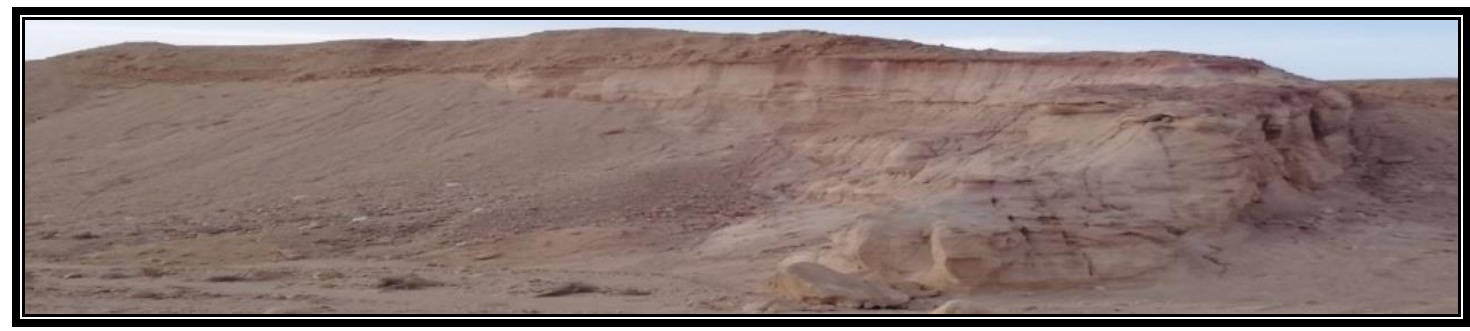

(صورة رقم ؟) التتابع الصخري لعصر الميوسين الأعلى شمال وادي أم جرف أحد روافد وادي غويبه

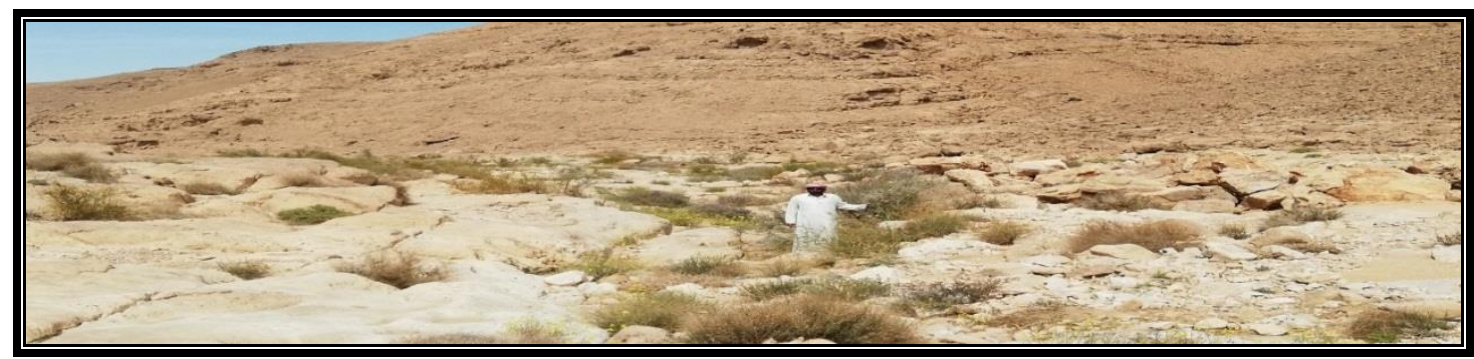

(صورة رقم ؛ ) رواسب الأودية بوادي عملوج 


\section{(جلول رقم 1) التكاوين الجيولوجية ومساحتها بمنطقة الدراسة الهو}

\begin{tabular}{|c|c|c|c|c|}
\hline النسبة \% & المساحة كم & التكوين & العصر | - العر & الزمن \\
\hline 10,29 & $\varepsilon 09, \leqslant 9$ & رواسب الأودية & \multirow{2}{*}{ البلايستوسين و الهولوسين } & \multirow{3}{*}{$\overline{\overline{3}}$} \\
\hline $1 \varepsilon, 1 \varepsilon$ & $\leqslant 19, \leqslant 0$ & 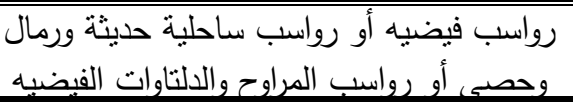 & & \\
\hline$r 9.7 r$ & $\Lambda \vee \Lambda .90$ & \multicolumn{2}{|l|}{ المجموع } & \\
\hline$\cdot, 10$ & $r_{0, \Sigma} \varepsilon r$ & رواسب البلايوسين & البلايوسبن & \multirow{7}{*}{ 弐 } \\
\hline$r, .9$ & $91, \wedge \mathrm{V}$ & تكوين حجول & الميوسين الأعلى & \\
\hline., $\mathrm{v} \mu$ & Y), 9. & تكوين جبل الأحمر & الأوليجوسين & \\
\hline $1, r 9$ & ऍ , $\Sigma\rceil$ & تكوين المعادي & الأيوسين الأعلى & \\
\hline$\varepsilon 1,99$ & $I Y \leqslant 0, r V$ & تكوين المقطم & الأيوسين الأوسط & \\
\hline$\varepsilon, \Lambda \mathrm{T}$ & $1 \leq \varepsilon, r \varepsilon$ & تكوبن أبو رمث & الأبوسبين الأسفل & \\
\hline$O r, \wedge \varepsilon$ & 1078,19 & \multicolumn{2}{|l|}{ المجموع } & \\
\hline$\varepsilon, \wedge \Lambda$ & $1 \leq \varepsilon, 9 \leq$ & تكوين الجلالة & الكريتاسي الأعلى & \multirow{5}{*}{ 牙. } \\
\hline$r, .9$ & $T Y, \cdot \varepsilon$ & تكوين مالحة & الكريتاسي الأسفل & \\
\hline 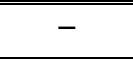 & 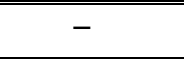 & سطح عدم نوافق & الجوراسي & \\
\hline r,vo & $111, r \pi$ & تكوين قصيب & الترياسي & \\
\hline $1 \cdot, \mathrm{Vr}$ & M $\mid \Lambda, Y Y$ & \multicolumn{2}{|l|}{ المجموع } & \\
\hline $1, r$ & ro,人 & تكوين أحيمر & \multirow{3}{*}{ الكريوني الأعلى } & \multirow{4}{*}{ 离 } \\
\hline$\varepsilon, 7 V$ & $1 r \Lambda, 74$ & تكوين روض الحمل & & \\
\hline$\cdot, 9$ & $r 7, V r$ & تكوين أبو الدرج & & \\
\hline $7, \vee \wedge$ & $r \cdot 1, Y r$ & \multicolumn{2}{|l|}{ المجموع } & \\
\hline $1 \ldots$ & ห९१०,४ & \multicolumn{2}{|c|}{ إجمالي المساحة الكلية } & \\
\hline
\end{tabular}

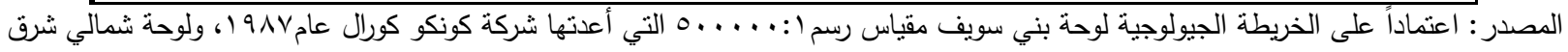

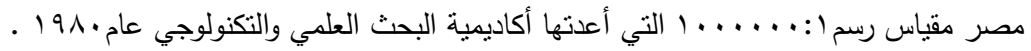

ب- خصائص السطح

تعد دراسـة خصـائص السطح الركيزة الرئيسية لتحليل الخصـائص الجيومورفولوجية لمنطقة مـا، وذلك بهدف الاستفادة القصوى منها قبل البدء في عمليات التخطيط المختلفة وذلك من خلال دراسة التالي : 1- الخصائص الانحداريه يوضـح (الثـكل ب) فئـات الانحدار بمنطقة الدراسـة وفقاً لتصنيف Young,1972 لفئات الاتحدار ، ومـن (الثكل ( ) م ايجاد المساحات التي تشكلها كل فئة من فئات الاتحدار حسب تصنيف Young,1972 ، كما

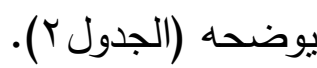

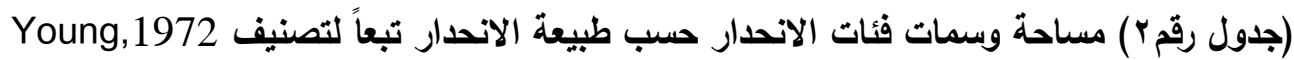

\begin{tabular}{|c|c|c|c|}
\hline المساحةة\% & المساحة كمَ & طبيعة الاتحدار & فئات الانحدار بالارجات \\
\hline YY,1T & $70 \mathrm{~V}, .1$ & أراضي مستوية والمستوية جداً & $r-\cdot$ \\
\hline$r \wedge, \vee q$ & AOr,AT & أراضي خفيفة الانحدار & $0-r$ \\
\hline IV,Yq & $01 Y, V \varepsilon$ & أراضي منوسطة الانحدار & $1 .-0$ \\
\hline $10,9 Y$ & $\sum V Y, \cdot Y$ & أراضي شديدة الانحدار نسبياً & $\mid \Lambda-1$. \\
\hline $1 r, r q$ & $r q V, r T$ & أراضي شديدة الانددار & $r 0-11$ \\
\hline 1,01 & $\sum 7, \wedge 9$ & أراضي شديدة الانحدار جداً & $\varepsilon 0-r_{0}$ \\
\hline$\cdot, \wedge \mathrm{V}$ & YO,AV & الحافات والجروف الرأسية & أكثر من \\
\hline$\%$ & r940,Tr & & الجملة \\
\hline
\end{tabular}




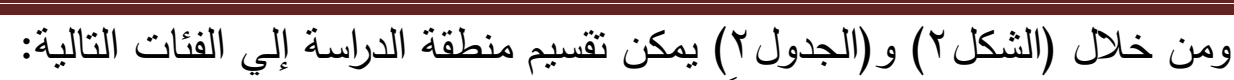

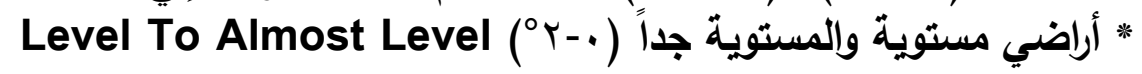

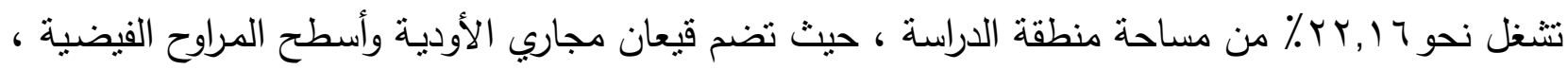

كما تظهر في بعض المواضع فوق سطح الهضبة.

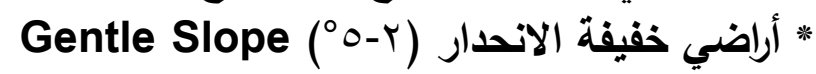

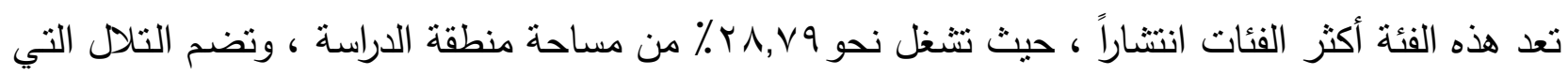

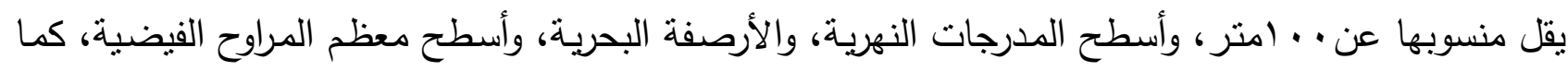

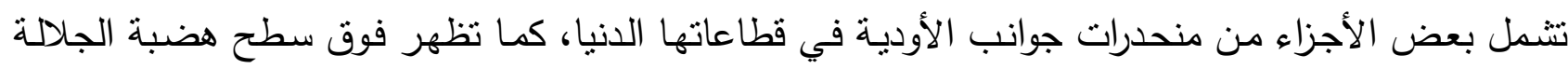
البحرية. وتتميز تلك الأراضي في أغلبها بسيادة الرواسب الدفككة الناتجة عن عمليات التجوية أو التي جلبتها

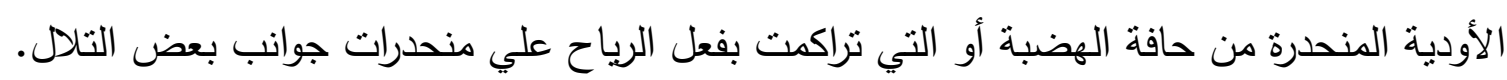

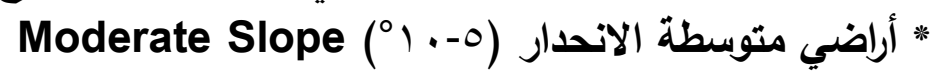

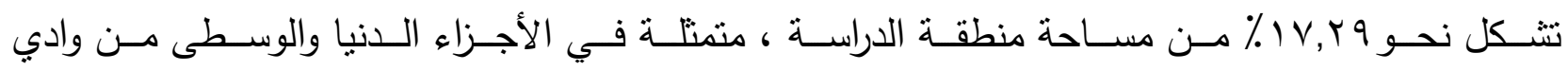

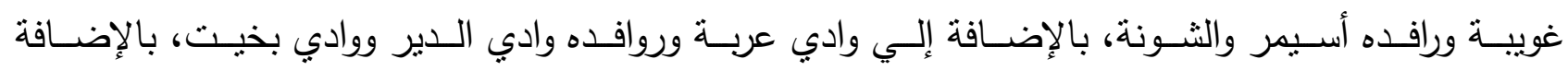

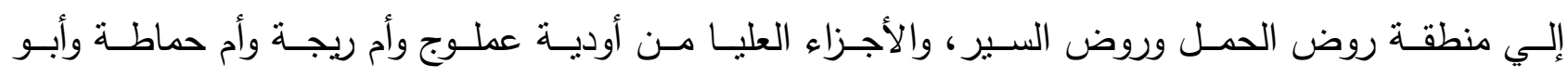

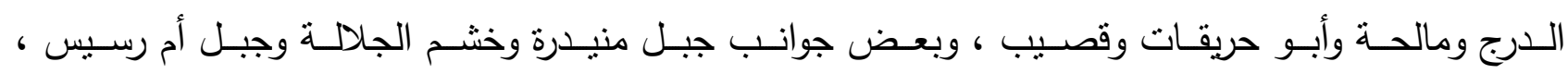
بالإضافة إلي سطح هضبة الجلالة البحرية .

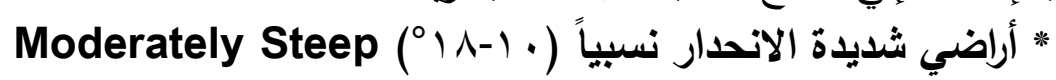
تستحوذ نحو بر 10,9 من مساحة منطقة الدراسة، وتتمل المنابع العليا لأودية منطقة الدراسة والمواضع العليا

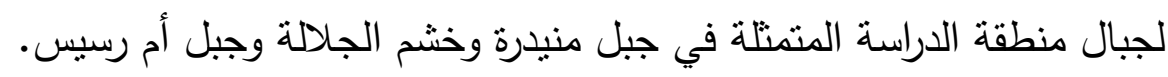

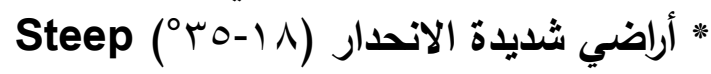

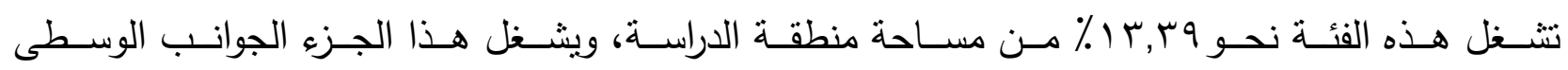

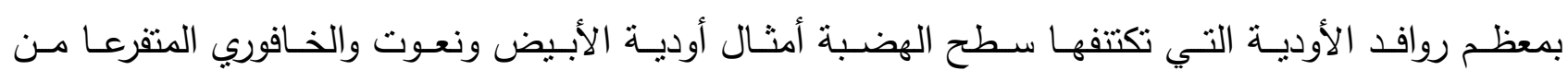

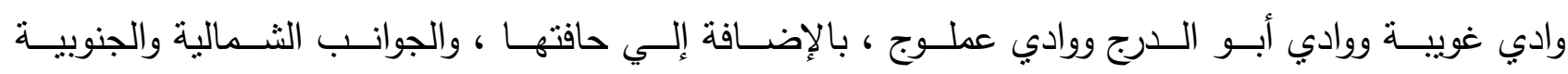
والثرقية والغربية لهضبة الجلالة البحرية.

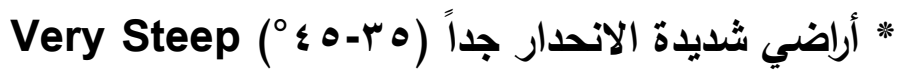

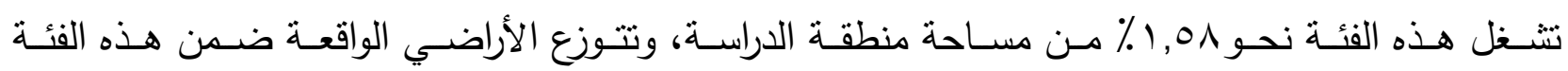

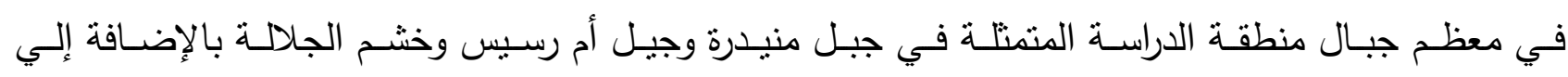

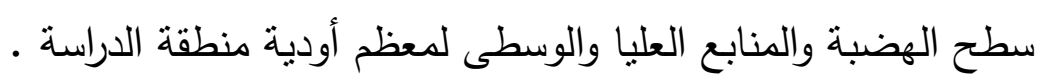

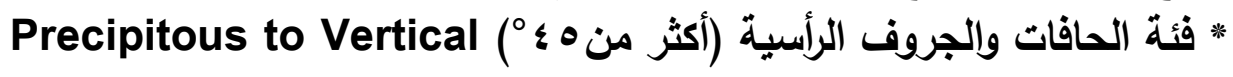

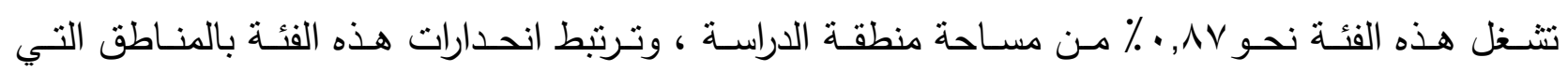

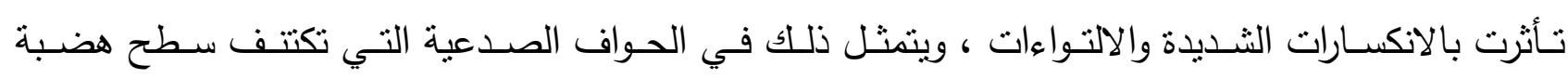
الجلالة البحرية وحافتها. 


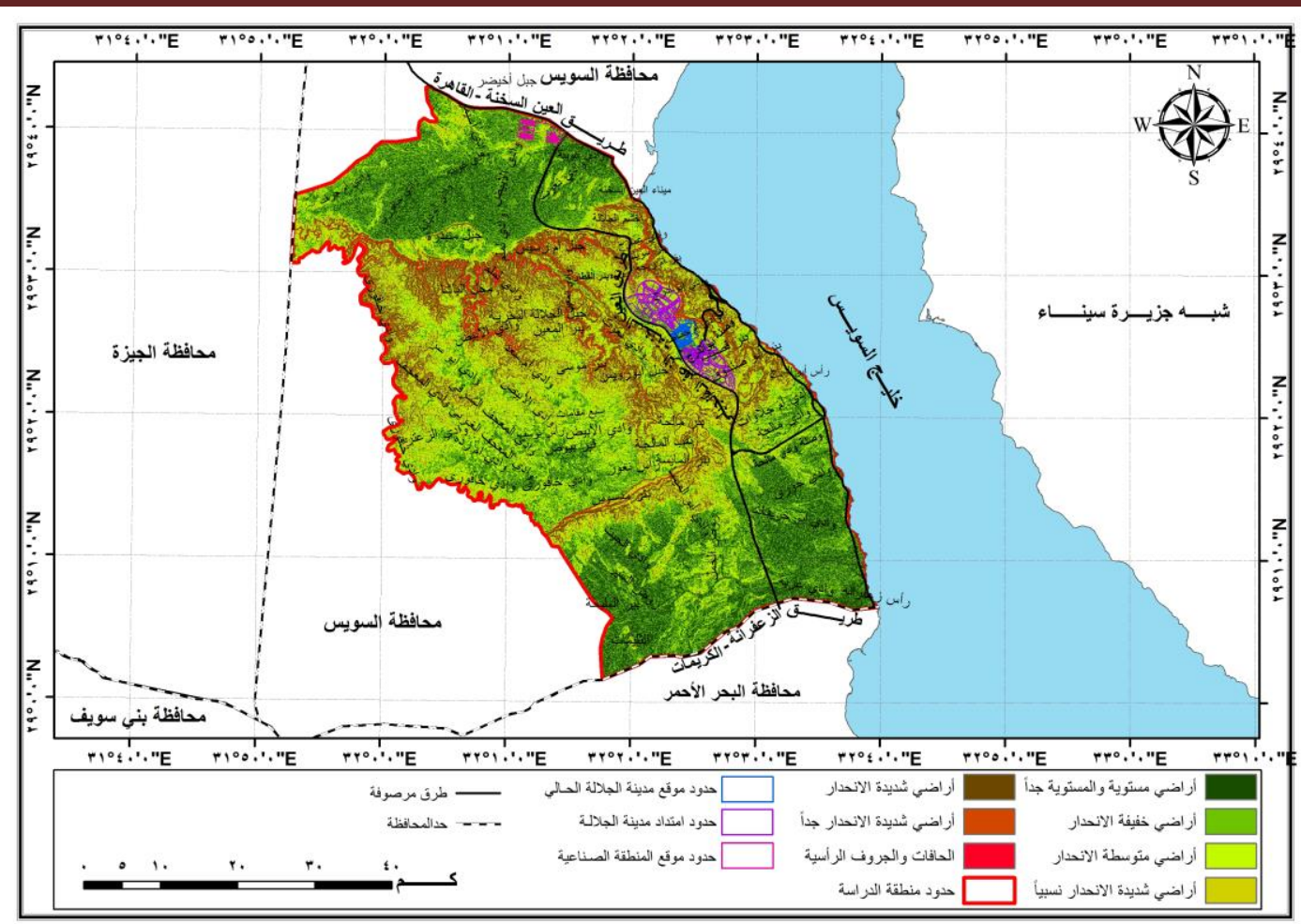

Young,1972) (شكل رقم ץ) فئات الانحدار بمنطقة الدراسة وفقاً لتصنيف

بspects اتجاهات الانحدار ترجع أهية تحديد اتجاهات الانحدارات بالمنطقة إلي تحديد كافة العوامل المؤثرة في استعمالات الأراضي،

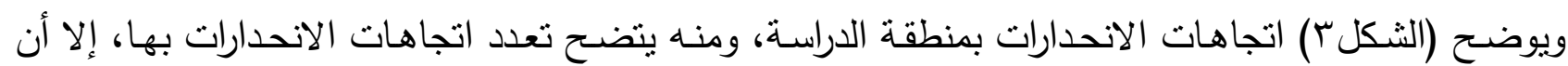
اتجاه الانحدارات نحو الثرق يعد الاتجاه السائد بمنطقة الدراسة.

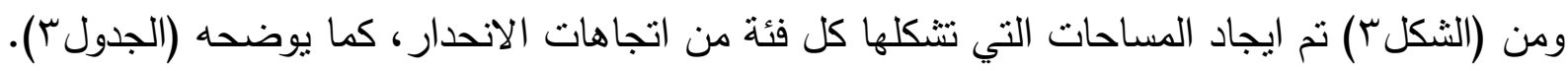

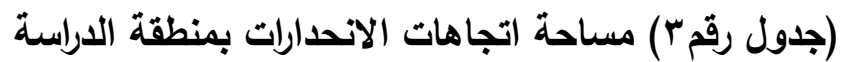

\begin{tabular}{|c|c|c|}
\hline المساحة\%٪ & المساحة كم & اتجاهات الانحدار \\
\hline$\cdot, \leqslant \wedge$ & $1 \varepsilon, Y Y$ & مستو \\
\hline 19,99 & r人0,1т & شمال \\
\hline $1 \pi, 70$ & $\varepsilon \cdot \varepsilon, T V$ & شمال شرق \\
\hline $1 \leq, \cdot V$ & $\varepsilon \mid V, r T$ & شرق \\
\hline $1 T, \leq 9$ & $\varepsilon \ldots, 19$ & جنوب شرق \\
\hline IY, E. & rTV,VO & جنوب \\
\hline $1 \cdot, 9 V$ & TYO,YA & جنوب غرب \\
\hline $1 \cdot, V Y$ & r)A, $\cdot 1$ & غرب \\
\hline $11, Y T$ & TrT, II & شمال غرب \\
\hline$\% 1 \ldots$ & rq40,7r & الجملة \\
\hline
\end{tabular}

ويوضح (الجدولr) خصائص اتجاهات الانحدارات بمنطقة الدراسة ، ومنه ينضح أن اتجاه الثرق هو الاتجاه

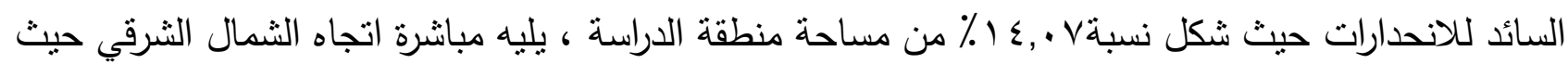

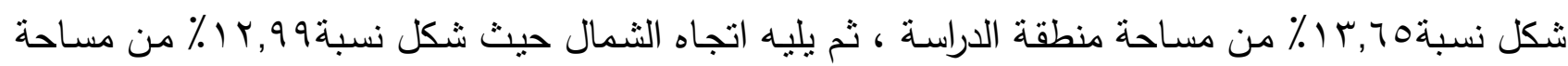

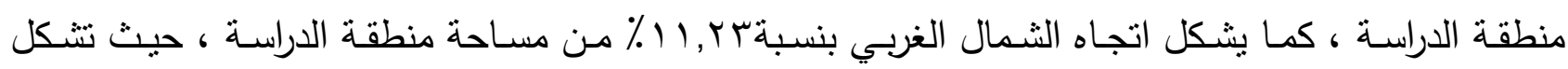




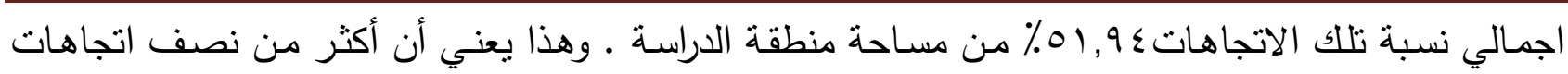

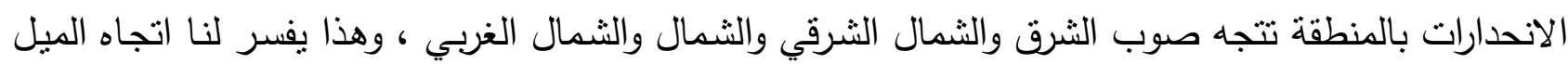
العام للظاهرات التضاريسية كمعظم سطح هضبة الجلالة البحرية وجبل منيدرة وجبل أم رسيس وخشم الجلالة

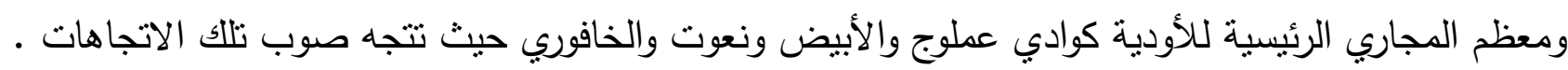

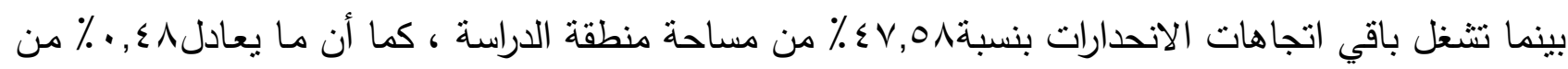

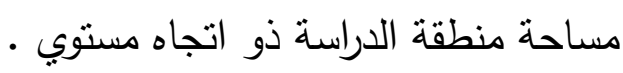

\section{ب- التضرس المحلي Lecal Relief} تقيد دراسة خريطة التضرس المحلي في معرفة مدي تضرس سطح المنطقة ، وذلك من خلال حساب متوسط

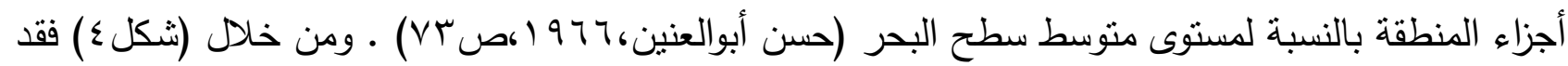
تم تقسيم منطقة الدراسة إلي ستة نطافات تضاريسية . ومن خلال تحليل (ثكل \&) يتضح أن القسم الأوسط بمنطقة الدراسة يعد أكثر أجزاء المنطقة ارتفاعاً ، ويقل

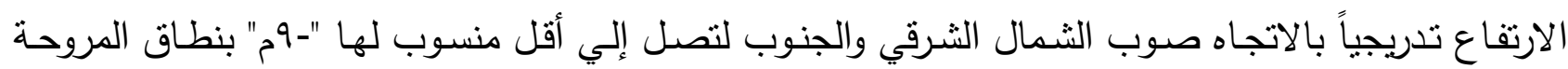
الفيضية لوادي عربة ـ ومن (الثكل ؟) تم ايجاد المساحات التي تتكلها كل فئة من فئات النطاقات التضاريسية ، كما يوضحه (الجدول \&).

(جدول رقم \&) مساحة النطاقات التضاريسية بمنطقة الدارسة

\begin{tabular}{|c|c|c|}
\hline المساحةة\% & المساحة كم & فئسبة النطاقات التضاريسية بالمتر \\
\hline$r Y, \varepsilon \varepsilon$ & $974,1 \%$ & $r \ldots>q-$ \\
\hline$I V, T Y$ & OYY,O & $\varepsilon \ldots>r \ldots$ \\
\hline$V, Y_{O}$ & $Y) \leqslant, 9 V$ & $\uparrow \ldots>\varepsilon \ldots$ \\
\hline$q, \vee \cdot$ & TAV,OT & $A \ldots>\uparrow \ldots$ \\
\hline $19, \varepsilon$. & OVo, rq & $1 \ldots>\wedge \ldots$ \\
\hline $1 r, 09$ & $\varepsilon \cdot r, I V$ & $\mid Y Y V-1 \ldots$ \\
\hline$\% 1 \ldots$ & r970,4r & الجملة \\
\hline
\end{tabular}

وبناءً عليه فقد نم تقسيم المنطقة حسب التضرس المحلي إلي الفئات الثالية.

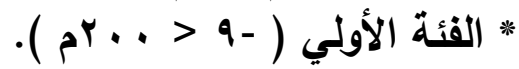

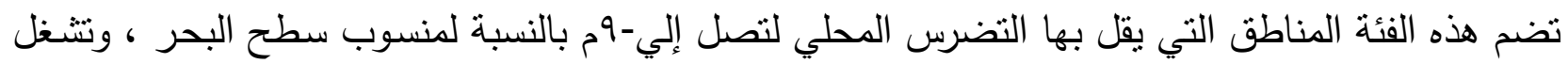

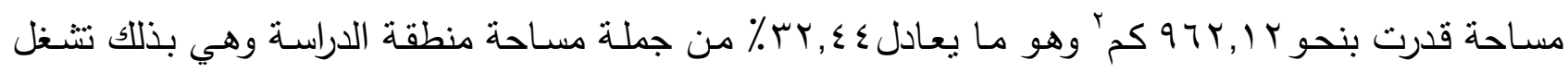

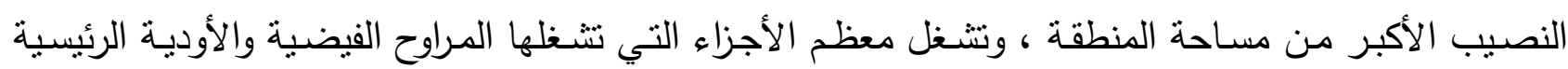

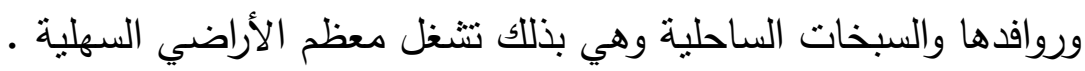

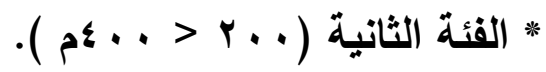

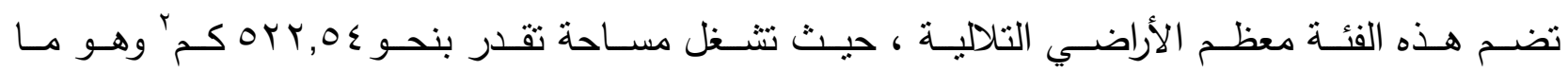

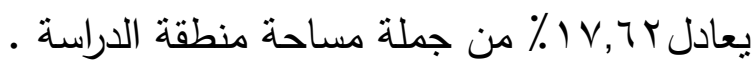




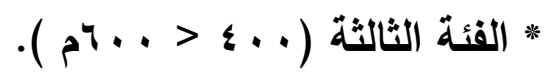

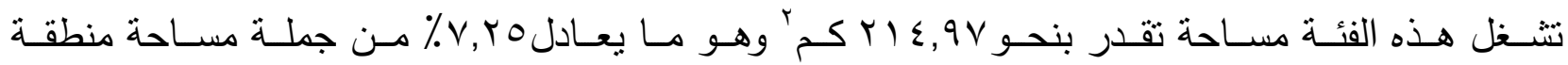

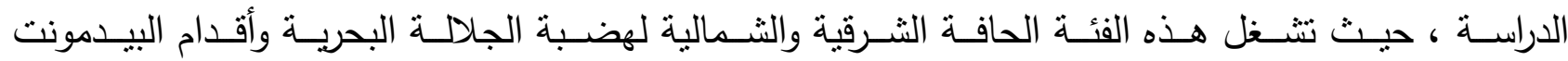

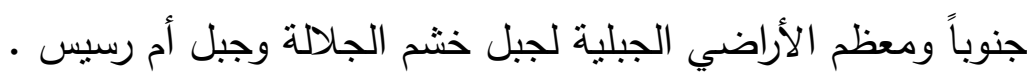

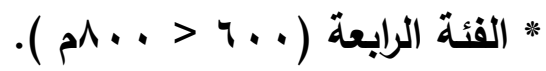

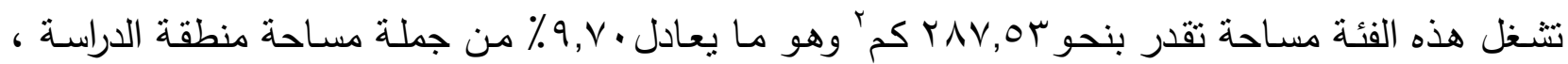

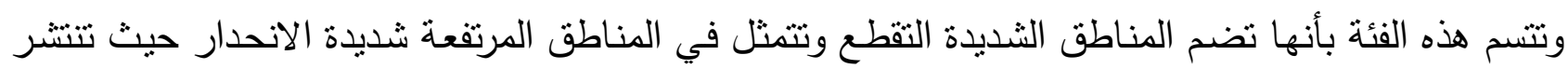

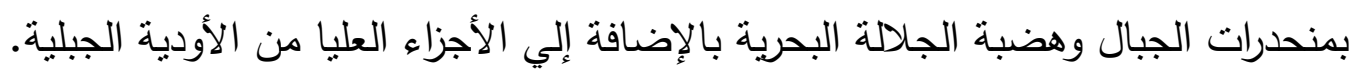

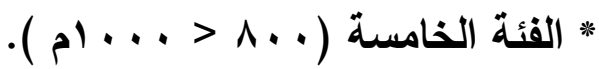

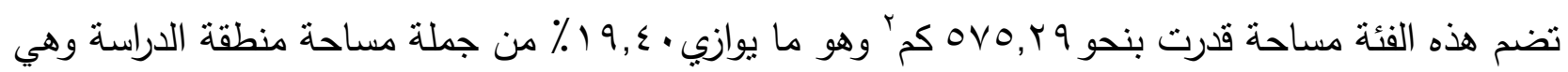

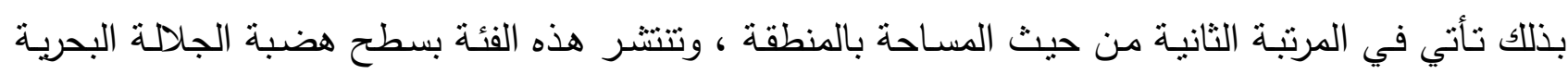

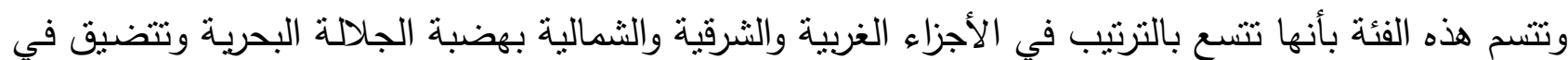
الأجزاء الوسطى منها.

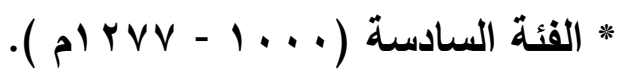

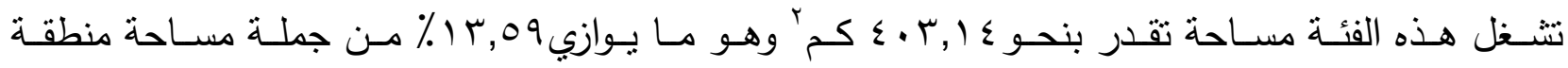

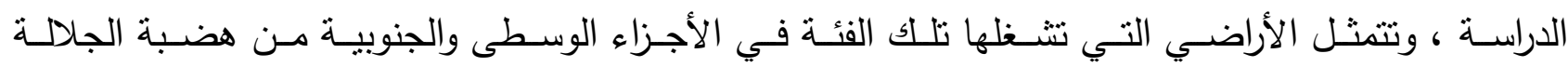

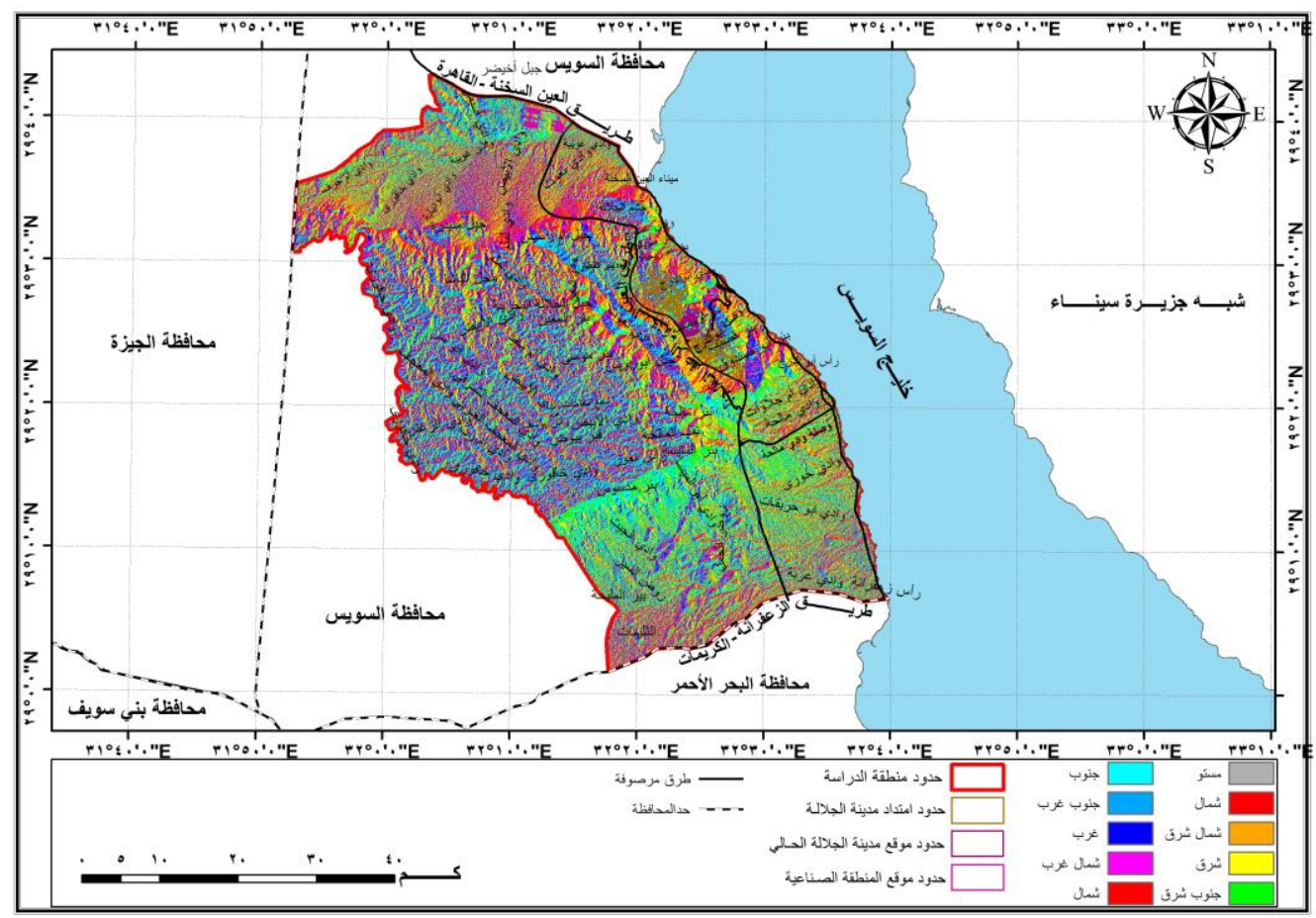

(شكل رقمץ) اتجاهات الانحدار بمنطقة الدراسة 


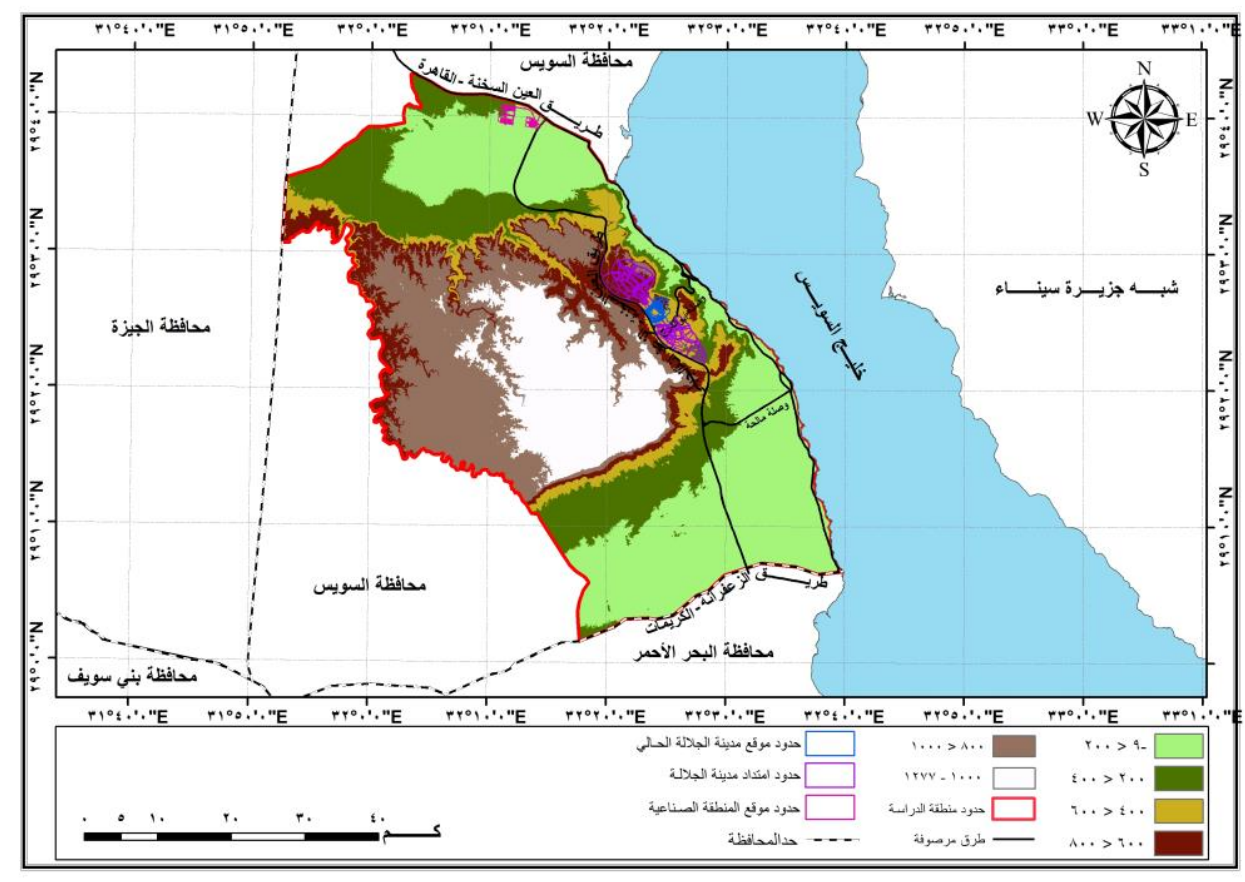

(شكل رقم ؛ ) فئات التضرس المحلي بالمتر بمنطقة الدراسة

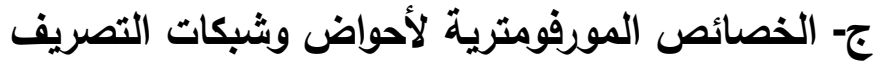

تم الاستعانة بنموذج الارتفاع الرقمي المنتج من الخرائط الطبوغرافية من إنثاء خريطة شبكة التصريف التصريف النهري

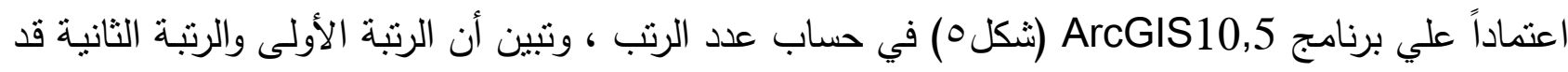

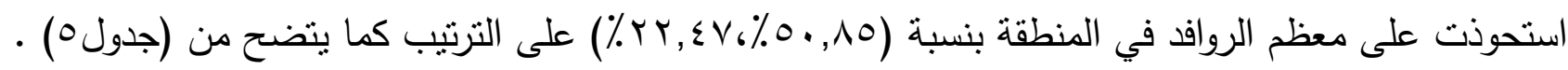

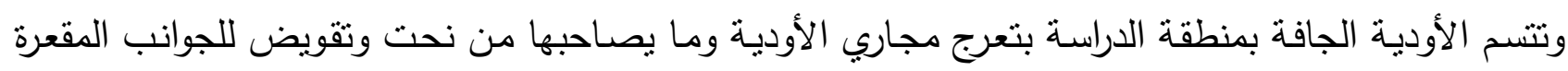

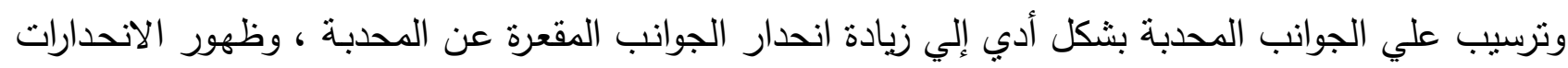

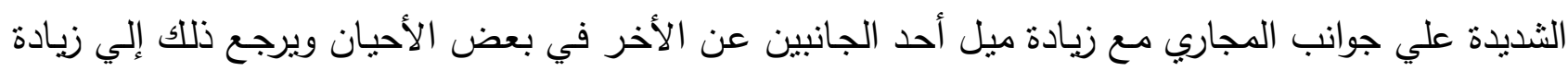

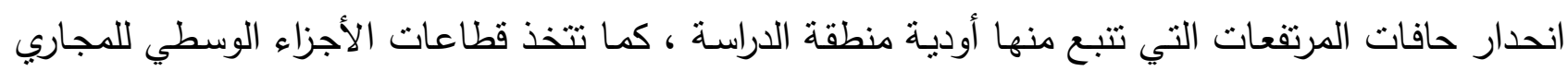

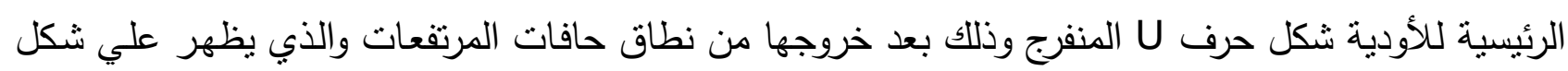

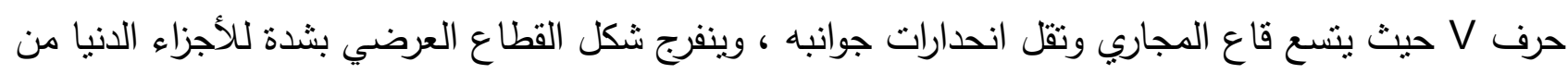

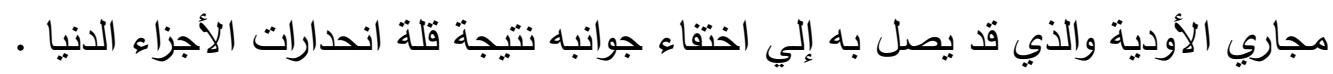

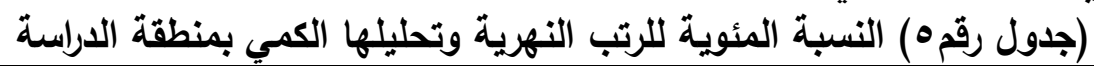

\begin{tabular}{|c|c|c|c|c|}
\hline الانحراف المعياري & متوسط أطوالها كم & الطول كم & النسبة المئوية \% & الرتبة \\
\hline$\varepsilon, 11$ & $\varepsilon, \vee 0$ & $O V \leq \varepsilon, r$ & $0 \cdot, \wedge 0$ & الأولى \\
\hline$r, q V$ & $0, \cdot r$ & TVVY, $\Sigma$ & $Y Y, \Sigma V$ & الثانية \\
\hline r,vo & $\varepsilon, 99$ & $1 \leqslant \wedge 9, r$ & $M, T V$ & الثالثة \\
\hline$r, 7 \Lambda$ & $\varepsilon, \wedge \vee$ & $V 77, r)$ & 7,71 & الرابعة \\
\hline 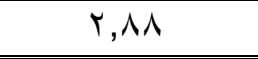 & $\varepsilon, \mu$ & $\varepsilon \wedge \vee, Y \vee$ & $\varepsilon, \varepsilon 1$ & الخامسة \\
\hline $1, \varepsilon V$ & $1, \wedge \varepsilon$ & ror, I $\leq$ & $r, \varepsilon r$ & السادسة \\
\hline$\cdot, \mu \vee$ & $\cdot, \leqslant 9$ & $r q, 7 r$ & $\cdot, \mu_{0}$ & السابعة \\
\hline$\cdot, I V$ & $\cdot, 11$ & 19,1 & $\cdot, Y_{1}$ & الثامنة \\
\hline
\end{tabular}


وتعتبر الدراسـة الخاصـة بأعداد المجاري ورتبها داخل كل حوض ركيزة أساسية في تحليل شبكة التصريف

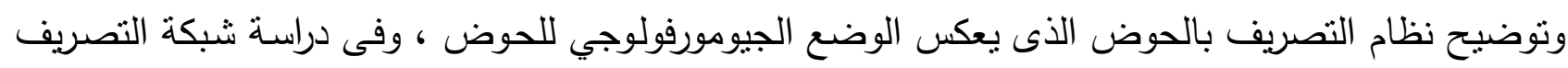

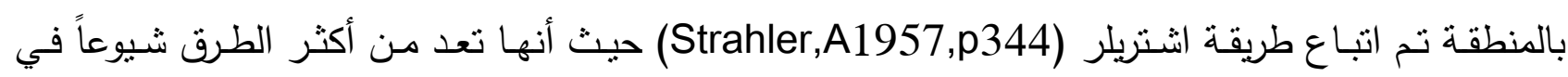

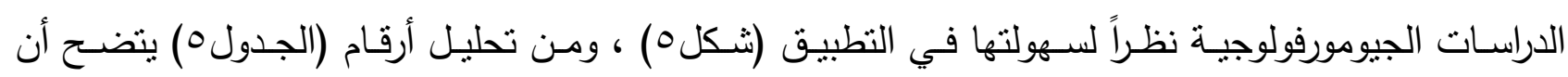
أحواض الدراسة تنقسم حسب الرثب إلى خمسة مجموعات هي (شكل آل):

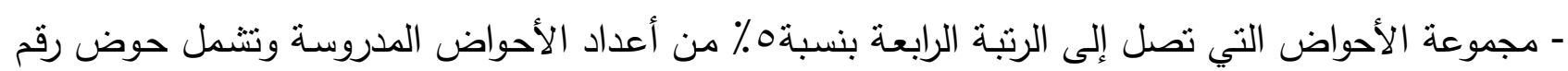

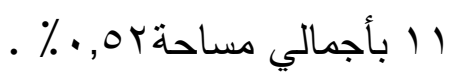

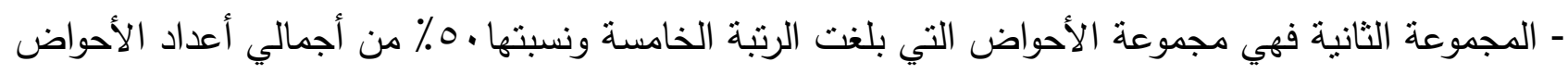

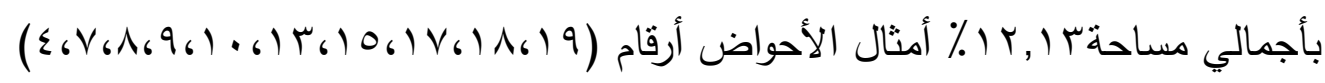

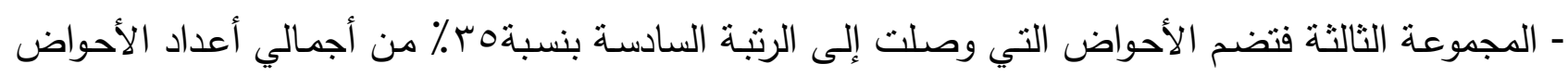

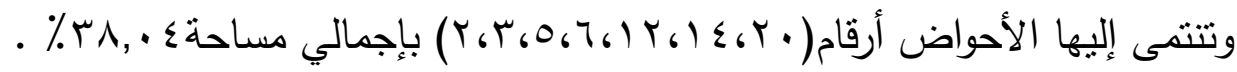

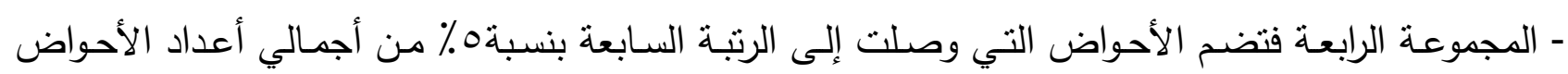

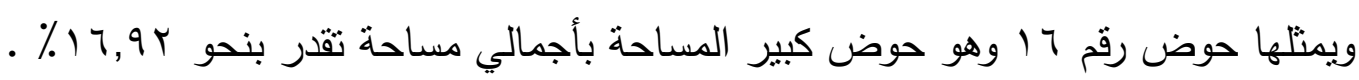

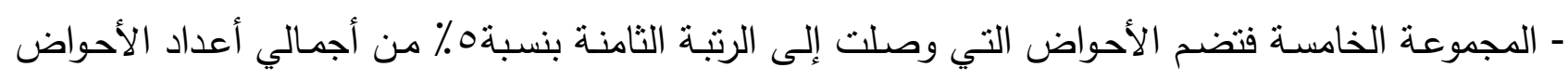

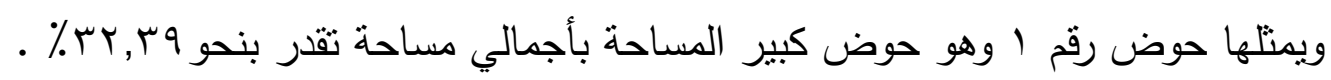

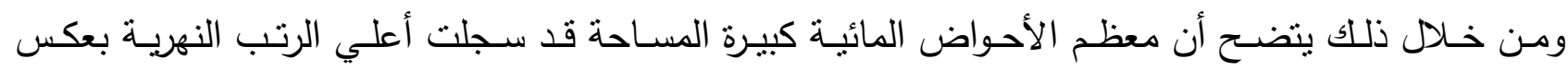

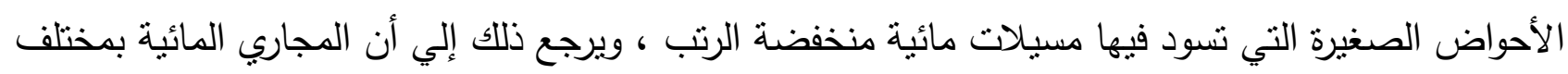

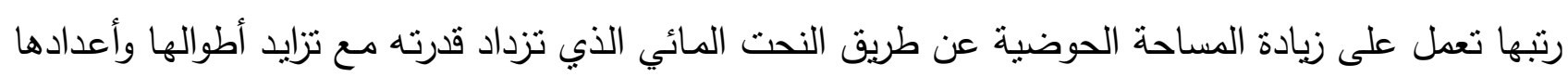

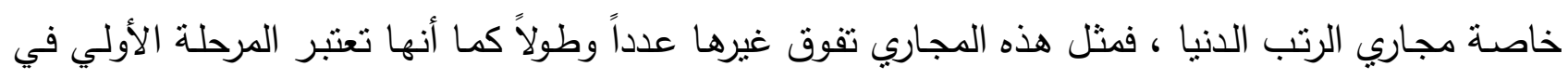

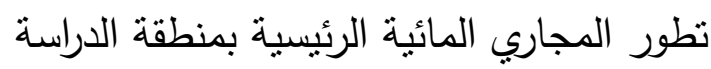




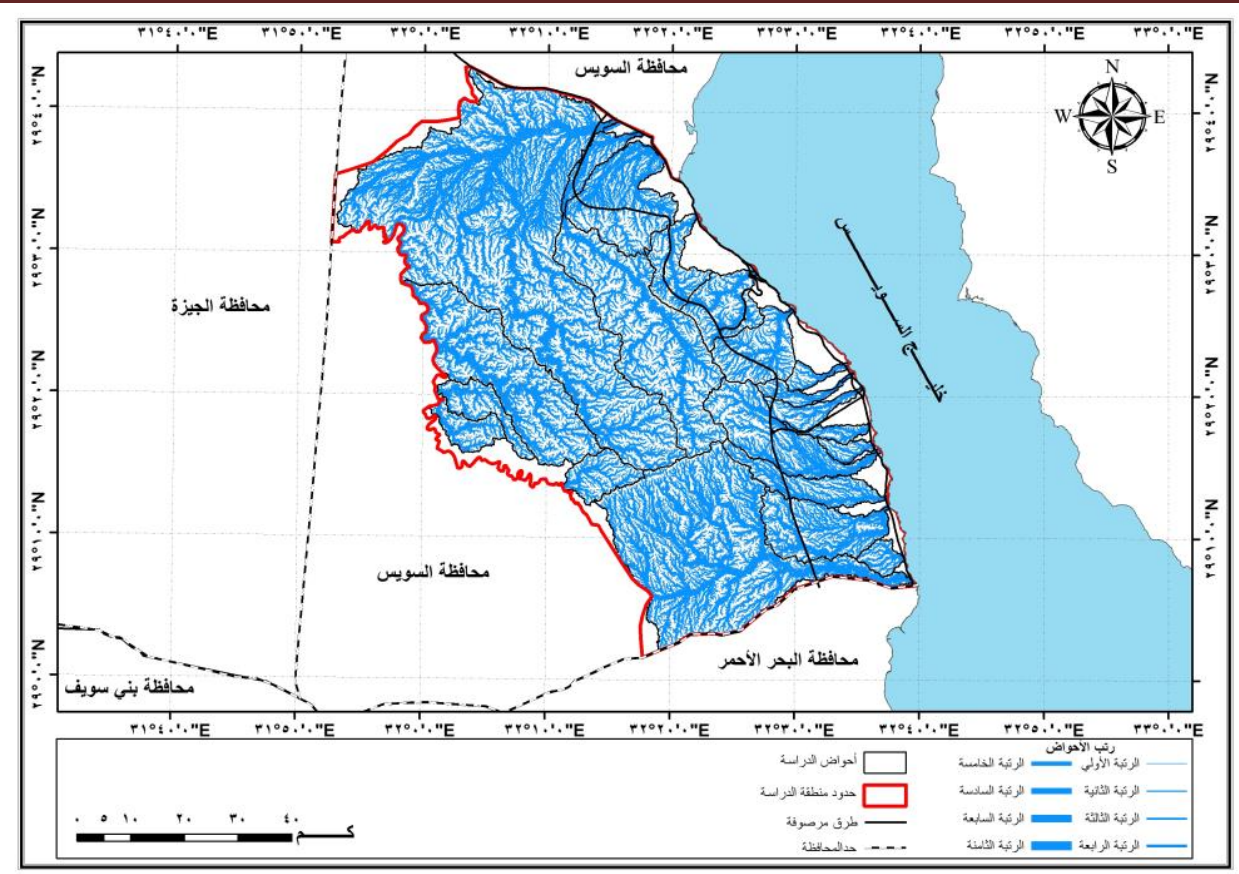

(شكل رقمه) شبكة التصريف النهري المنتجة باستخدام نموذج الارتفاع الرقمي من الخرائط الطبوغرافية .

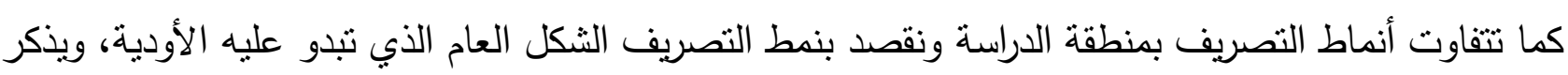

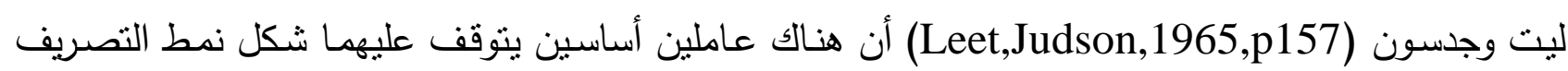
هما البنية الجيولوجية من حيث خصائص الصخور ونوعها وتركيبها والتراكيب الثانوية التي تنؤثر في المنطقة ،

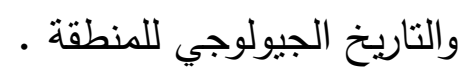
حيث أدي تتوع التكوينات الجيولوجية والخصائص التركيبية والليثولوجية إلي تتوع أنماط التصريف بالمنطقة

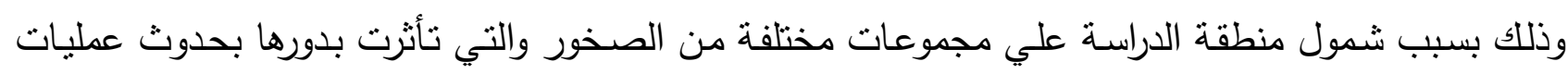
الطي والتصدع فضلاً عما حدث من ذبذبات مناخية خلال عصر البلايستوسين ـ ومن فحص شبكة التصريف بمنطقة الدراسة يمكن تمييز أنماط التصريف بالمنطقة إلى عدة أنماط ومنها:

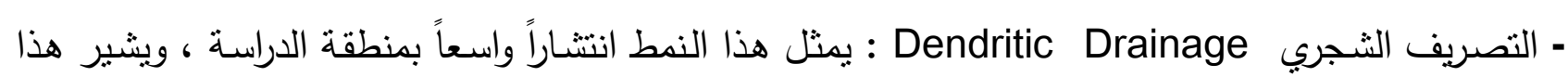
النمط إلى المناطق ذات التجانس الصخري ، وتتقارب روافده العليا من بعضها مما يعطي الثبكة شكلاً كثيفاً

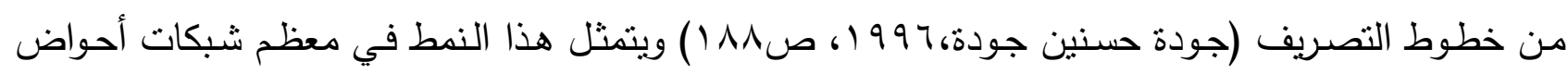

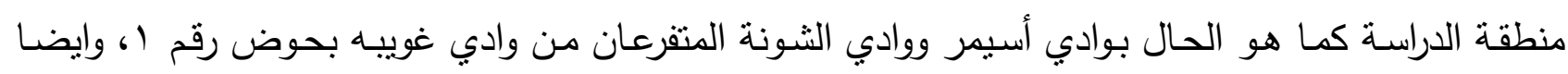

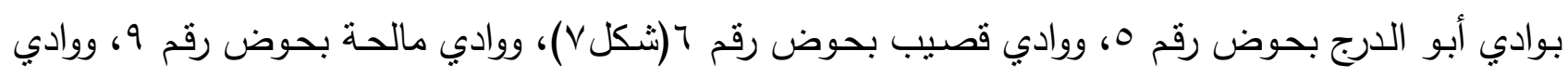

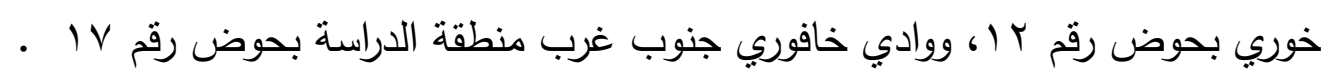

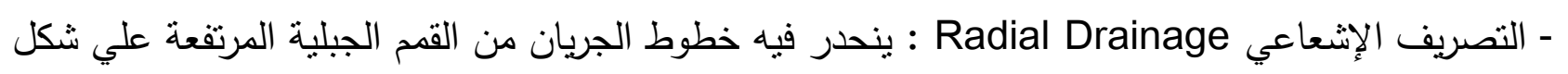

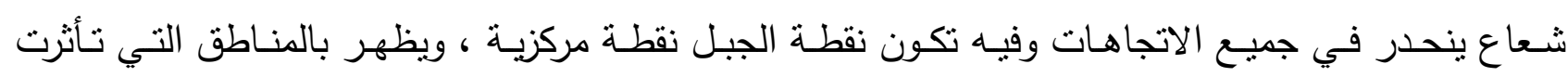

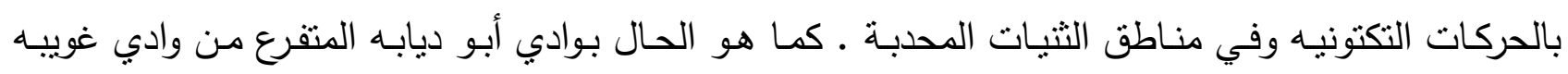

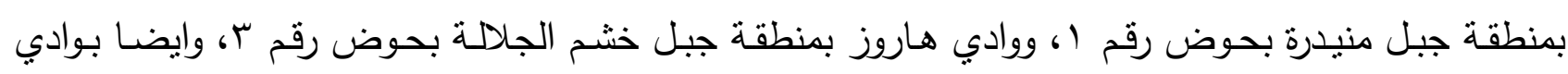

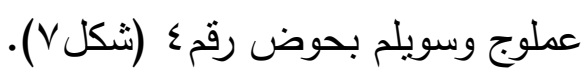


- التصريف المتوازي Parallel Drainage : يبدو هذا النمط علي هيئة خطوط جريان منوازية إلي حد ما

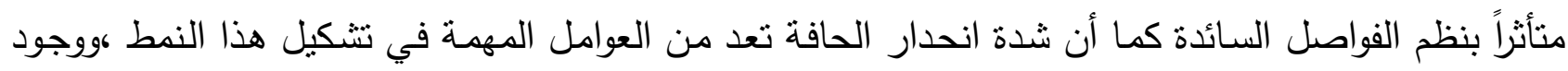

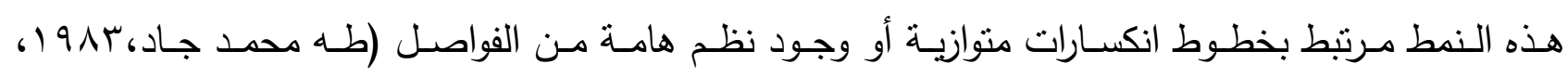

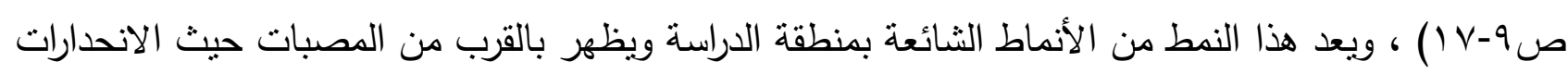

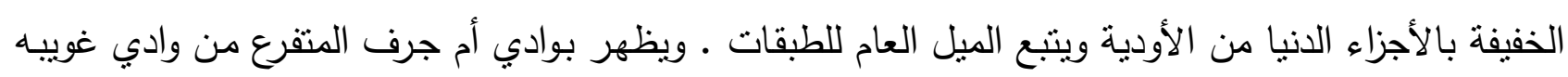

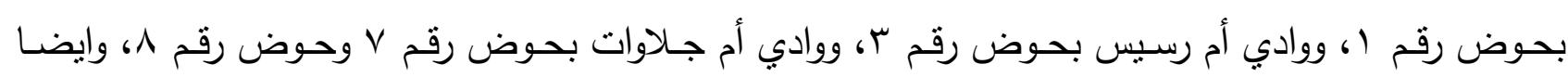

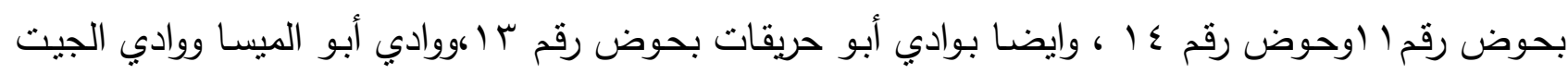

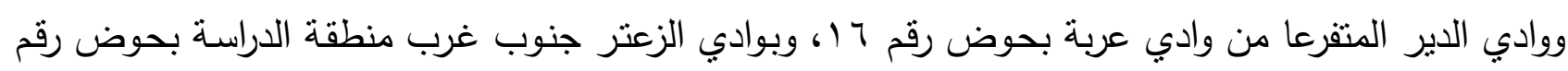

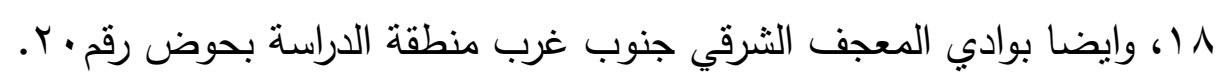

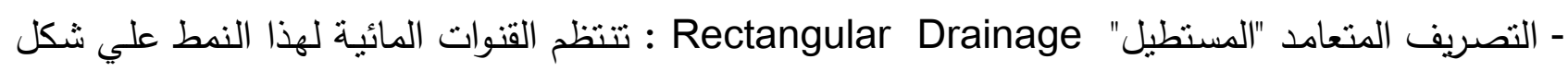

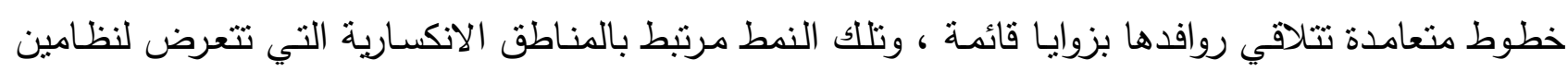

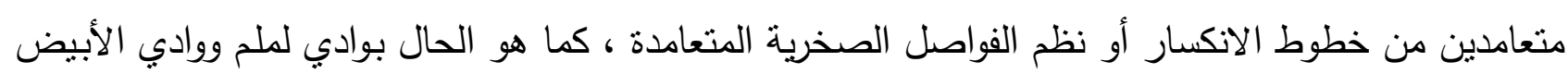

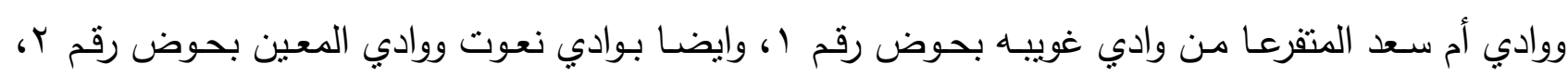

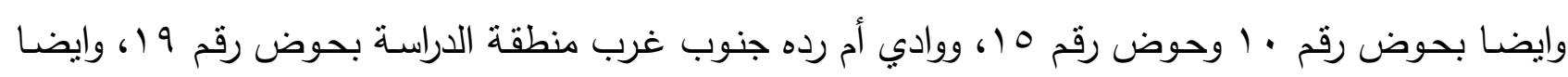

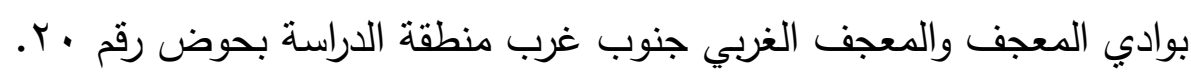




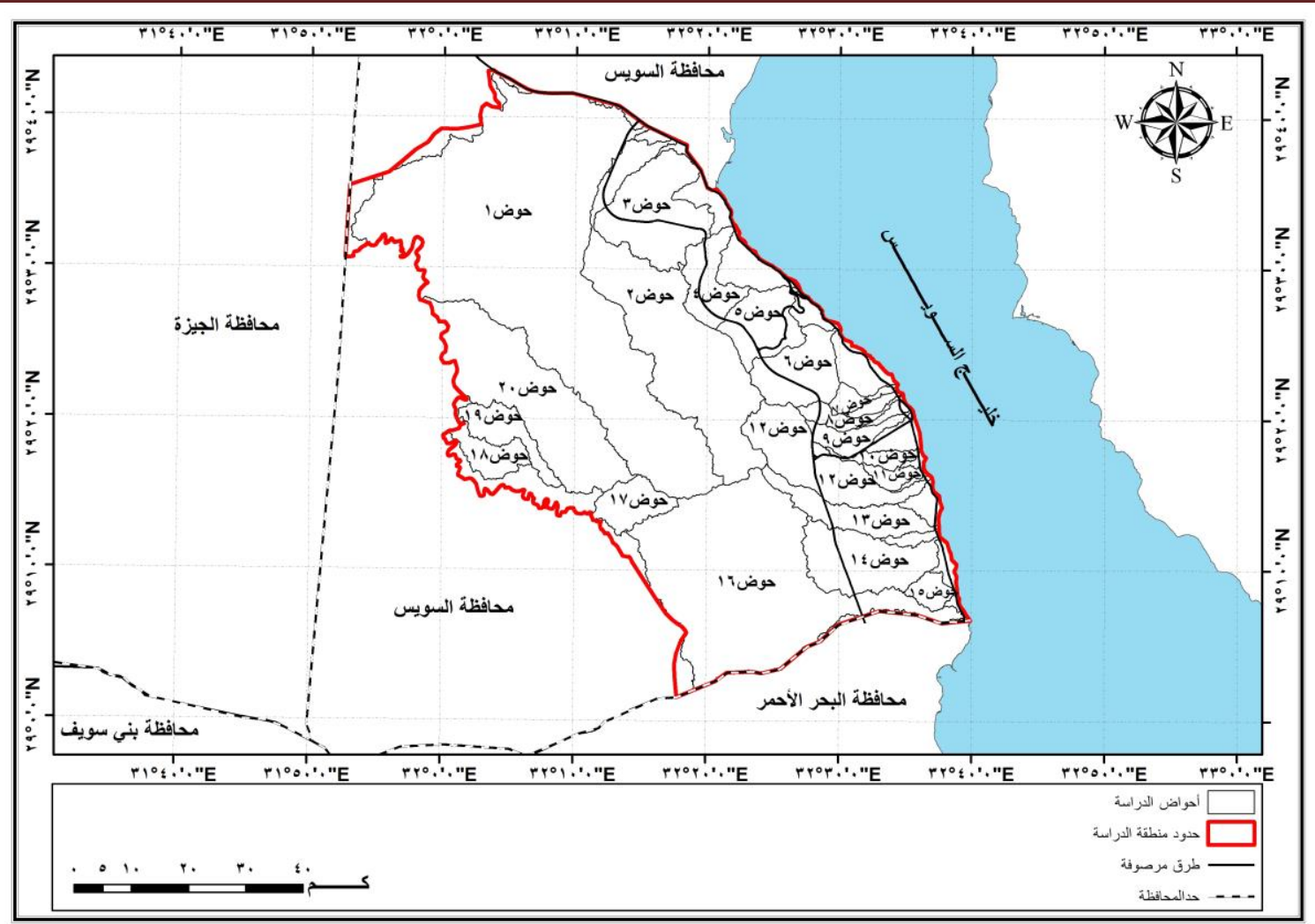

(ثكل رقم 7) أرقام الأحواض بمنطقة الاراسة

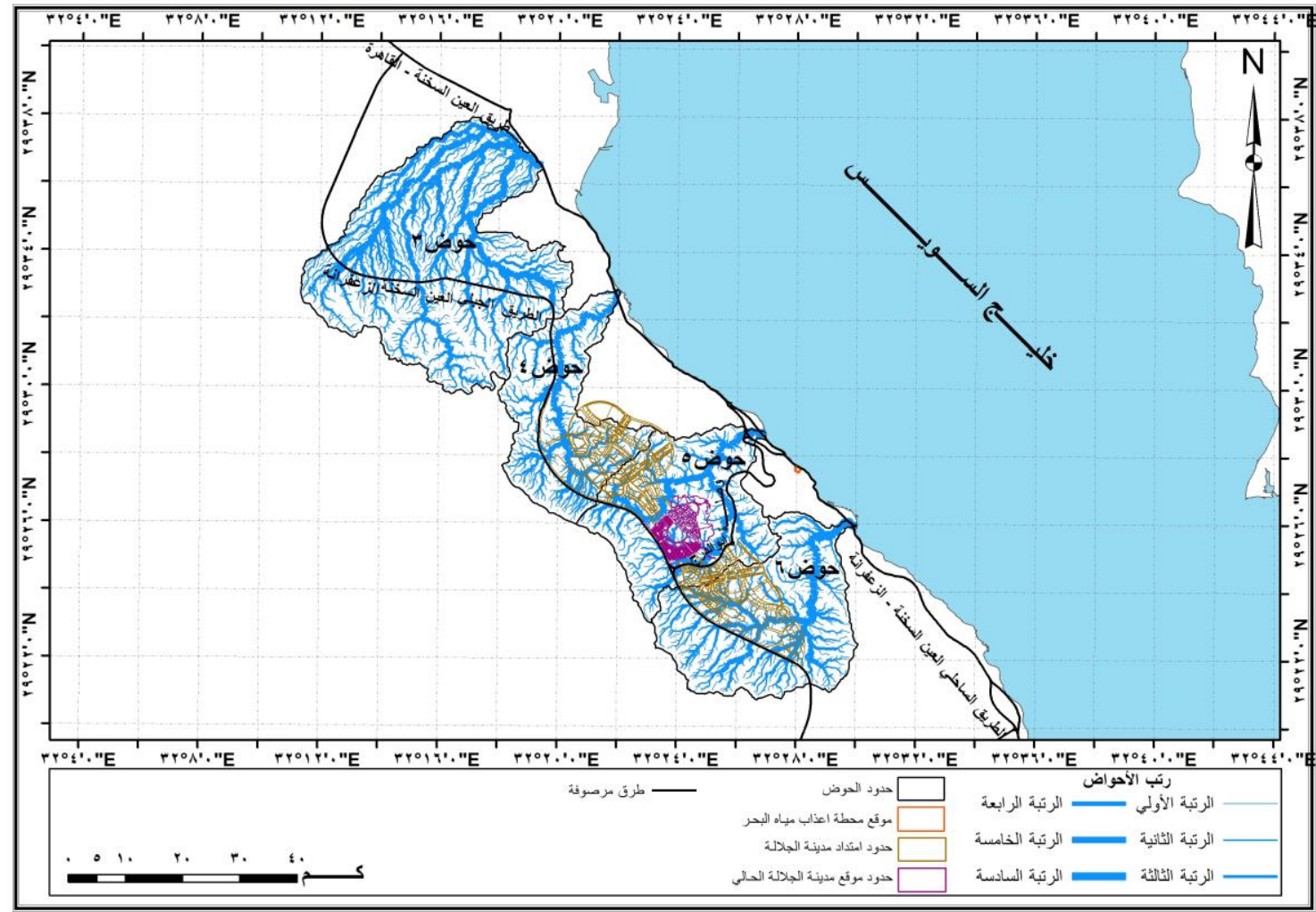

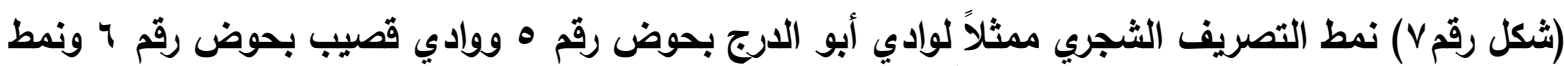

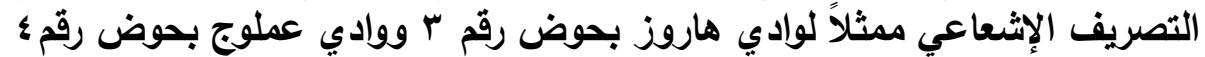


د/ على عبدالحميد هجرس وأخرون

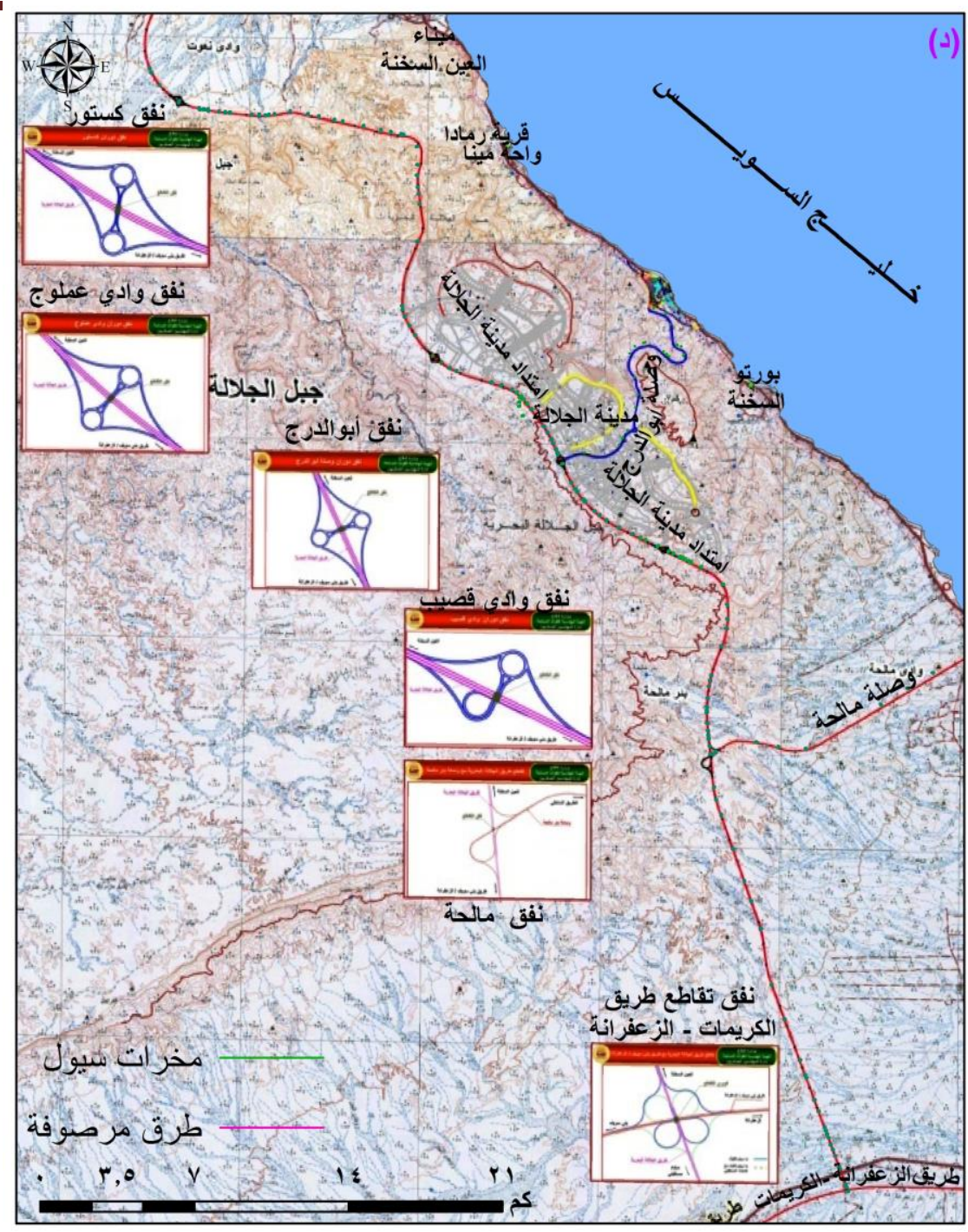

العدد الخامس و العثرين يونيو ا ب ب

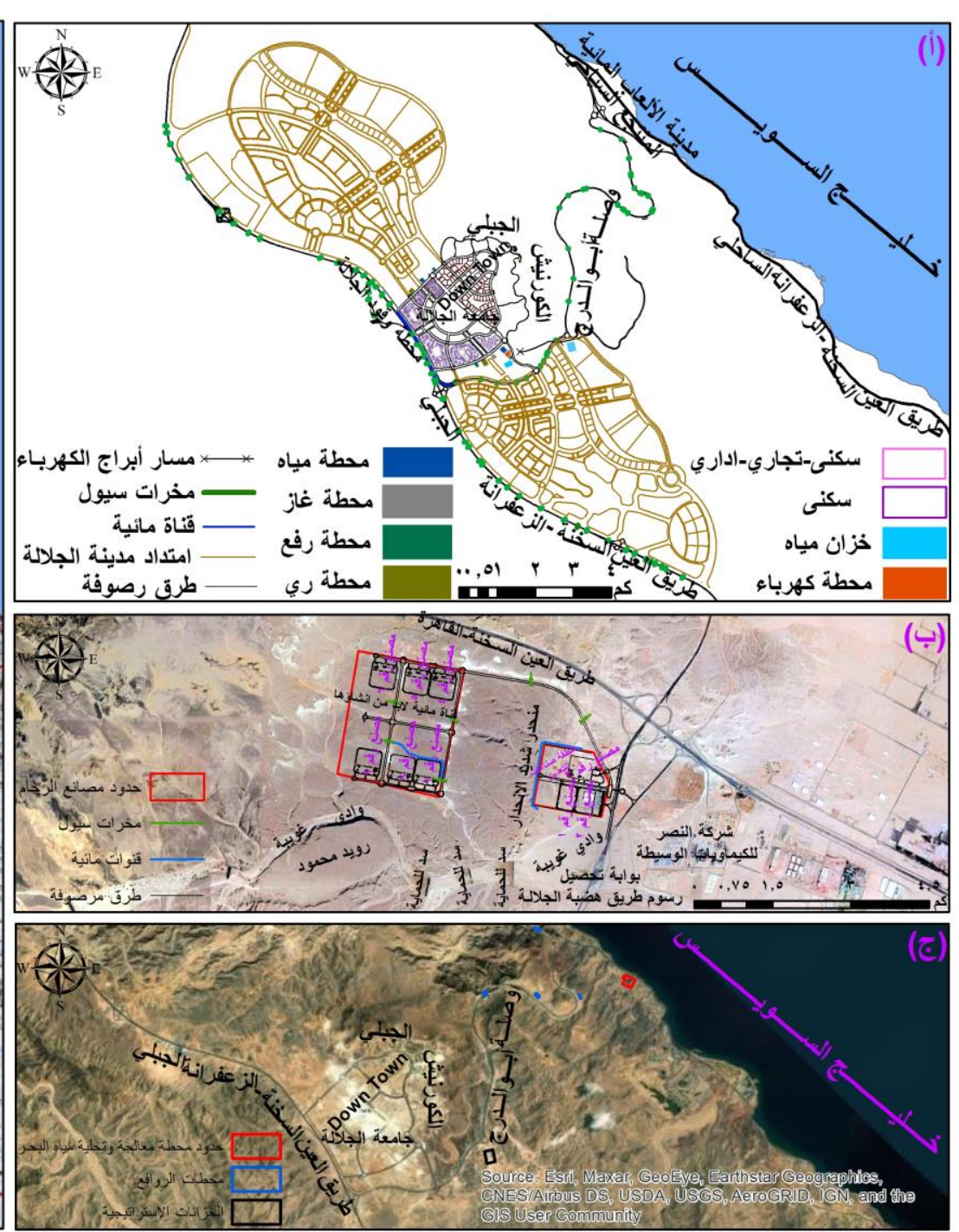

(شكل رقم^) أ.مشروع انثاء مدينة الجلالة البحرية ، ب. حدود المنطقة الصناعية ، ج. حدود محطة معالجة وتحلية مياه البحر والذزانات الاستراتيجية ،د. طريق هضبة الجلالة البحرية الجبلي ووصلاته الفئة الفرعية 
ثانياً- حصر وتقييم مشروعات التنمية بمنطقة الجلالة البحرية

حيث يتمثل مشروع تعمير منطقة الدراسة في المحاور الثالية: أ- انثاء مدينة الجلالة:

حيث تم إنشاء مدينة الجلالة أعلى هضبة الجلالة البحرية ضمن مجمع الجلالة البحرية على ارتفاع

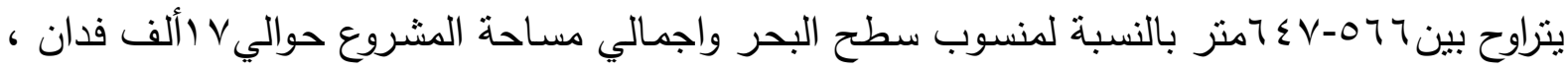

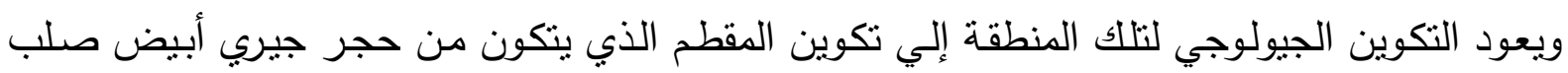

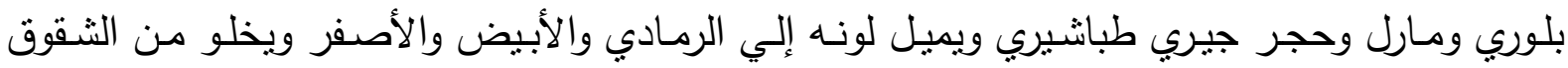

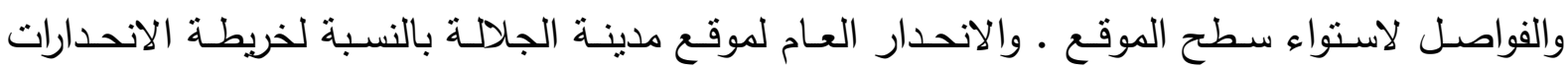

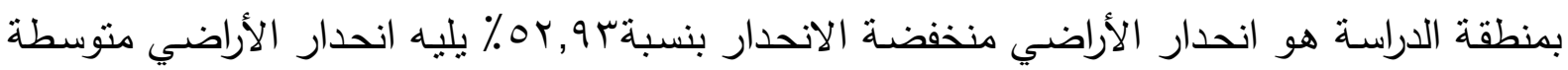

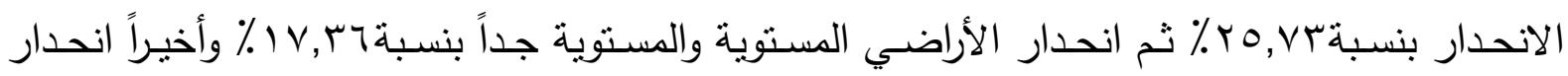

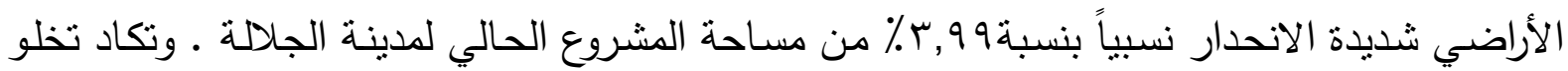
مدينة الجلالة من الأودية الجافة ذات الرتب العالية والذي نتكل خطورة على الديا الموقع العام للمدينة وفقاً

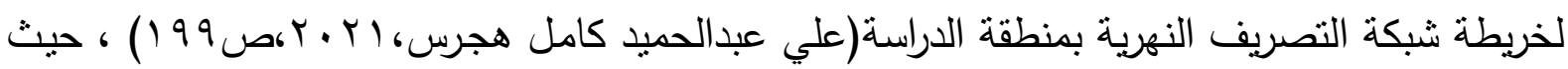

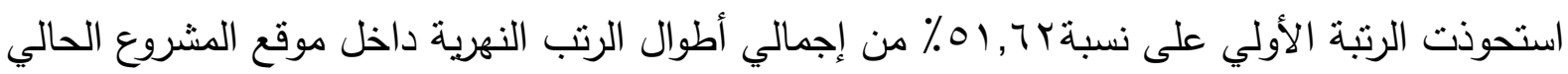

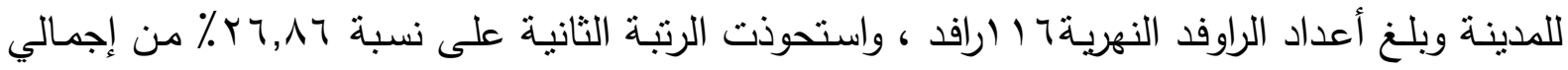

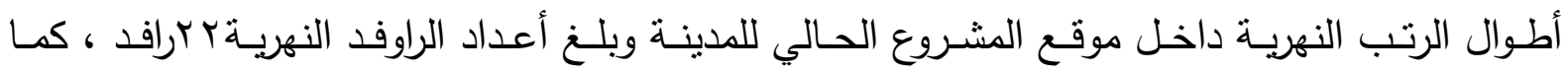

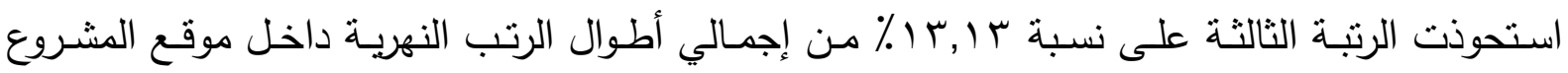

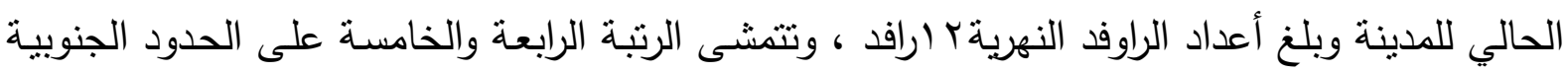

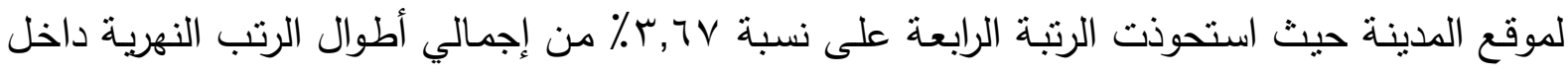

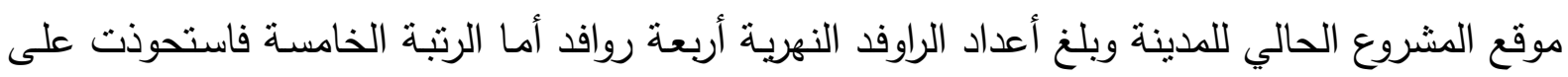

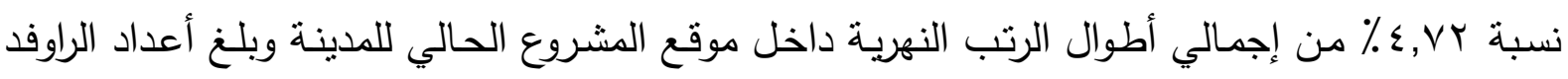
النهرية رافد نهري واحد. وهذا إن دل على شيء فيدل على على اختيار الموقع المثالي لإقامة المدينة عليه من

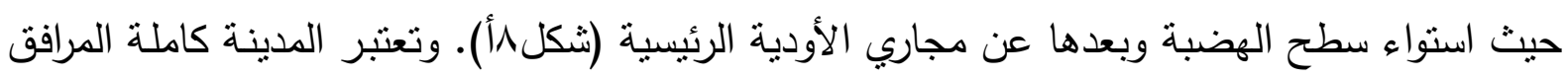

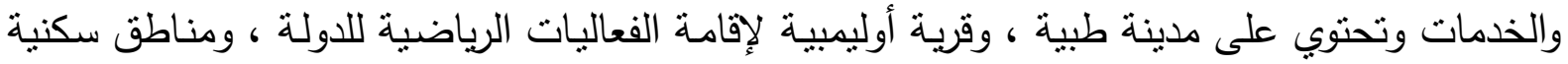
سياحية وأخرى لمحدودي الدخل ومناطق خدميـة لقاطني المدينة ، ويندرج من مشروع مدينة الجلالهة

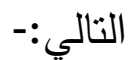

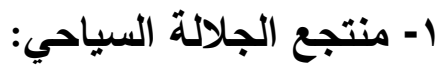

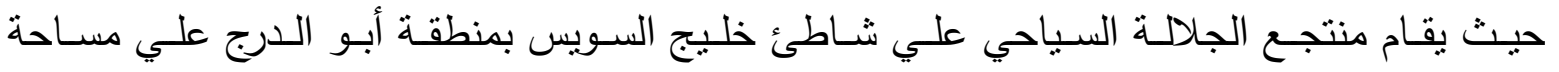

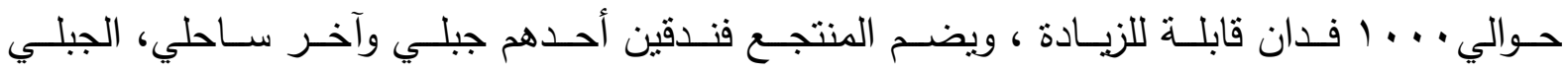

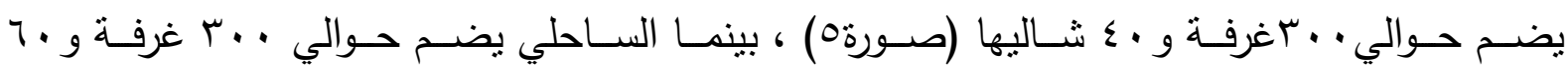




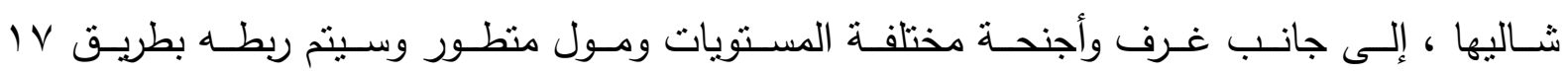
كيلو متر، وتليفريك بطول كيلو متر، بالإضافة إلى مدينة ألعاب مائية ومارينا لليخوت .

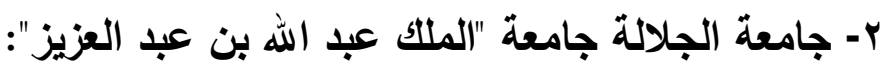

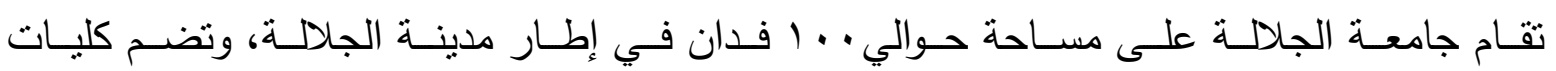

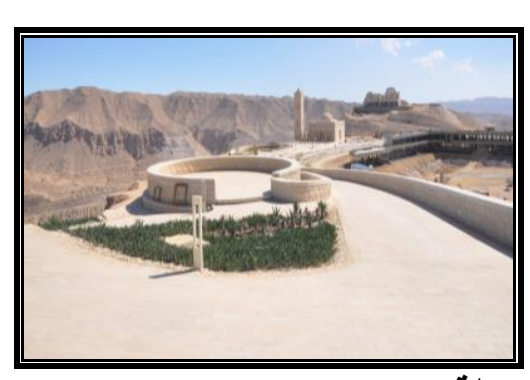
متطورة يحتاج إليها المجتمع المصري في تخصصات غير نمطية.
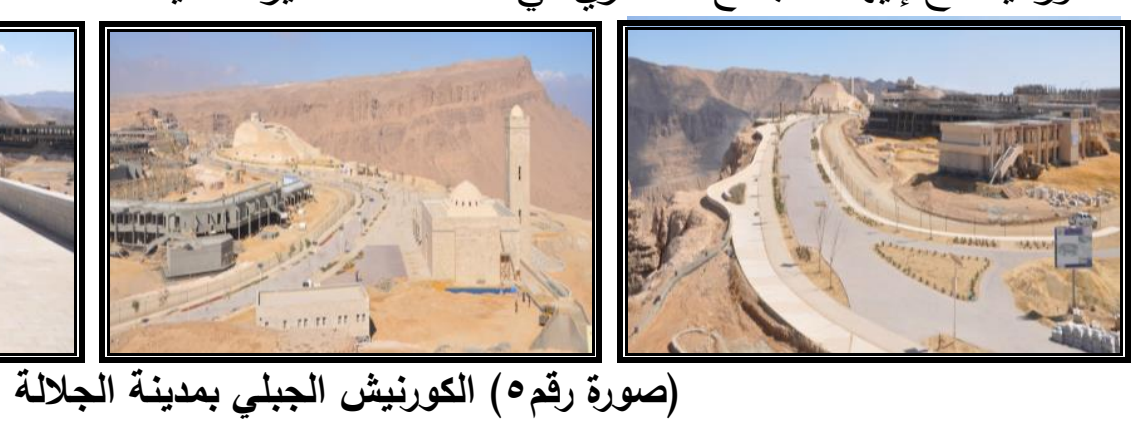

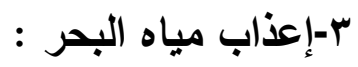

تم انشاء محطة معالجة وتحلية مياه البحر شمال فندق العين السخنة بالقرب من منطقة وصلة أبو

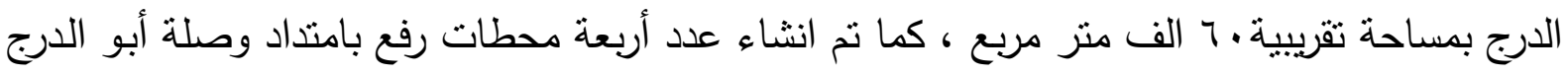

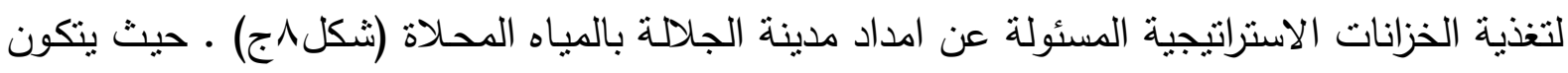
مشروع محطة معالجة وتحلية مياه البحر بمنطقة الدراسة من العناصر الرئيسية والتي تتمثل في نظام

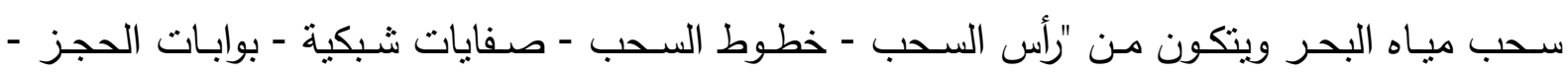

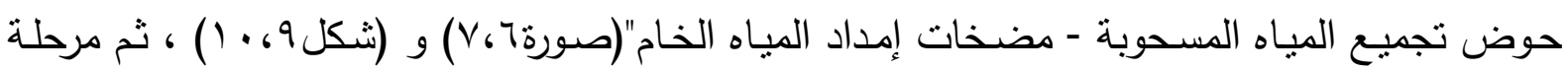
المعالجة الأولية وهي عبارة عن "الضبط الكيميائي - مرشحات الوسائط المضنغوطة - خزانات الغسيل

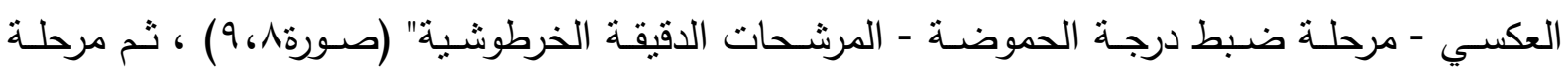

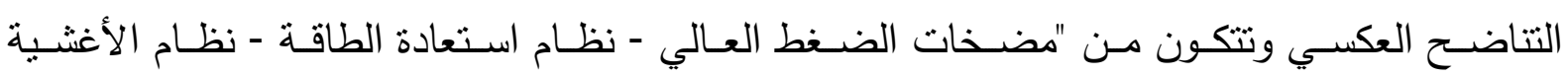

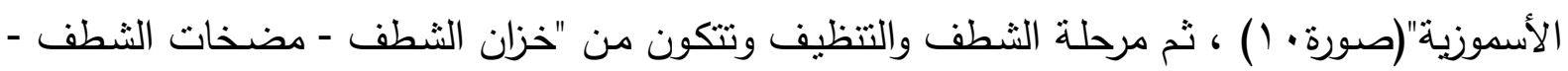

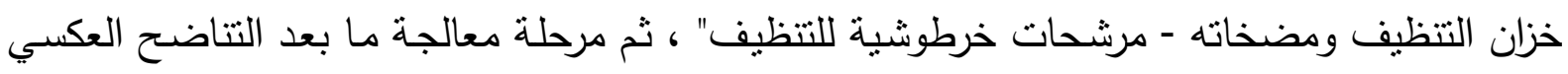

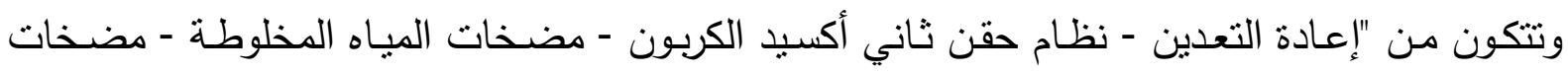

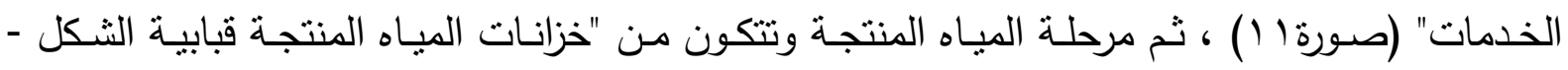

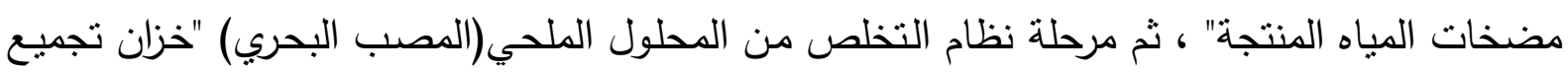

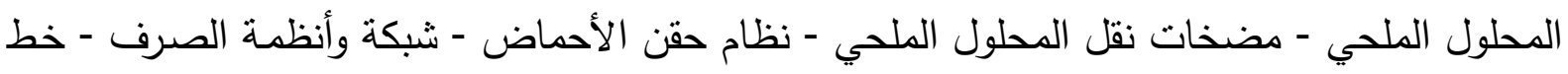

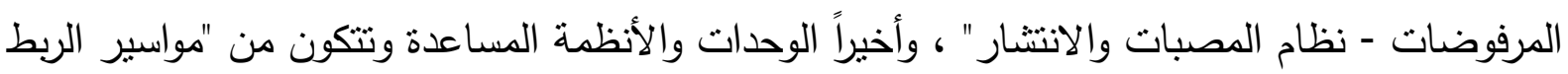

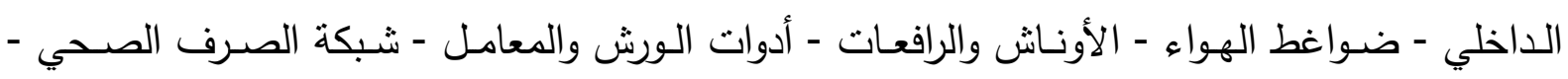
شبكة الثـرب الداخليـة للعاملين بالمحطة - شبكة إطفاء الحريق - شبكة المراقبـة التليفزيونيـة - أنظهـة الاتصالات - الأسوار والبوابات - إقامة العاملين - المولدات الكهربية" . 

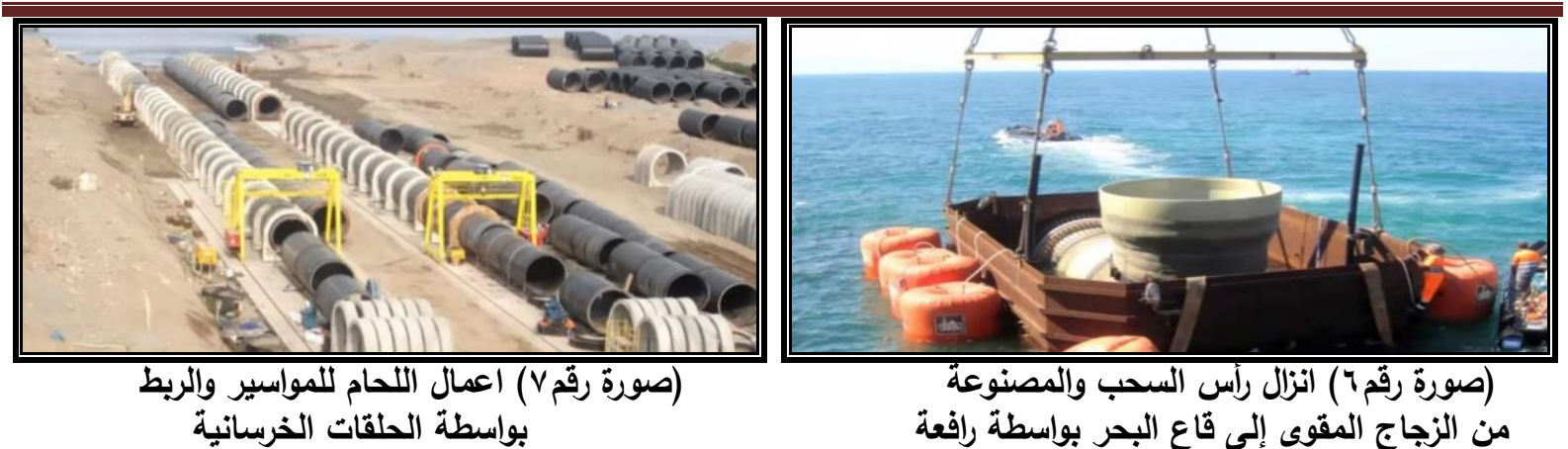

(صورة رقم ج) انزال رأس السحب وإلمصنوعة المقاعة

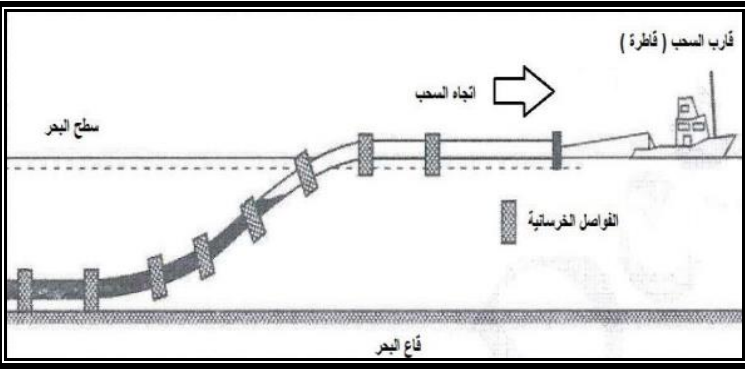

من الزجاج المقوى إلى قاع البحر بواسطة رافعة البعة

(ثكل رقم 9) نموذج لخط السحب البحري (ثكل رقم • 1) عملية الغمر المتدرج بواسطة الإغراق المتحكم به
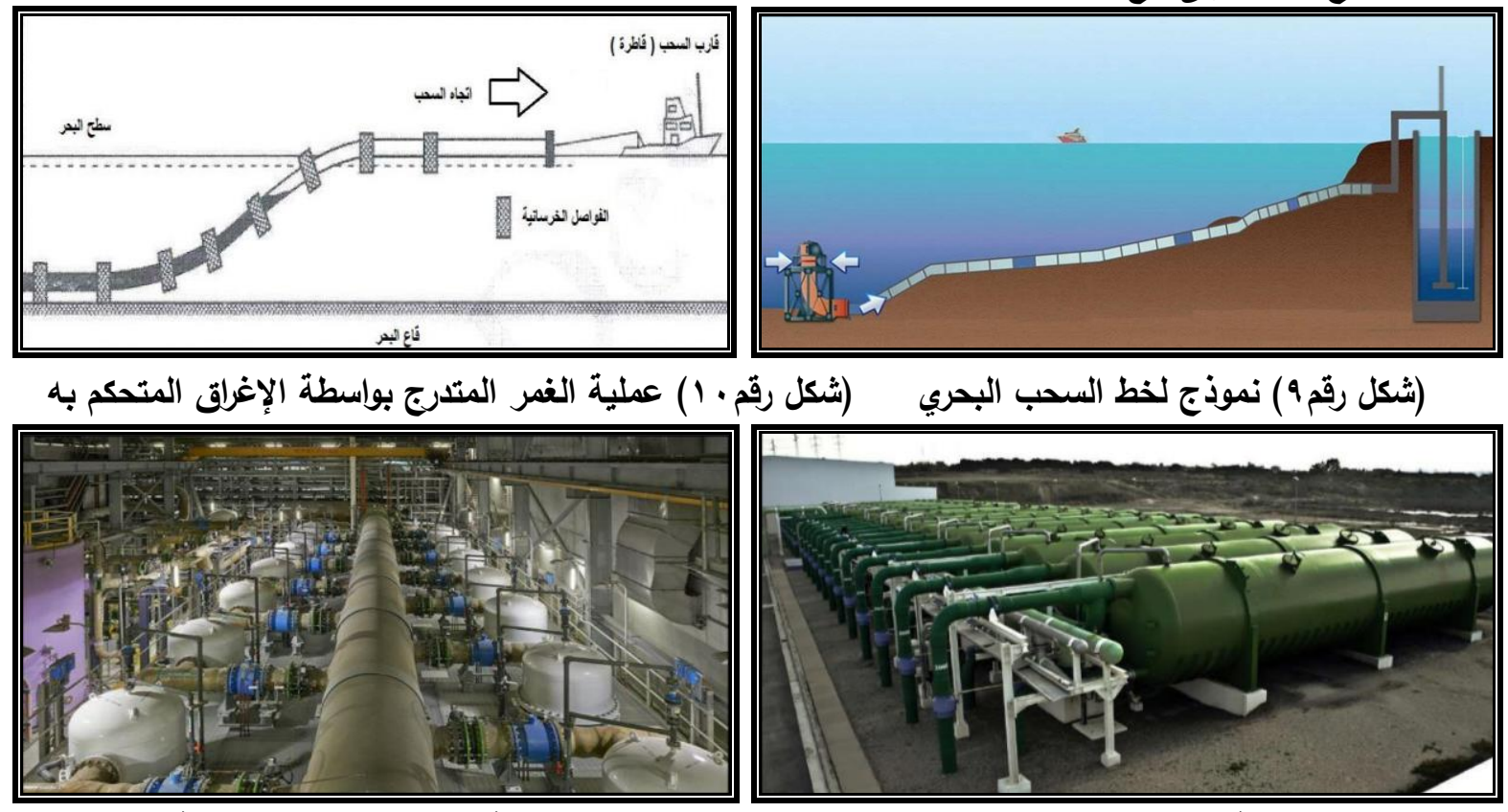

(صورة رقم 9) وحدات الترشيح الدقيق

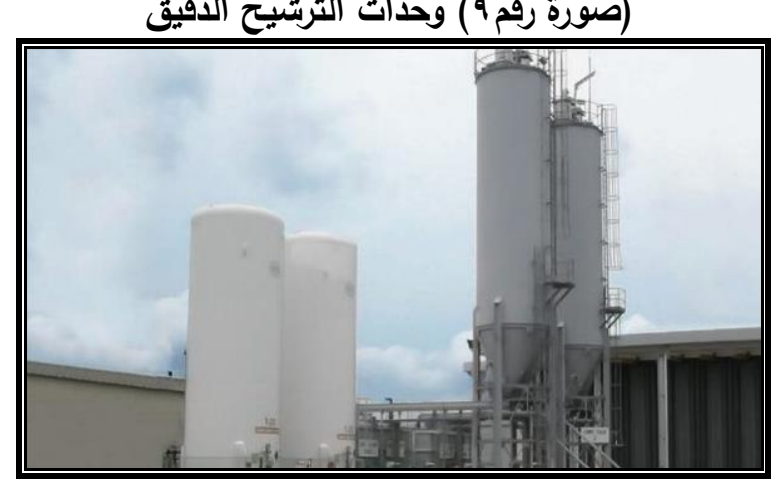

(صورة رقم 11) نظام اعادة التعدين للماء
(صورة رقم^) مرشحات الوسائط

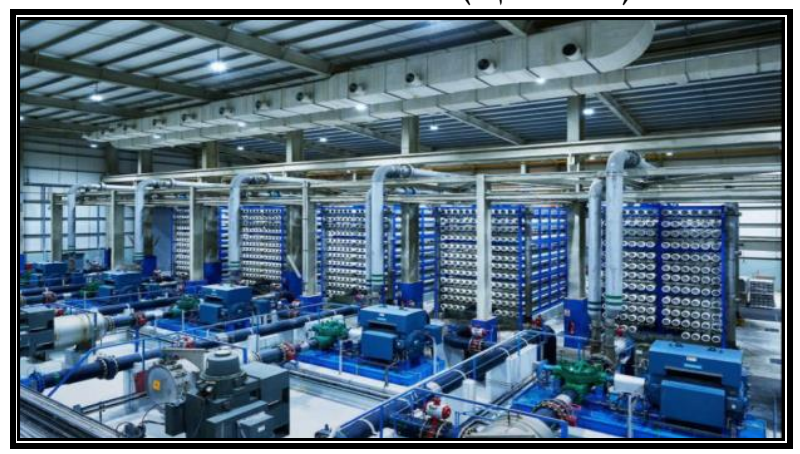

(صورة رقم + 1) وحدات التناضح العكسي

حيث تم تصميم المحطة لكى تقوم بإنتاج مياه محاله بقدرة ـ 0 الف متر مكعب يومياً وذلك بناء على البيانات التصميمية التالية من درجة حرارة مياه البحر تتراوح من • ب - ـ سدرجة مئوية ، ودرجة ملوحة مياه

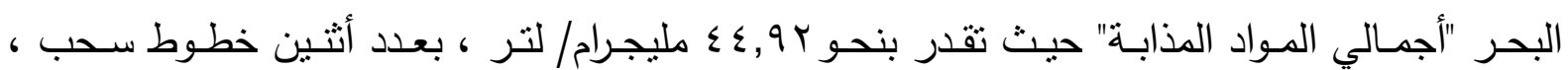
بأجمالي قدرة السحب اليومي بنحو هVrالف منز مكعب/ يوم ، بعدد عشرة خطوط للمعالجة الأسموزية ، بدرجة عكارة مياه التغذية بنحو NTU5. وتعمل المحطة بتكنولوجيا التتاضـح العكسي"ReverseOsmosis"حيث يتم سحب مياه البحر داخل محطة المعالجـة والتي يتت بها تمريـر ميـاه البحر مـن خلال الغشـاء الأسموزي ليتم انتاج ميـاه محـلاه بالإضافة إلى مياه بحر عالية الملوحة كمنتج ثانوي يتم التخلص منها بإعادتها إلى البحر (ثكل (1) . 


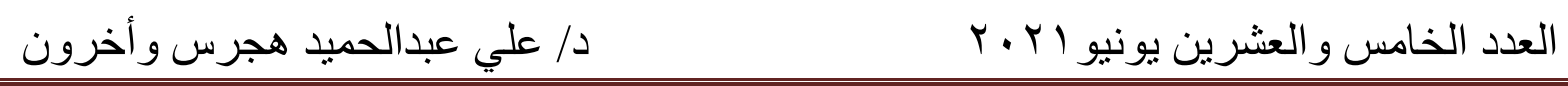

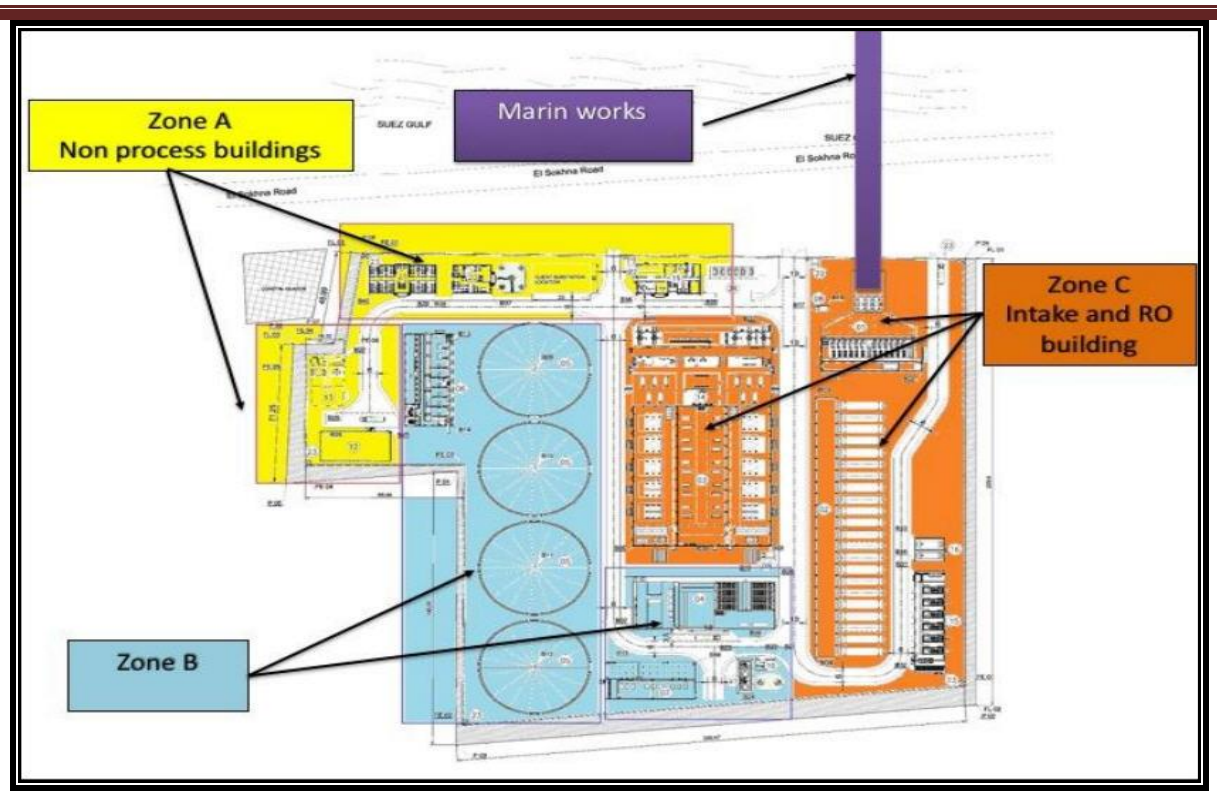

(شكل رقم 11) المخطط العام لمحطة معالجة وتحلية مياه البحر

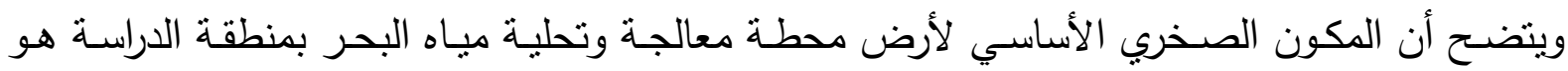

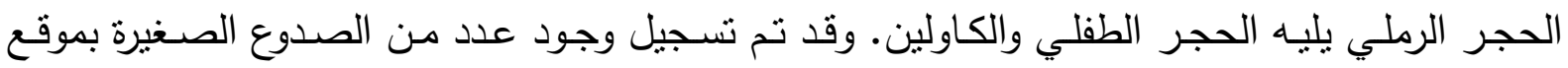

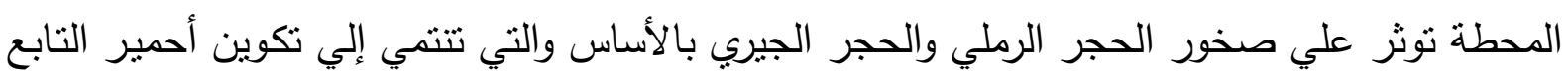
لعصر الكربوني الأعلى وتكوين مالحة التابع لعصر الكريتاسي الأسفل (صور باس ال).

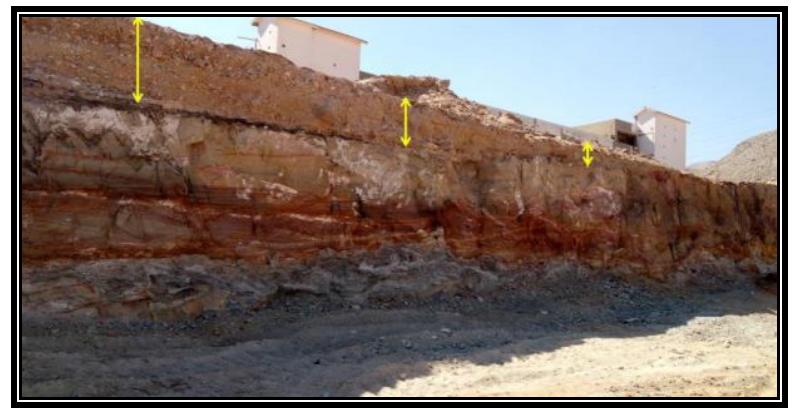

(صورة رقم Y 1) الاختلاف في سمك طبقة الحجر الرملي والجيري والطفلة بأرض المحطة

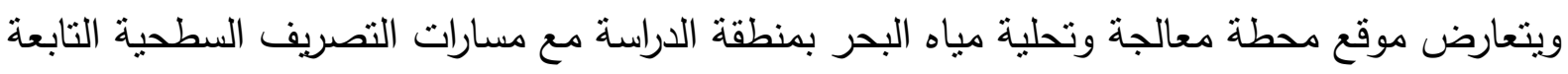

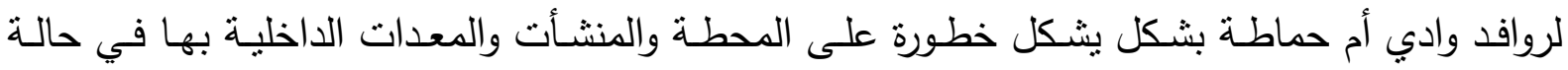

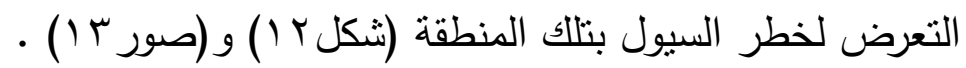

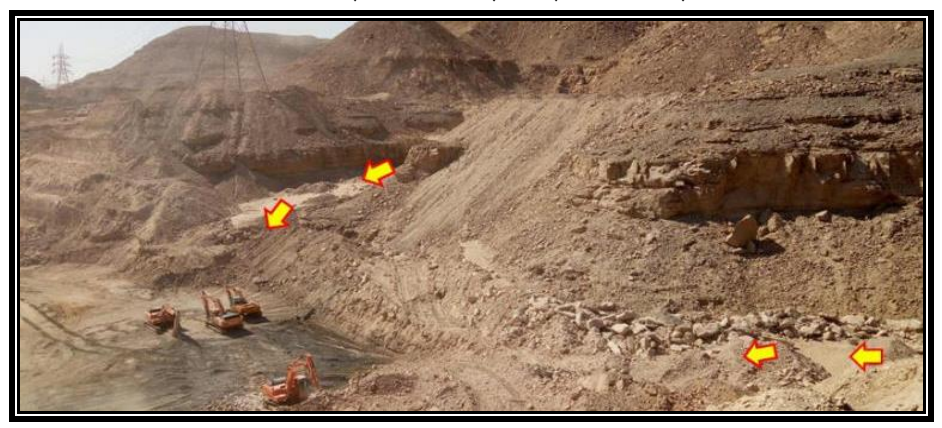

(صورة رقم ب 1 ) مسارات التصريف السطحية باتجاه موقع المحطة بشكل يشكل خطورة وتعرضها لخطر السيول 


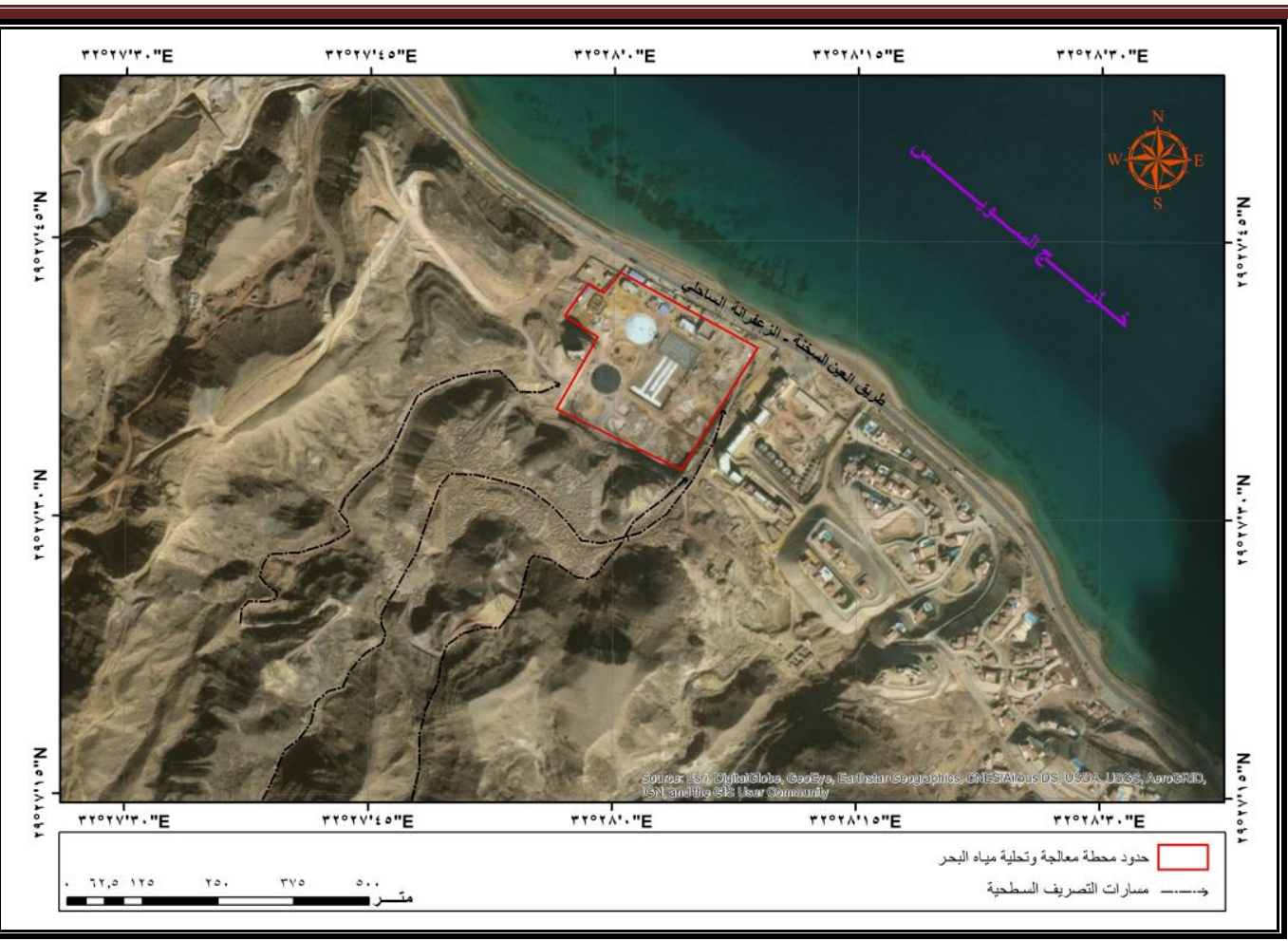

(شكل رقم r 1) موقع محطة معالجة وتحلية مياه البحر وتعارضها مع مسارات التصريف السطحية بشكل يشكل خطورة

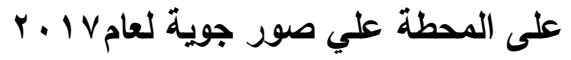

ب- طريق العين السخنة - الزعفرانة الجبلي "طريق هضبة الجلالة البحرية ووصلاته الفرعية" :

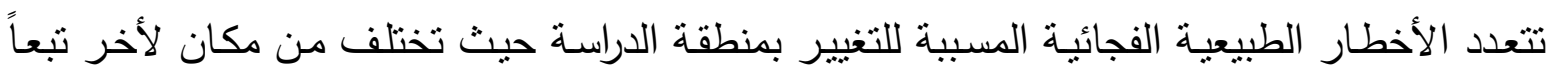

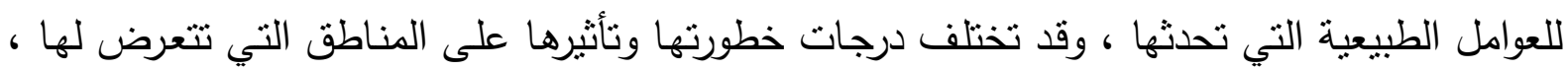

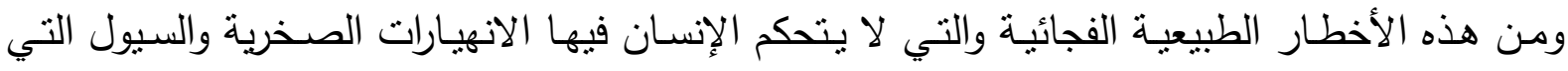

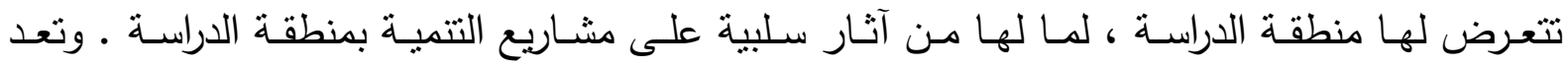

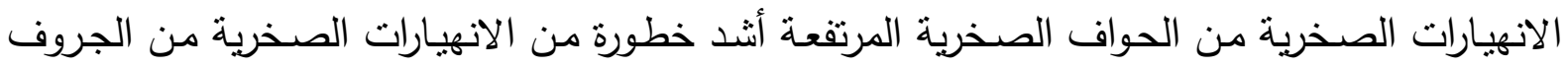

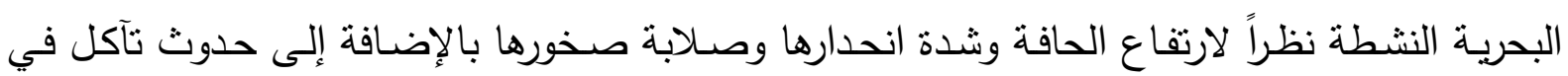

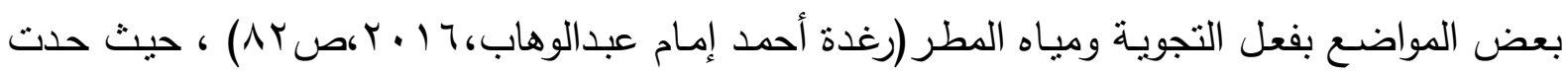

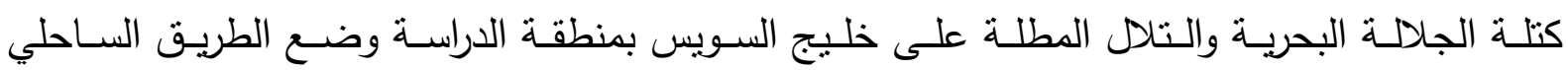

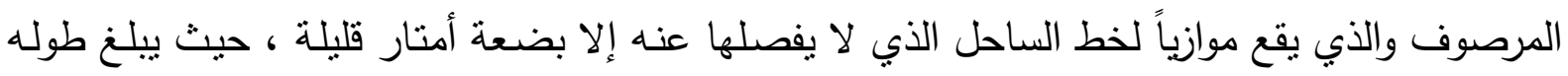

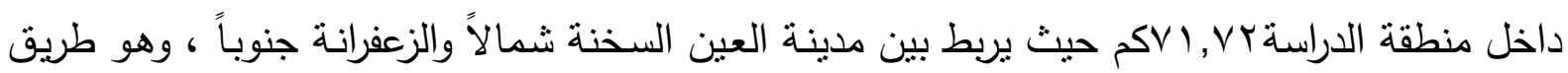

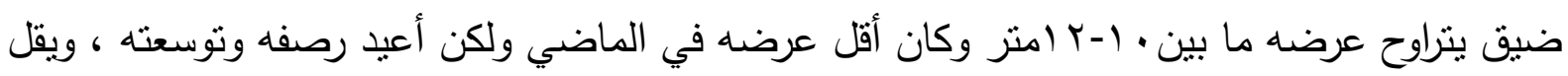

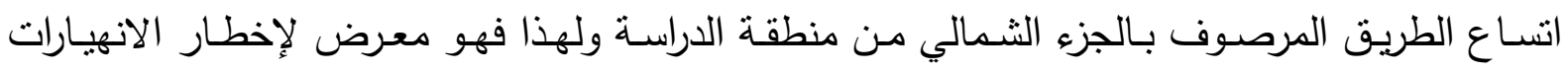
الصخرية الفجائية حيث تظهر الحافة في كثثر من المواضع كحائط صدعي شاهق الارتفاع (صورة؛ ( )

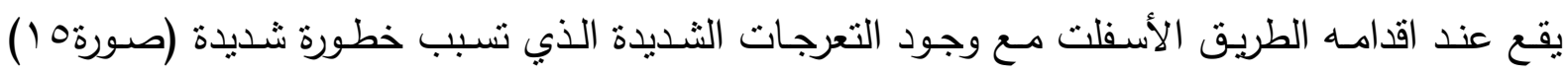

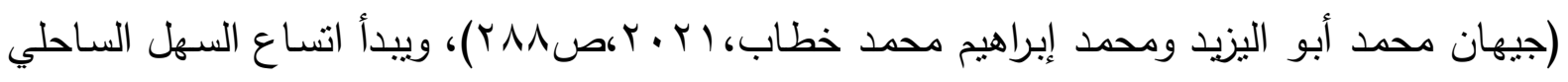

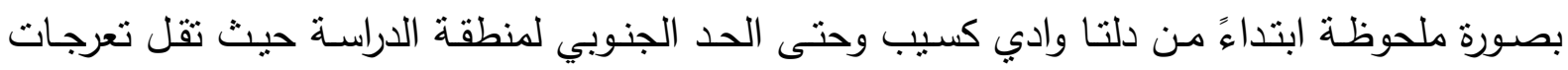


الطريق ويزداد ابتعاده عن خط الساحل ويتسم الطريق في هذا الجزء بقلة انحداره ، وبالتالي فهو أقل خطورة عن الجزء الثمالي ولكنه يتميز الطريق في هذا الجزء بأنه أكثر تعرضـاً لأخطار السيول نظراً

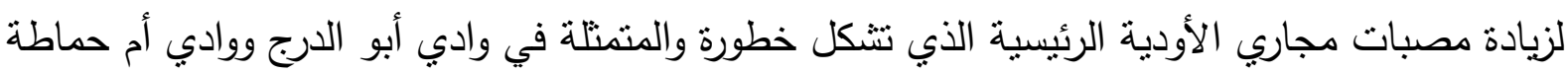
ووادي كسيب .
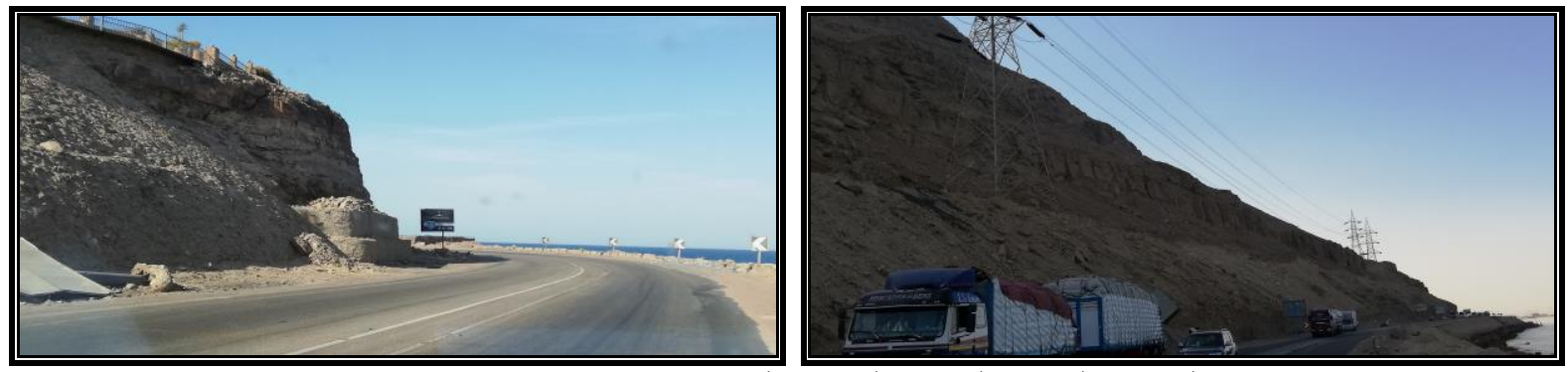

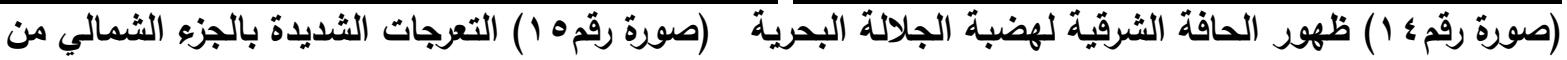
الطريق الساحلي والذي تسبب حوادث ميتيته. كائط صدعي يوثر علي الطريق الساحلي.

ولمعالجة تلك الأخطار تتبهت الدولة لذلك فقامت بأنشاء طريق العين السخنة - الزعفرانة الجبلي "طريق

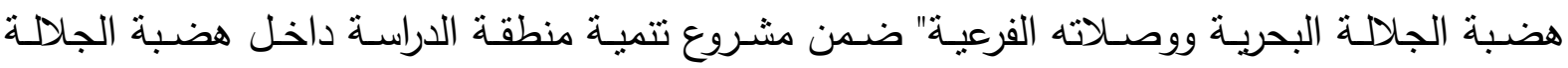

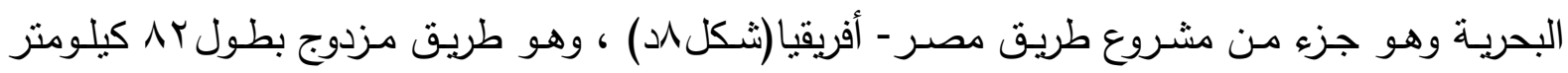

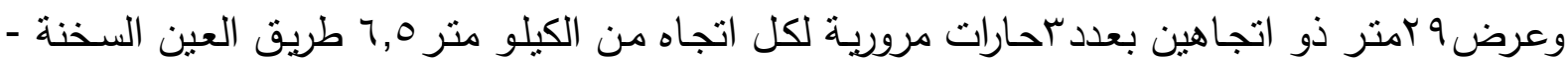

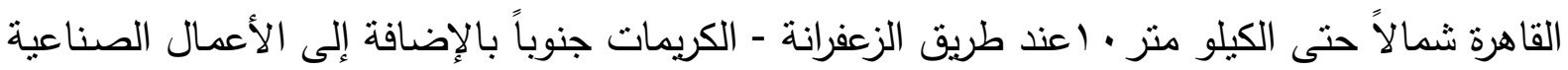

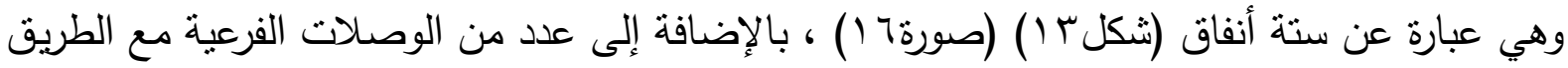

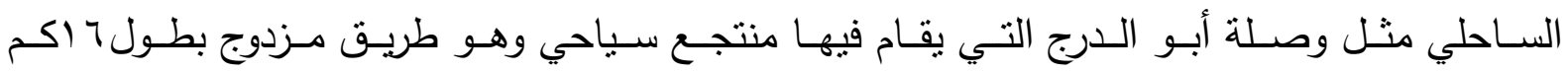

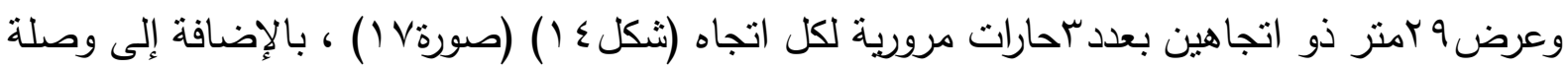

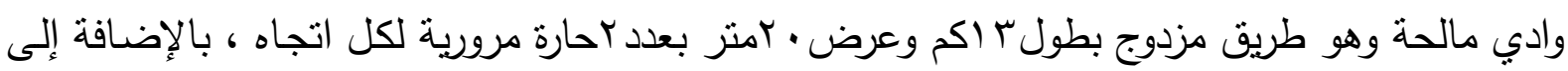

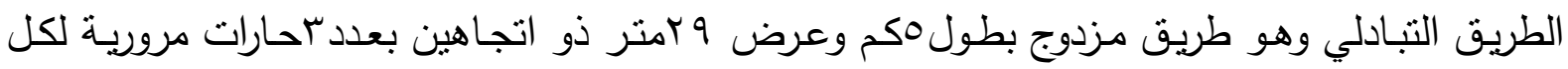

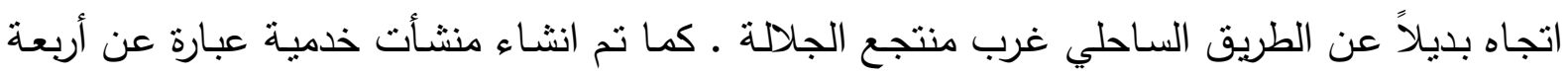

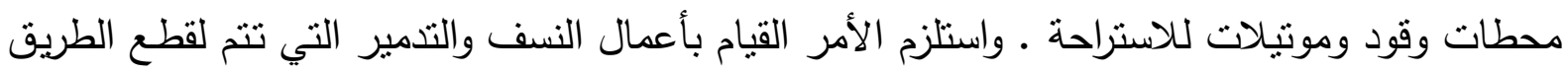

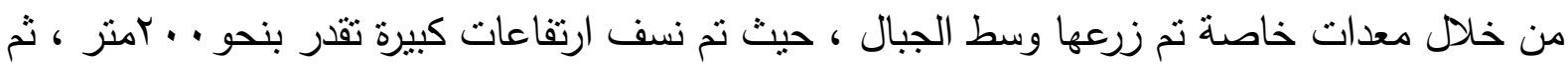

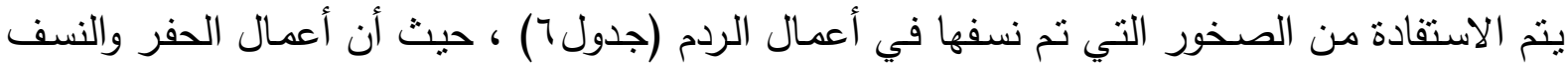
يُينى بها جسم ترابي للطريق. وترجع أهمية طريق هضبة الجلالة البحرية ووصلاته الفرعية إلي أنه سوف يتفادى كل سلبيات طريق

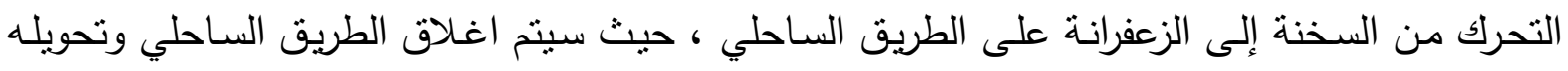

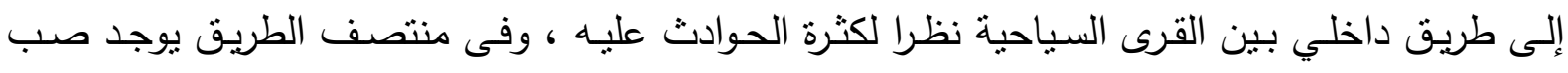

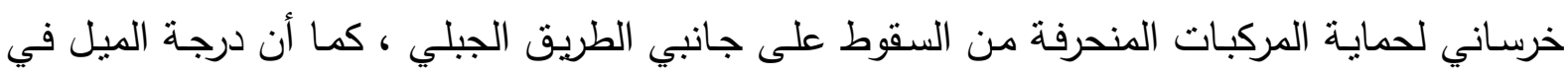

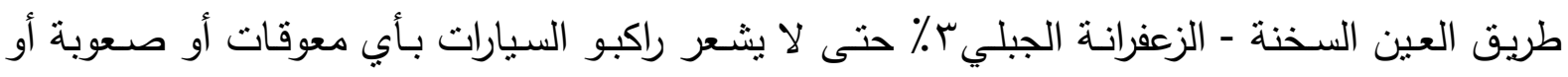

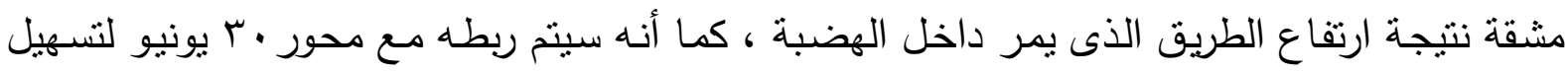


حركـة التجـارة بين مصـر ودول قارة افريقيا ، وكذلك ربط المشروعات الزراعيـة والسياحية والمنـاطق

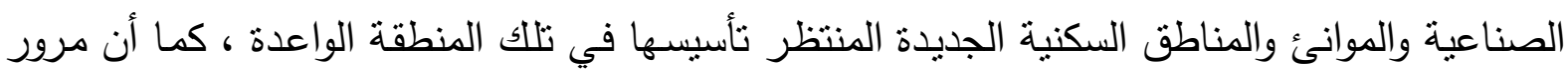
الطريق الجديد بمنطقة المحاجر التي يوجد بها جميع أنواع الخامات المهمة ، مثل الرئل الرخام وخام الكولينا

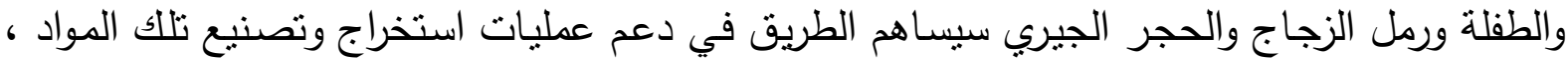

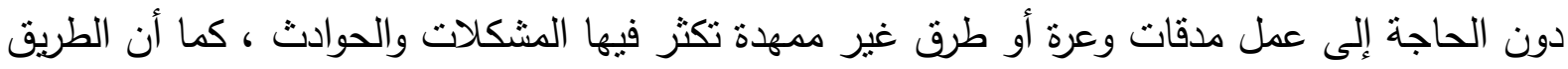

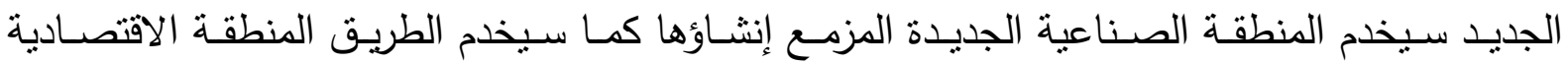

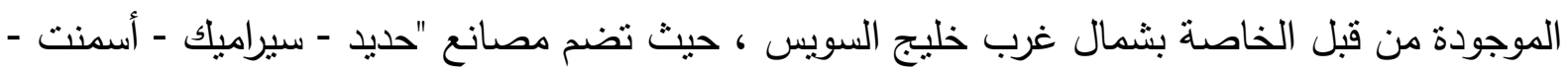
بتروكيماويات" ، كما سيسكل الحركة من الجنوب إلى ميناء العين السخنة .
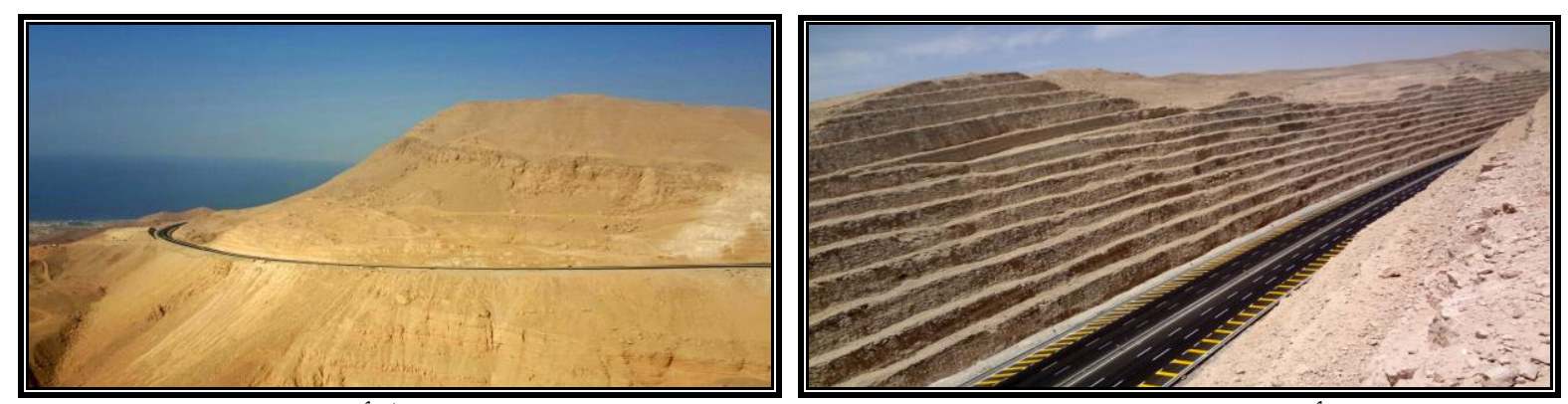

(صورة رقم V ) وصلة أبو الارج بطول ؛ اكم

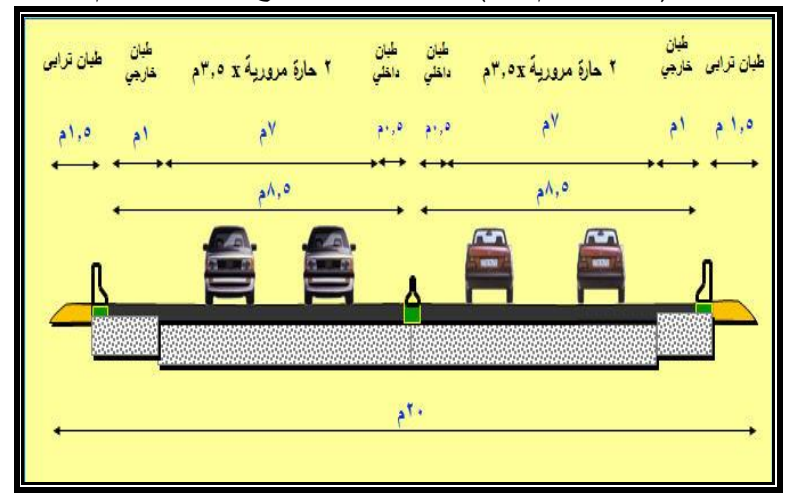

(شكل رقم ب 1) طريق مزدوج ثلاثة حارة مرورية لكل اتجاه بطول ب ركم (شكل رقم ؛ ( ) طريق مزدوج اثثين حارة مرورية لكل اتجاه
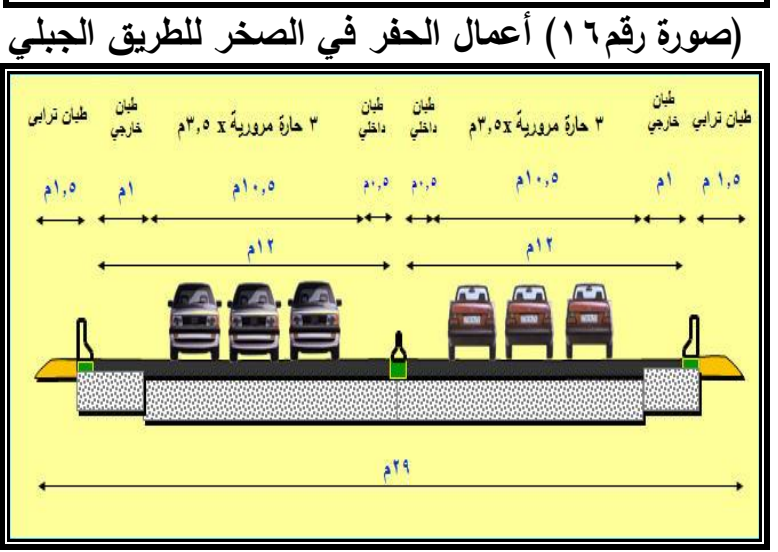

(جدول رق ؟) كميات الحفر والردم بطريق هضبة الجلالة ووصلاته الفرعية

\begin{tabular}{|c|c|c|c|}
\hline كميات الردم م" & كميات الحفر م" & الطول كم & اسم المشروع \\
\hline $01 \ldots \ldots$ & $0.0 \ldots .$. & Ar & طريق هضبة الجلالة البحرية \\
\hline$v_{Y} \ldots . .$. & $110 \ldots .$. & 17 & وصلة أبو الدرج \\
\hline $17 \ldots$ & $9 \ldots$. & 14 & وصلة وادي مالحة \\
\hline $100 \ldots$ & $\wedge \ldots \ldots$ & 0 & الطريق التبادلي \\
\hline "r..... & rq..... & ro & المرحلة الأولى لنشبكة طرق مدينة الجلالة \\
\hline vo... & ro.... & $r$ & طريق الفندق الجبلي \\
\hline $90 \ldots$ & $r \ldots .$. & $r, 0$ & طريق منتجع الجلالة الجبلي \\
\hline $00 \ldots$ & $1 \cdots$ & $r, 0$ & طريق محطة وقود الجلالة \\
\hline $1 Y \ldots \ldots$ & $\wedge \ldots$ & $r, 7$ & طريق قاعة المؤتمرات \\
\hline TVRTO... & Атrq.... & 174,7 & الإجمالي \\
\hline
\end{tabular}

المصدر: (الهيئة الهندسية للقوات المسلحة ،919 ـ ب، بيانات غير منشورة) 
تمثل المياه أهم العوامل المشكلة لأسطح أحواض منطقة الدراسة ، ويظهر تأثيرها بوضوح على

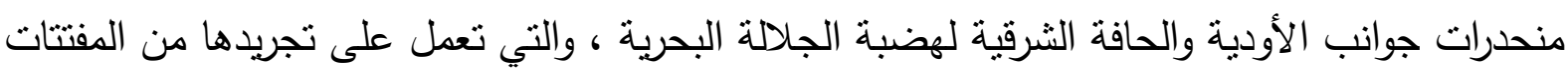

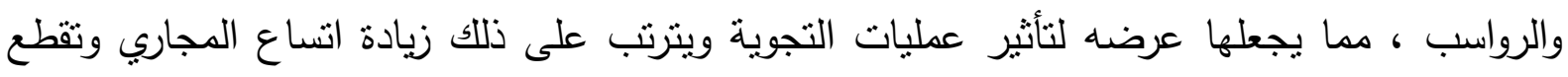
المنحدرات بواسطة المسيلات المائية الني تعمل على تراجعها ، حيث تعد السيول من الظواهر الفجائية

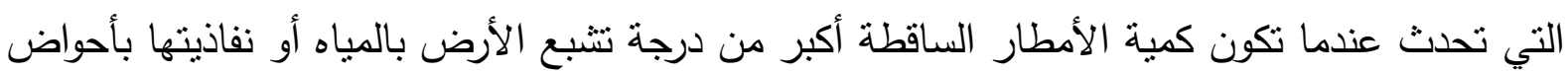

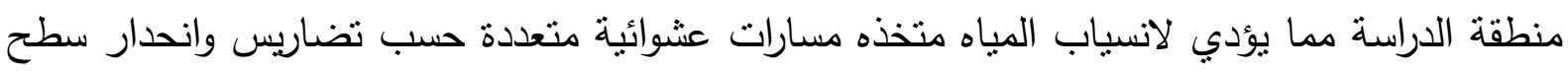
اراضي الأحواض والتي تتحد مكونه مجاري سيلية تصب في مجاري الأودية الرئيسية لتتنهي بمروحة

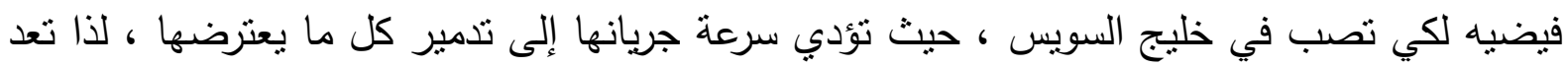

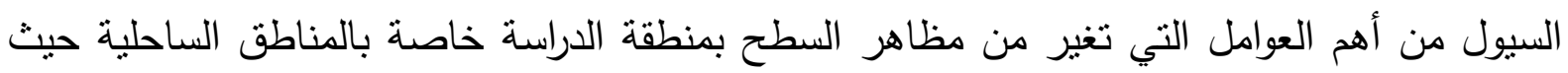

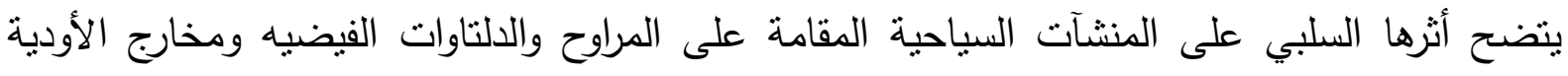

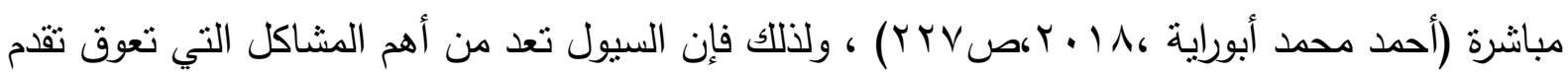

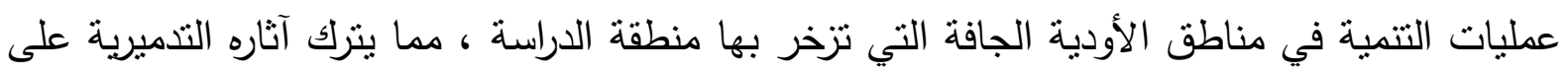

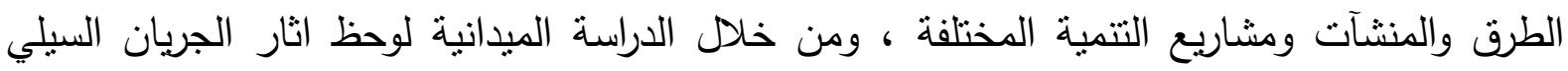

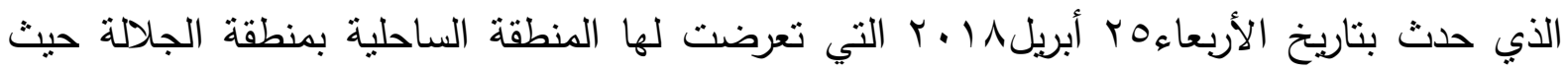

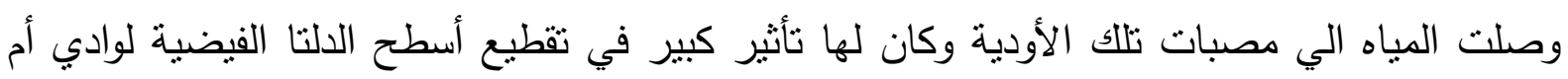

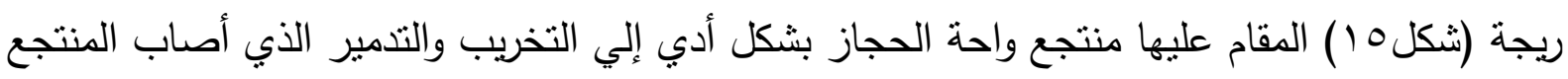

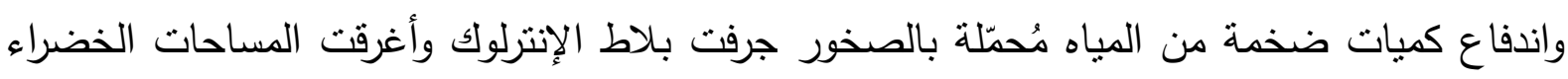

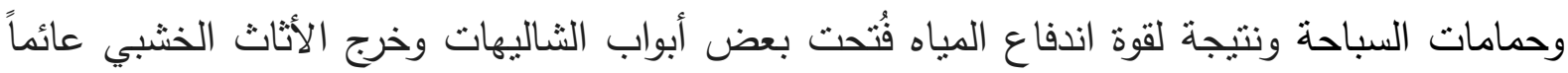

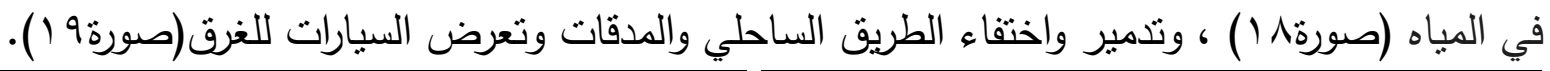
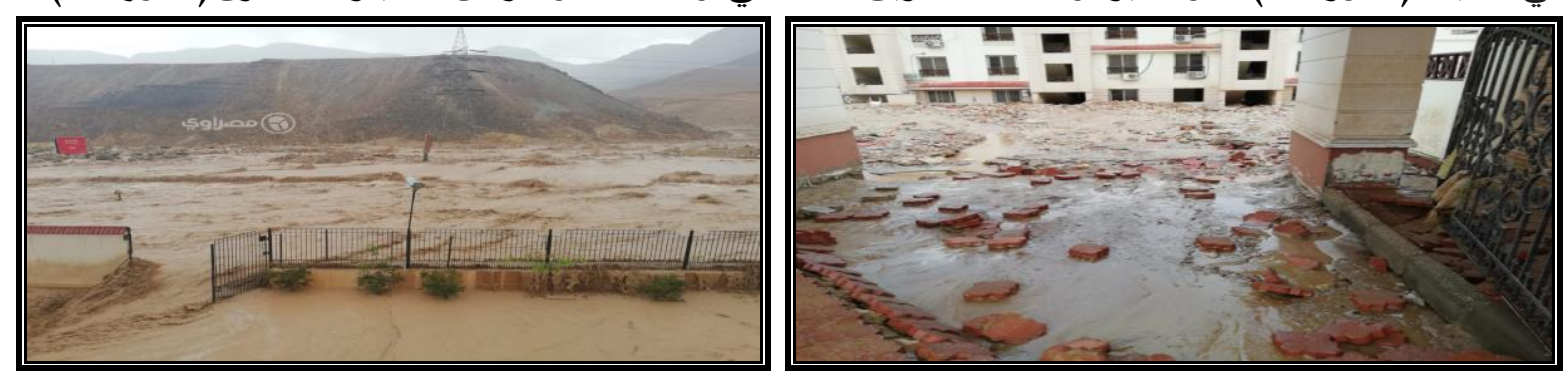

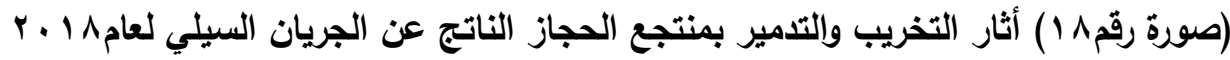
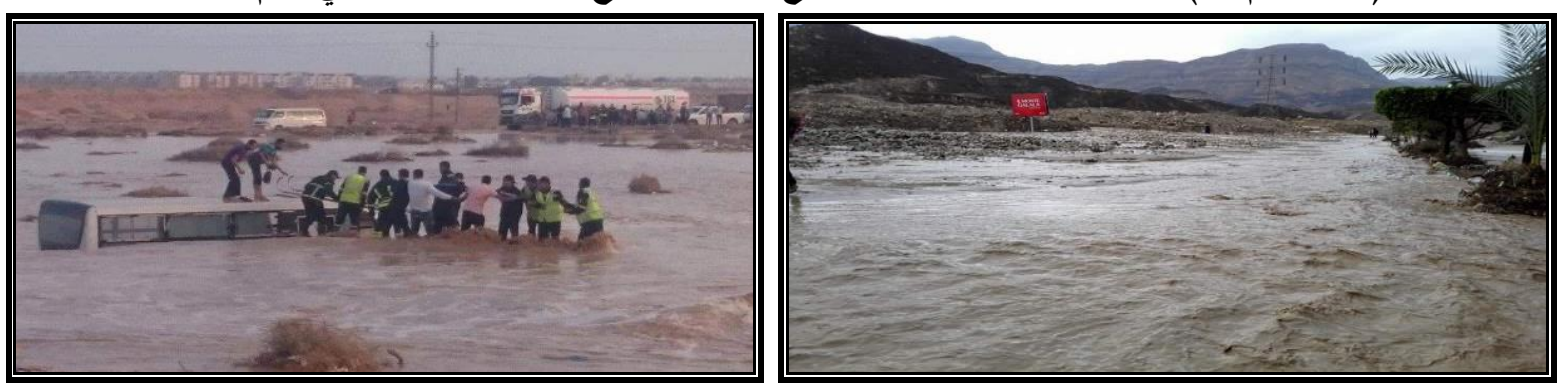

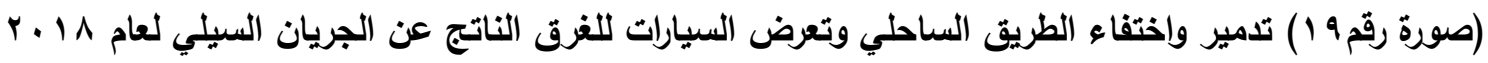




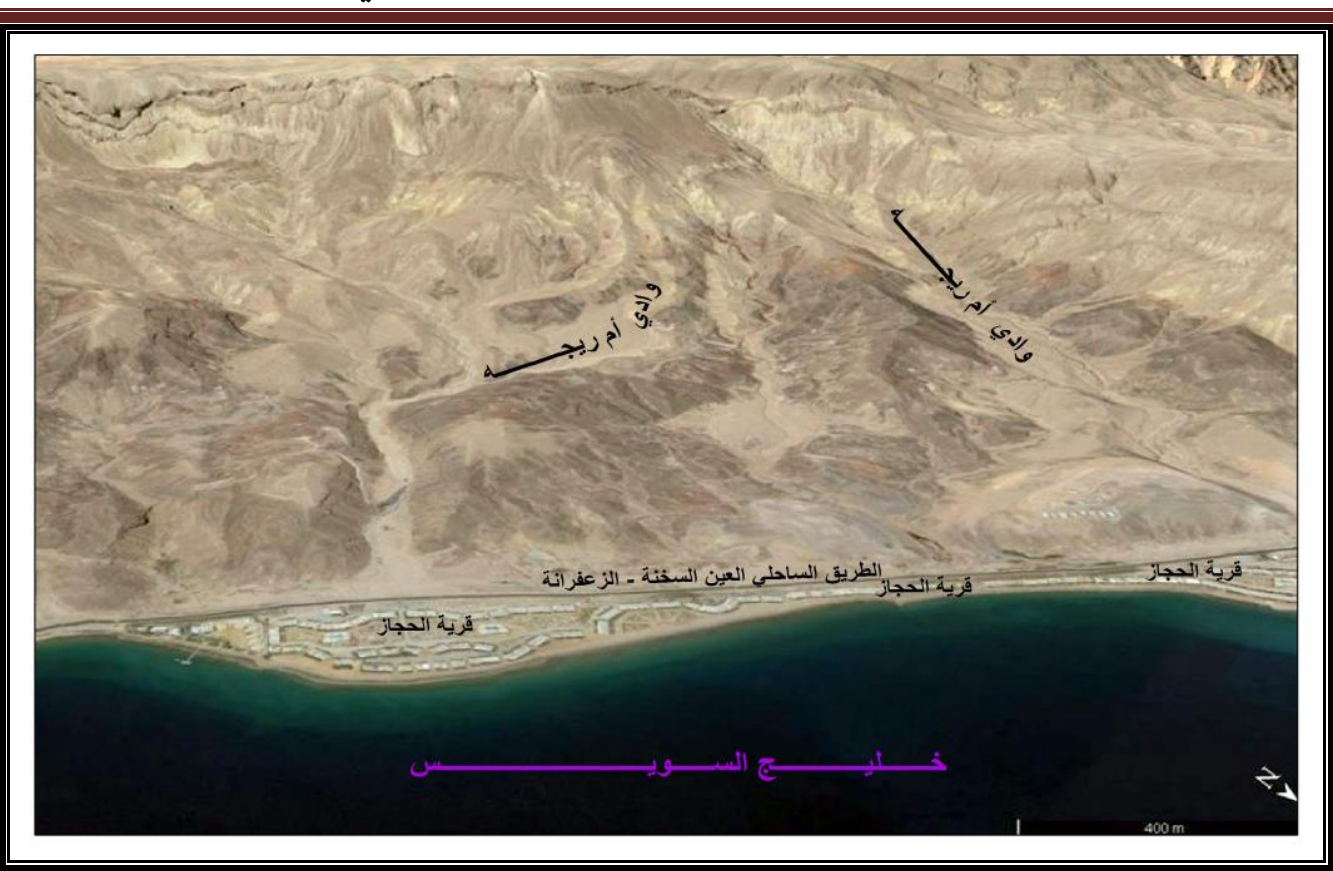

(شكل رقم 1 ) موضع قرية الحجاز بالمروحة الفيضيه لودي أم ريجه والتي تعرضت للتخريب بفعل سيل

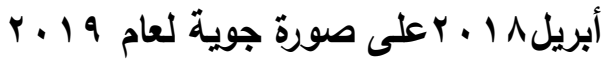

ولتجنب تلك الأخطار الفجائية الناتجة عن الجريان السيلي بمنطقة الدراسة تتبهت الدولة لذلك فقامت

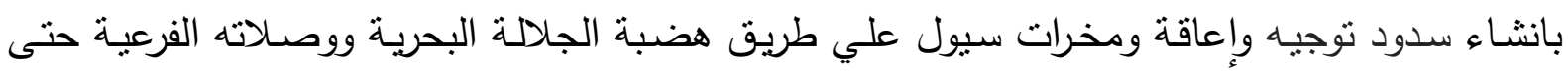

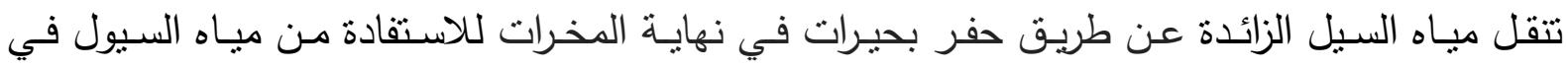

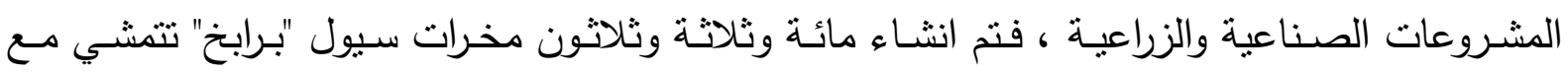

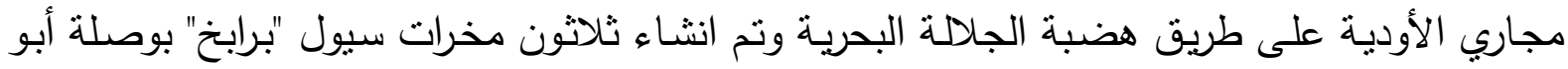

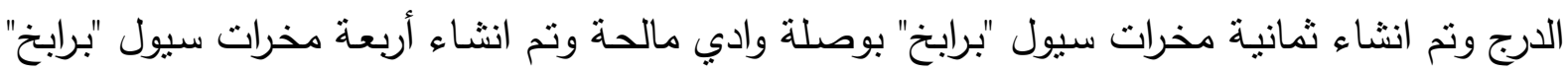
بالطريق التبادلي الذي يقع غرب منتجع الجلالة (صورة · ب) •
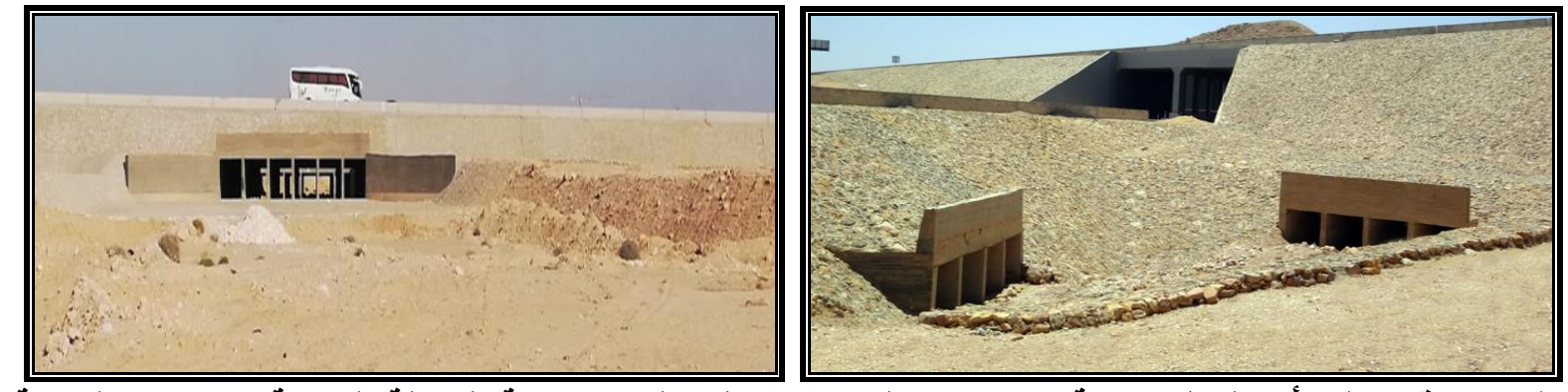

(صورة رقم · r) الأعمال الصناعية مخرات سيول "برابخ" علي طريق هضبة الجلالة البحرية ووصلاته الفرعية

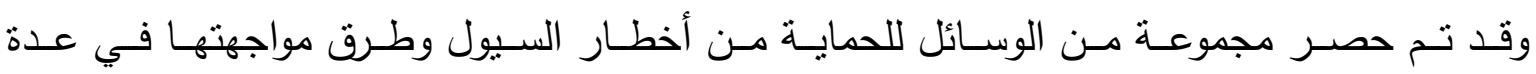

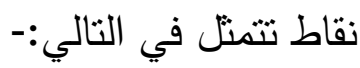

- إنشاء مجموعة سدود من المواد الصخرية المفككة على الروافد الرئيسية للأودية بحيث لا يزيد كل من

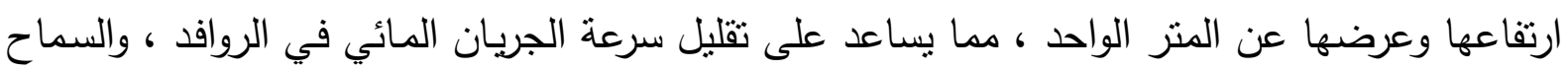

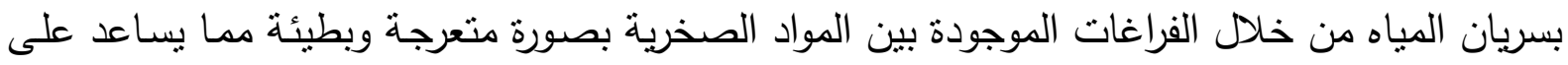

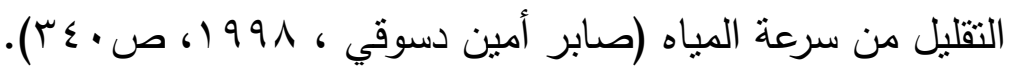




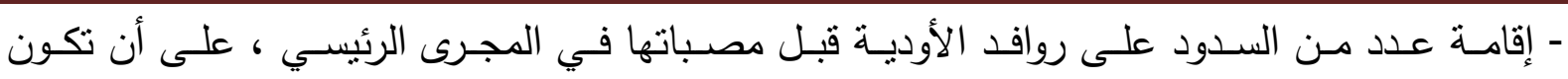

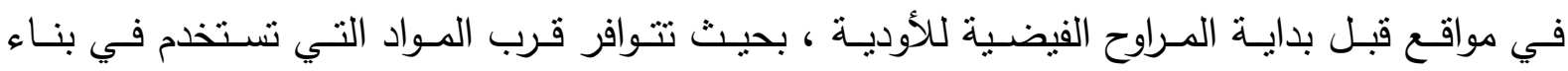

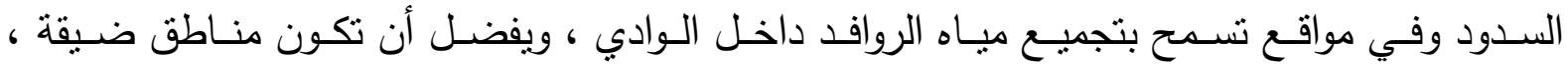

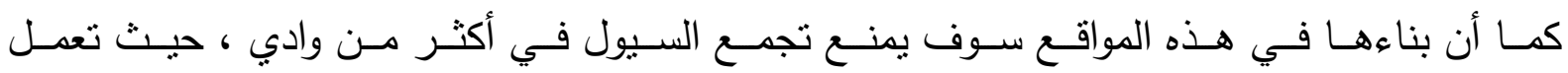

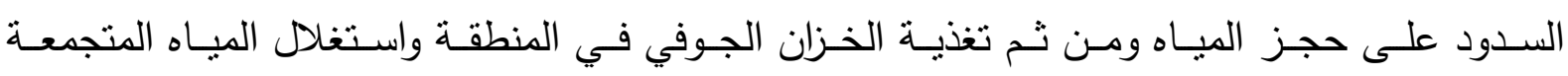

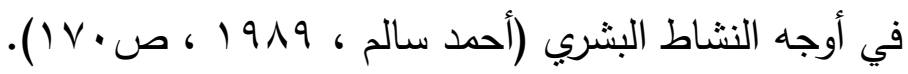

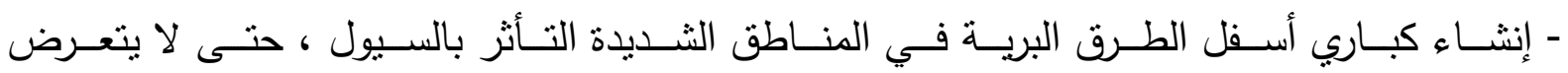

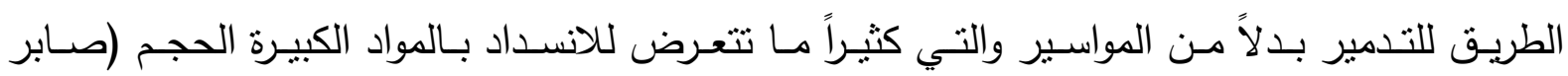

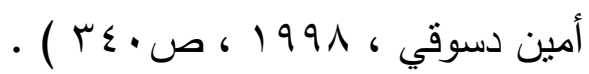

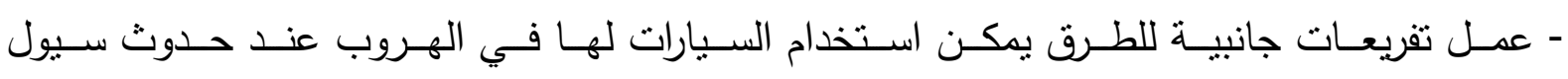

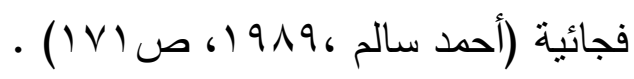

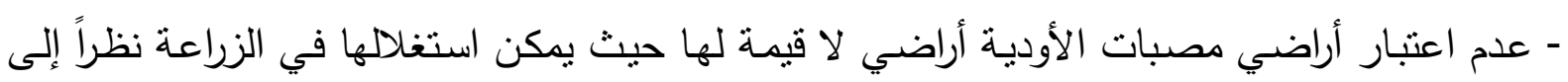

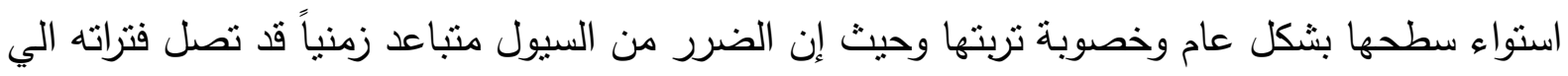

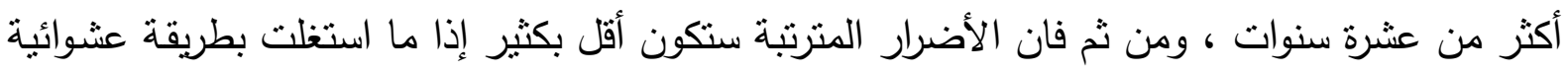

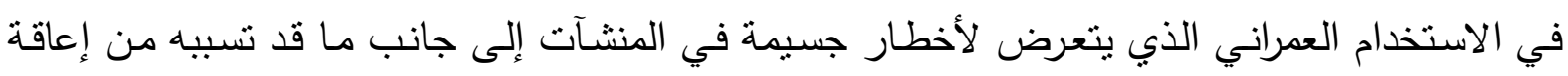

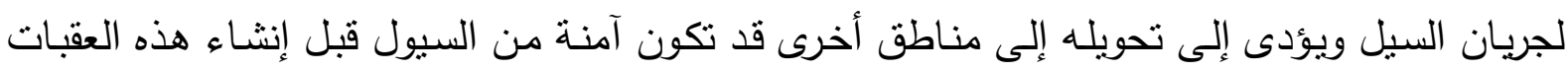

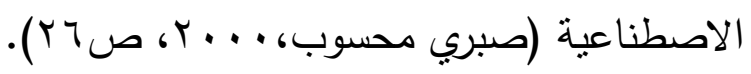
- عدم بنـاء المسـاكن في مجـارى السيول وكذللك التخطيط السـليم لإنشـاء الطـرق والمنشـآت بعيدا عن مجارى السيول لتفادى أخطارها المدمرة والتي تصل أحيانا إلى وفاة بعض الأل الأفراد. - توظيف نظم الاستشعار عن بعد Remote Sending في إعطاء معلومات مؤكدة عن تحليل بيانات

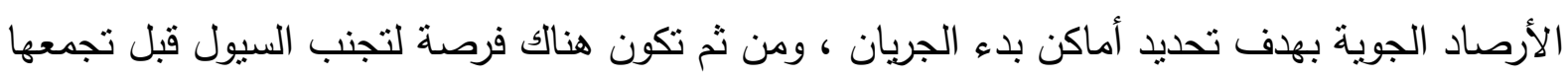

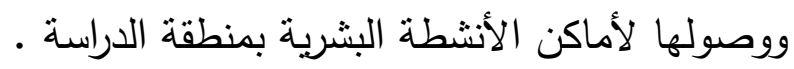
- إنشاء نظم الإنذار المبكر في المناطق الثديدة التأثر بالسيول بإستخدام أحد أنواع الإثـارات التحذيرية، وإقامة محطات تسجيل مجهزة في المناطق الحرجة وربطها ببعضها البعض البنار الكترونياً.

ج-المنطقة الصناعية: تقام المنطقة الصناعية الجديدة لتطوير وتعظيم الاستفادة من منطقة المحاجر التي يوجد بها جميع

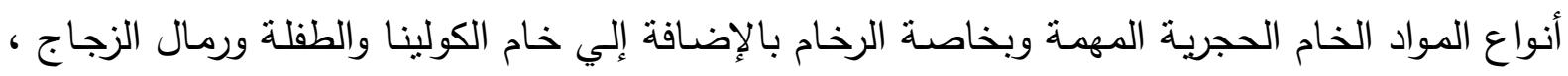

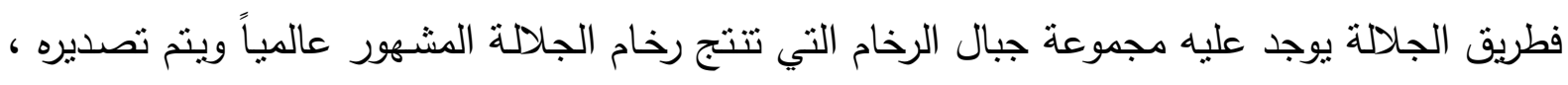

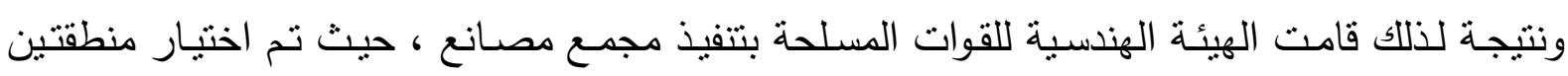
جنوب طريق العين السخنة - القاهرة بالقرب من بوابة تحصيل رسوم طريق هضبة الجلالة ، فالمنطقة 


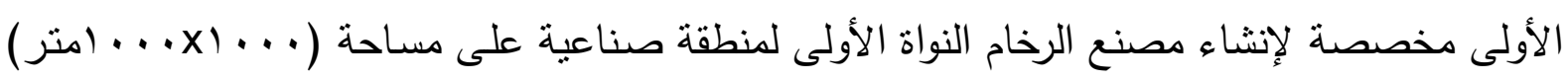

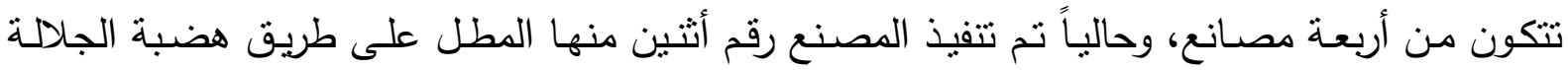

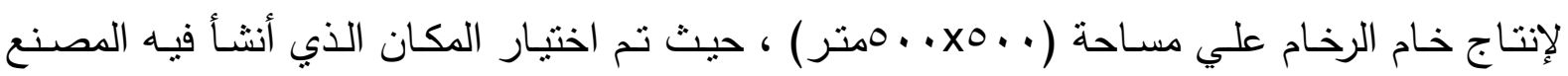
ليتوسط أماكن نواجد المادة الخام حيث محاجر الجلالة ، ويتكون المصنع رقم الثنين الذي يعمل حالياً من

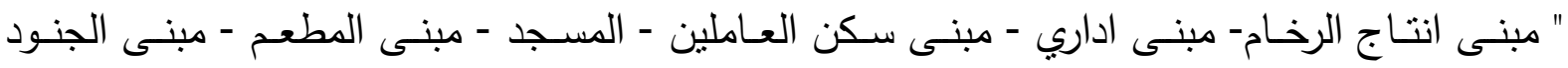

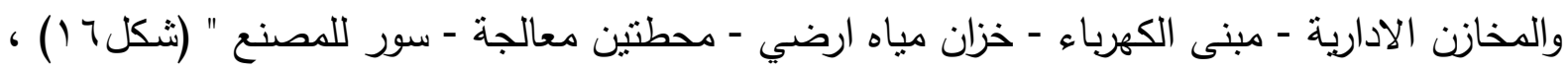

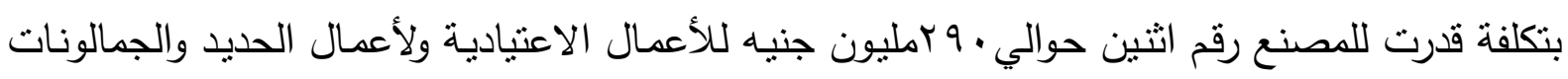

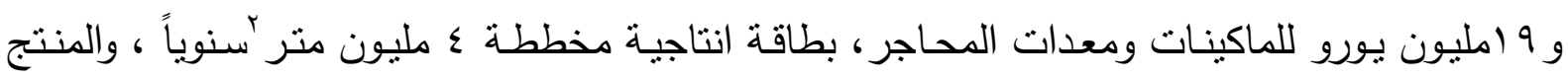

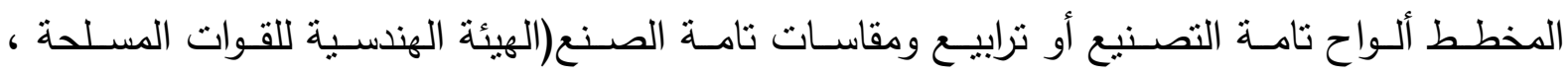

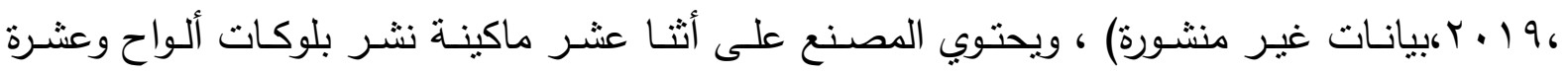

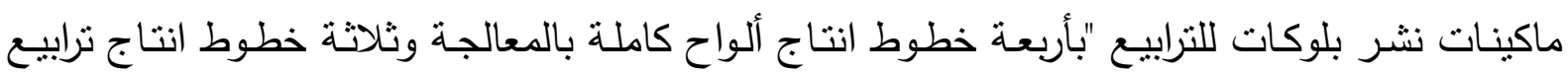

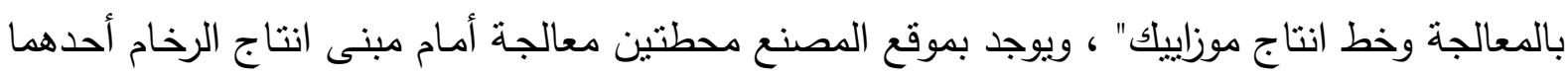

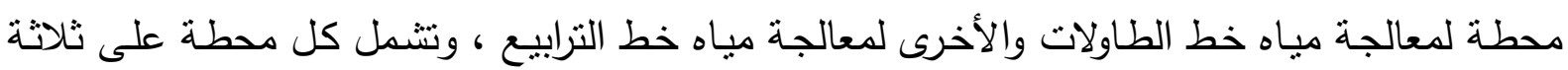
صوامع أثثين منها لترسيب المياه قبل المعالجة والصومعة الأخرى لتخزين المياه بعد المعالجة وترتبط كل

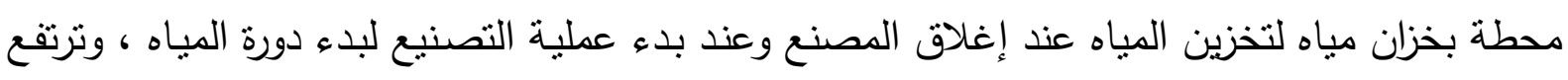

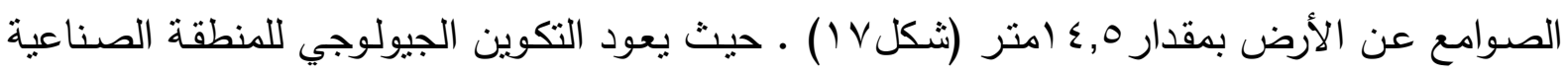

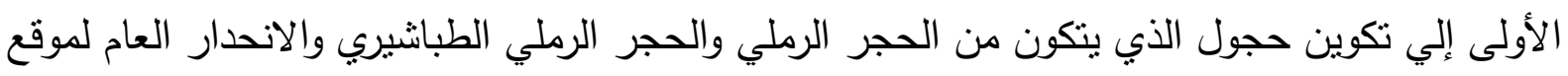

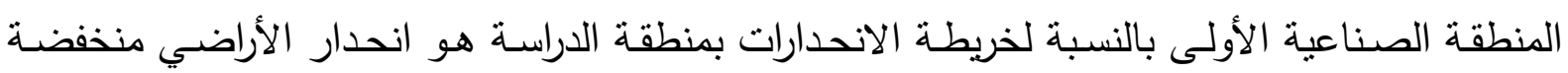

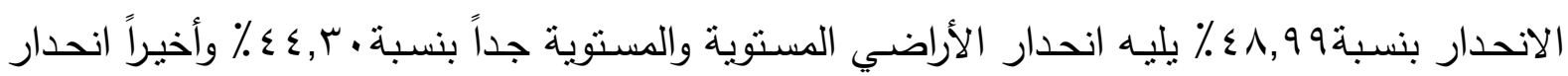

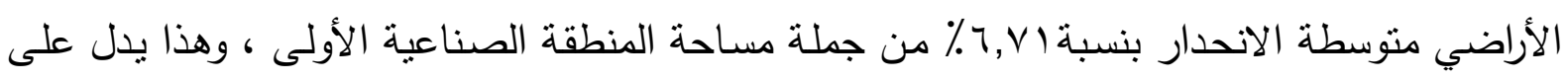

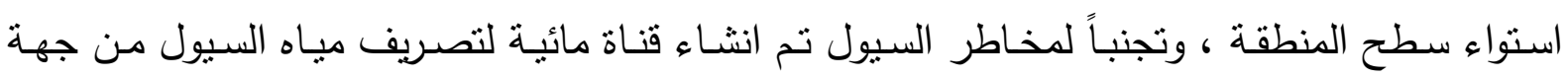

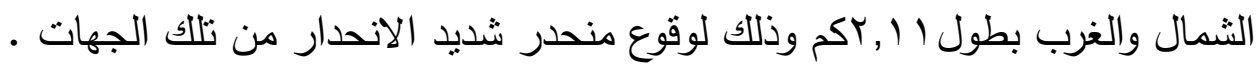

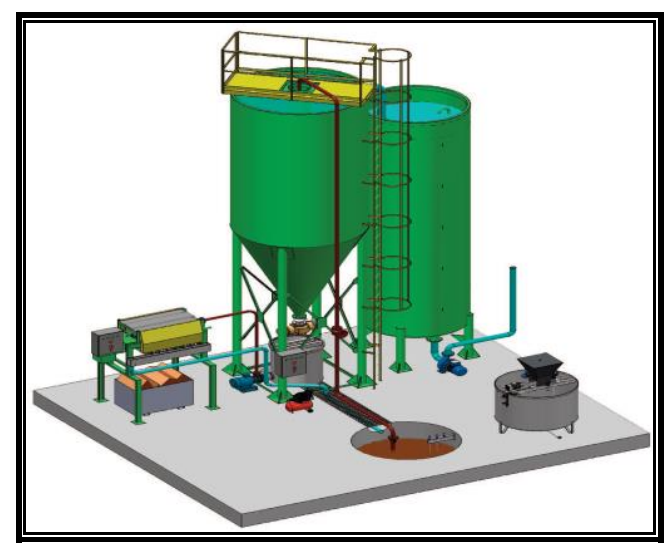

(تشكل رقم V ) نموذج ثلاثي الأبعاد لمحطة معالجة مياه خط الطاولات والترابيع

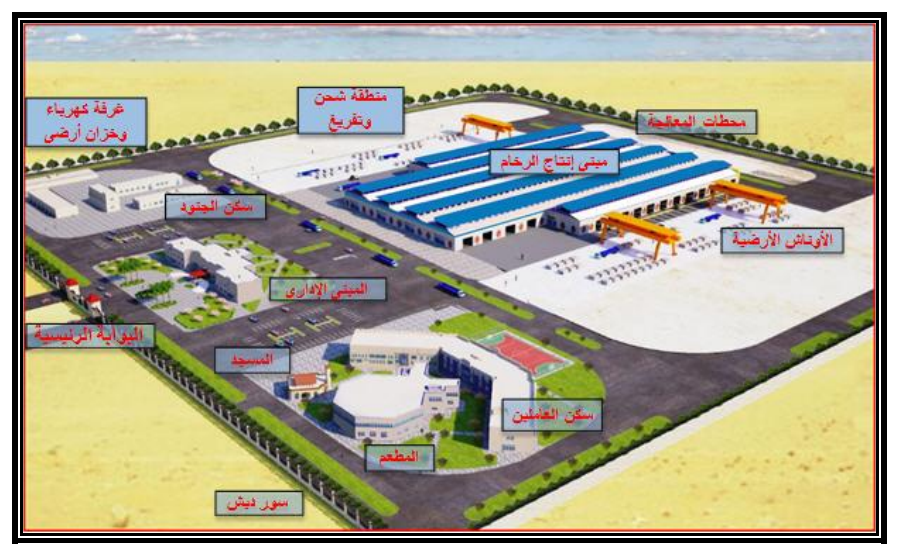

(شكل رقم 1 ) ) موقع مصنع الرخام رقم أثنين من منظور ثلاثي الأبعاد بمنطقة الدارية 


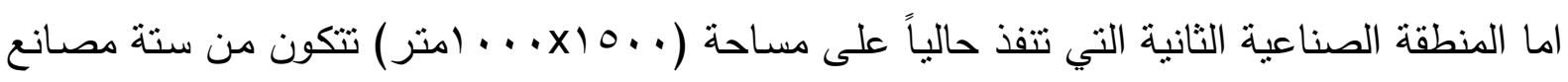

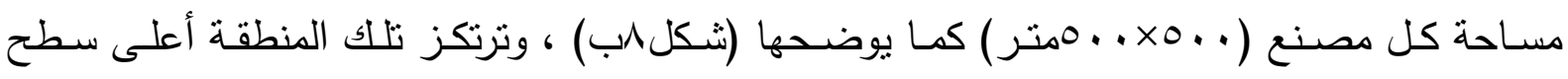

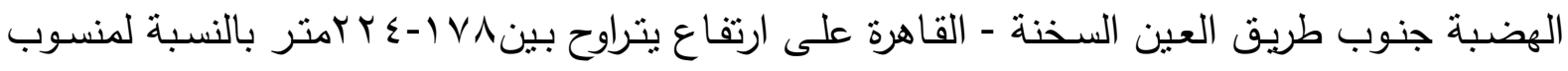

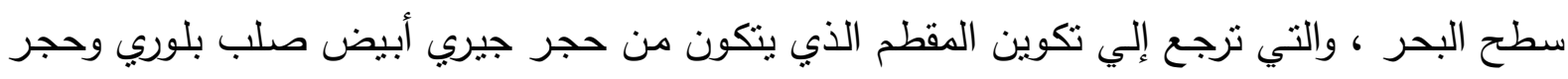

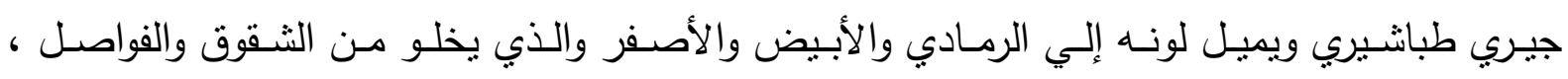
والانحدار العام لموقع المنطقة الصناعية الثانية بالنسبة لخريطة الانحدارات بمنطقة الدراسة هو الإنيض الحدار

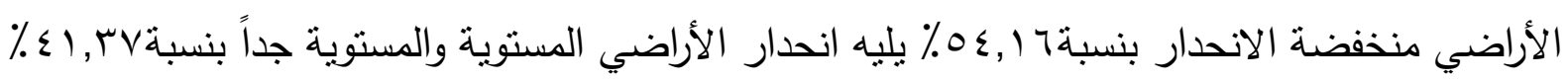

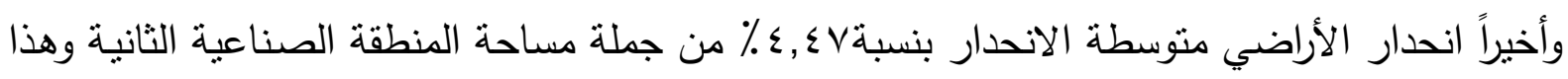

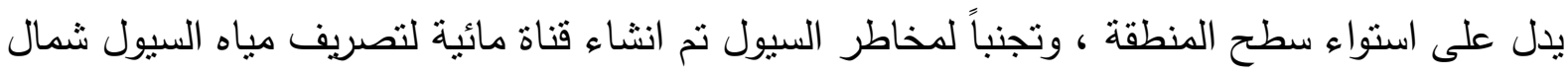

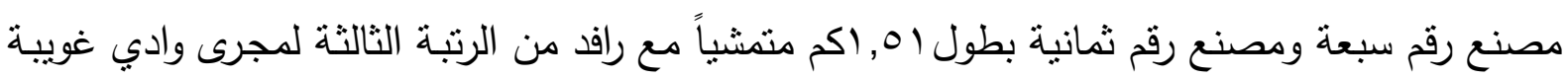

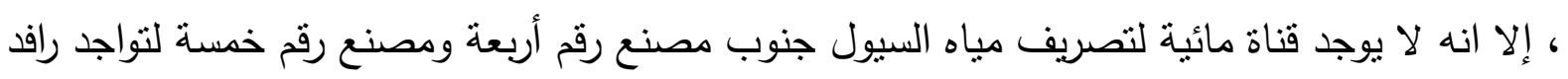

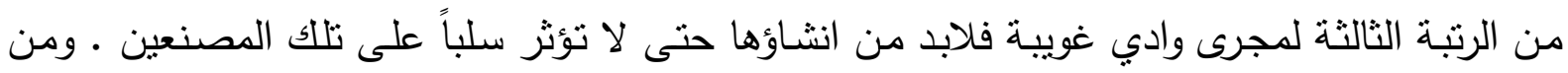

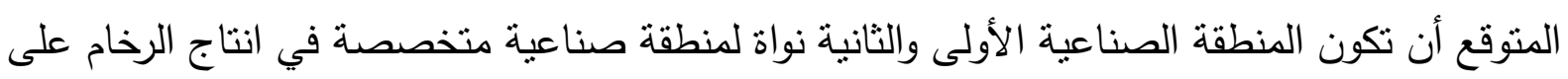

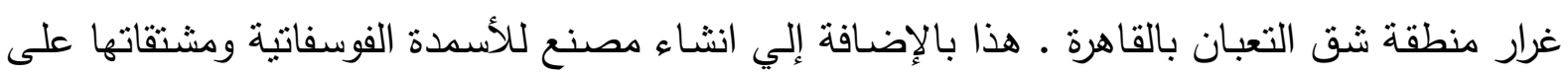

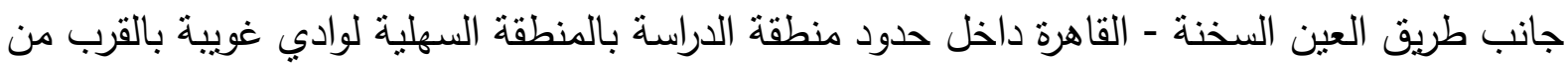
بوابة تحصيل رسوم طريق العين السخنة - القاهرة.

النتائج:

وأسـفرت الدراســة بأهيــة الاسـتفادة مـن المنطقـة فـي إقامـة المشـروعات التتمويــة وزيــادة فـرص

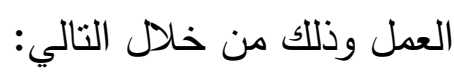

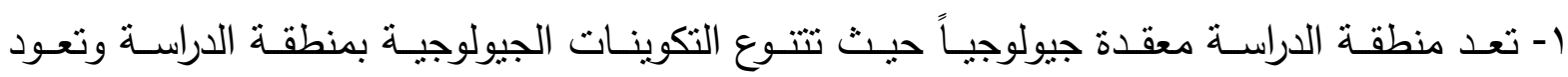

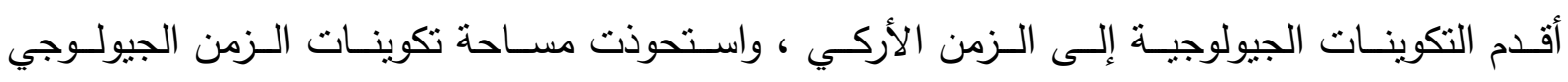

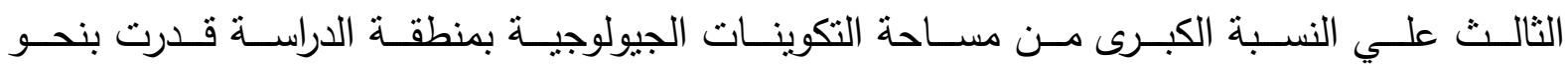

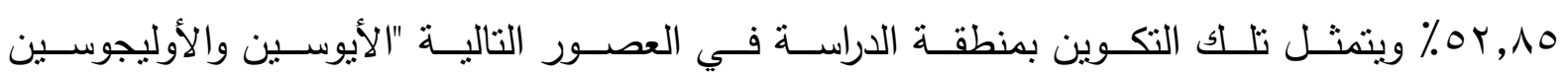

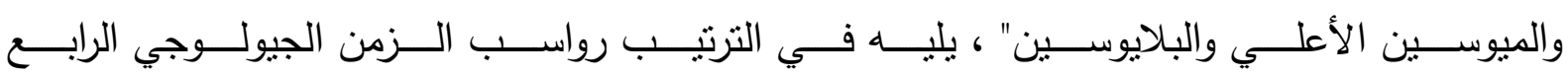

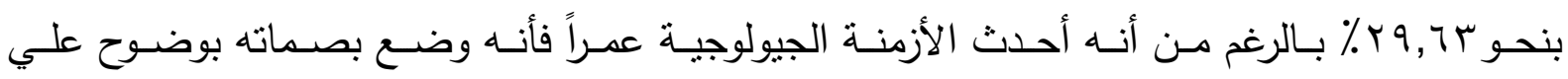

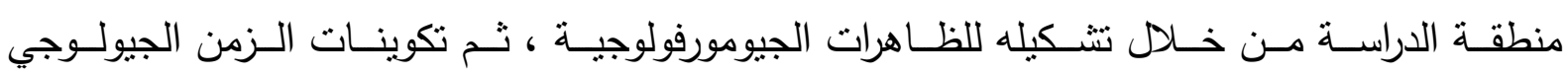

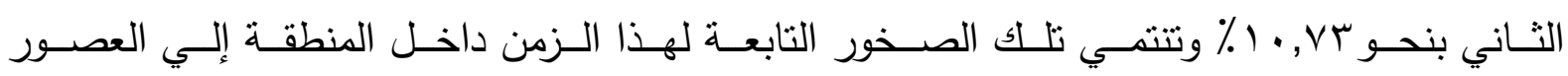

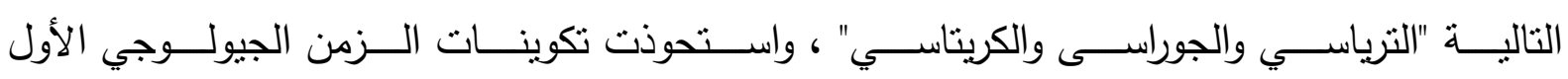

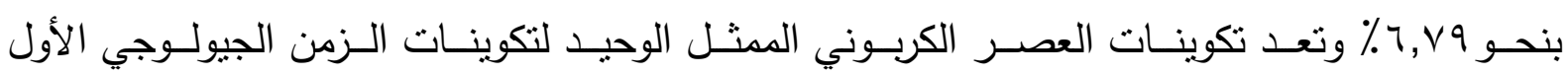
بمنطقة الدراسة. 
r- نساعد خريطة الانحدار بمنطقة الدراسة علي معرفة خصائص انحدارات سطح المنطقة ، حيث تم

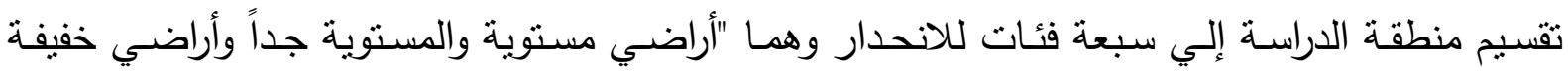

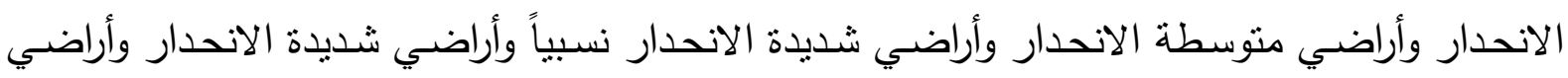

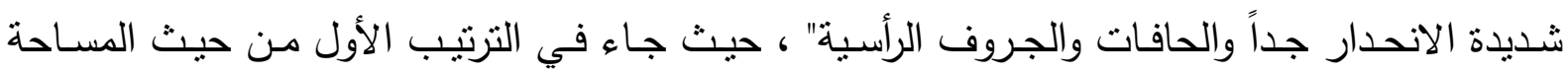

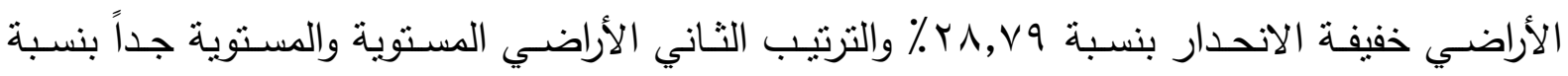

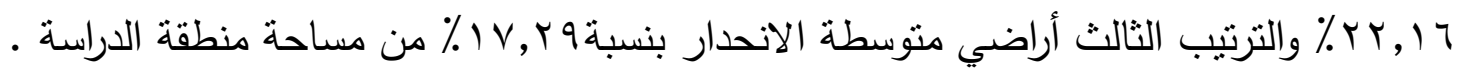

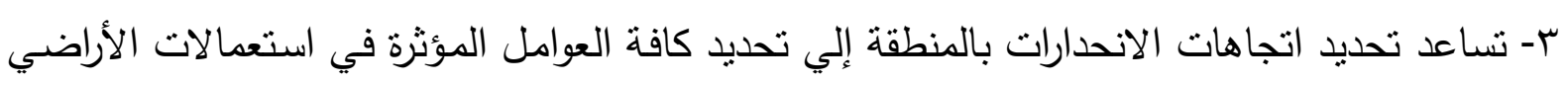

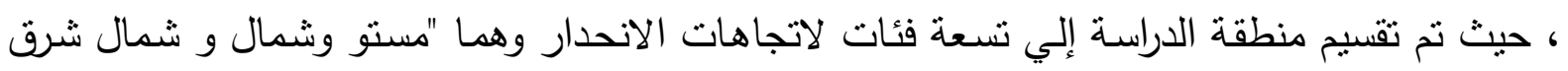
وشرق وجنوب شرق وجنوب و جنوب غرب وغرب وشمال غرب " حيث أن اتجاه الثرق هو الاتجاه

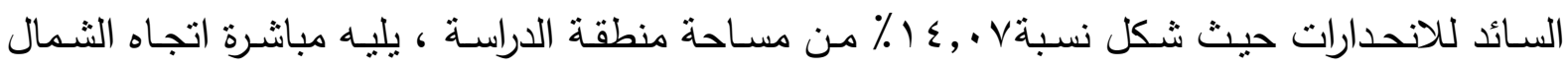

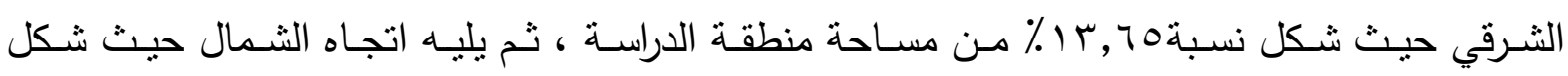

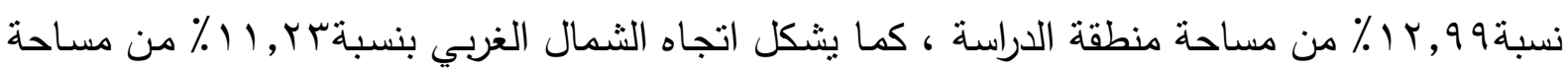

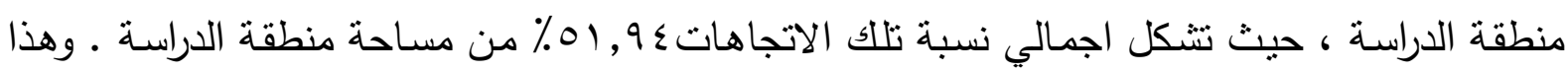
يعني أن أكثر من نصف اتجاهات الانحدارات بالمنطقة تتجه صوب الثرق والثمال الثرقي والثمال

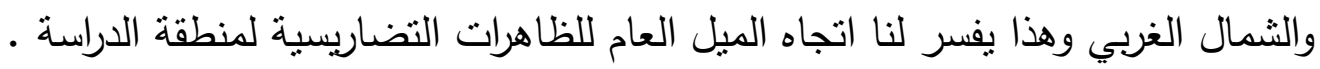

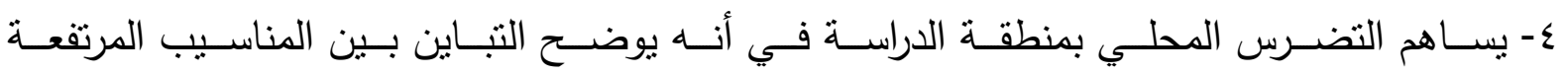

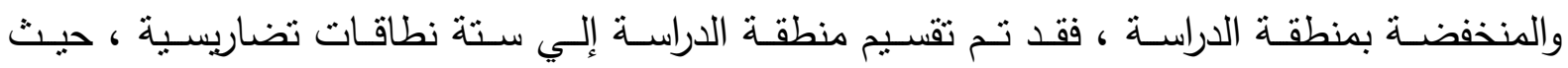

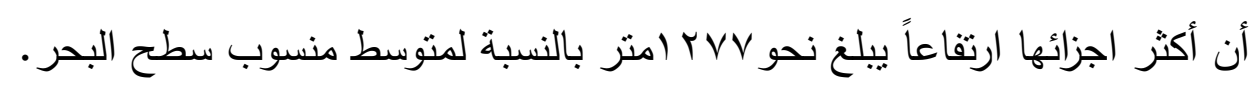

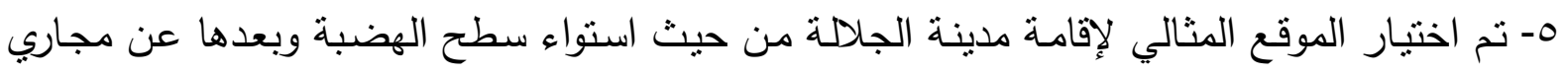
الأودية الرئيسية حيث أن الانحدار العام لموقع مدينة الجلالمة استحوذ على النسبة الكبيرة منها انحدار

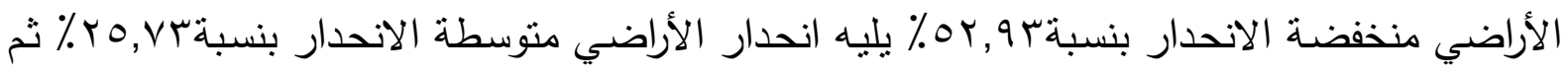

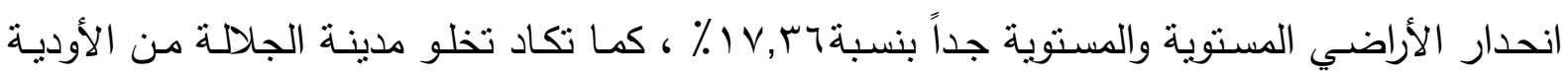

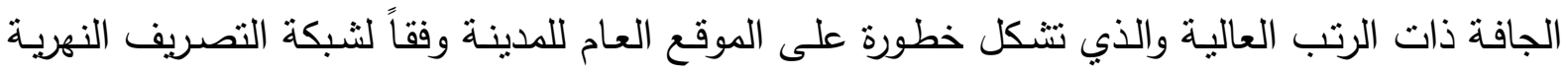

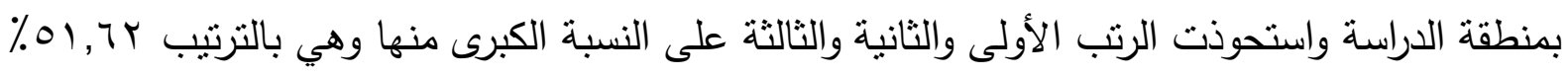

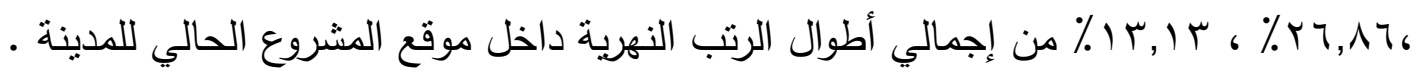

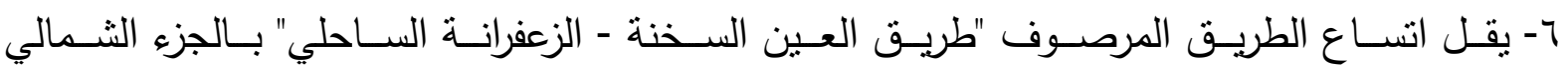

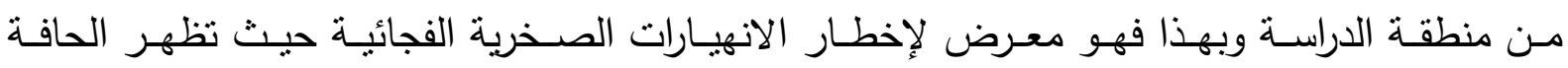

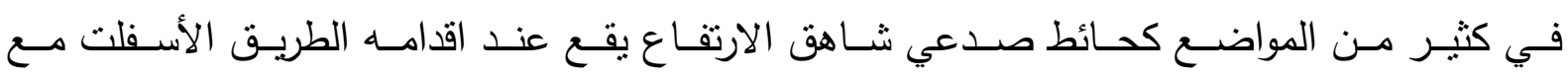
وجود التعرجات الثديدة الذي تسبب خطورة شديدة . 


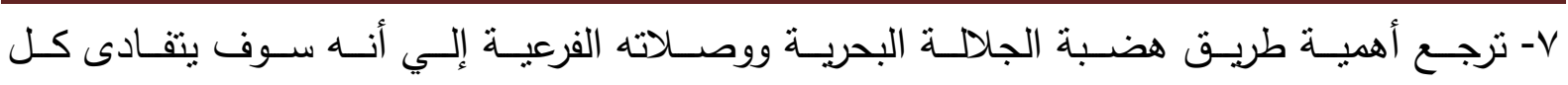

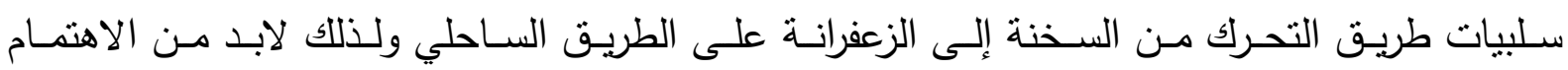

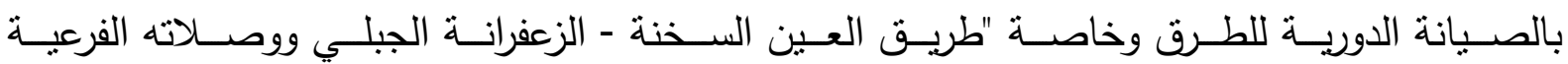

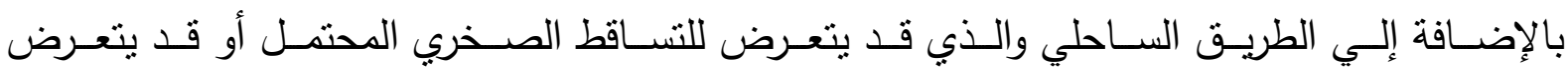

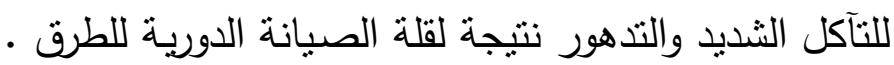

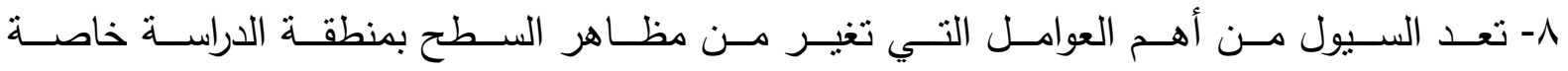

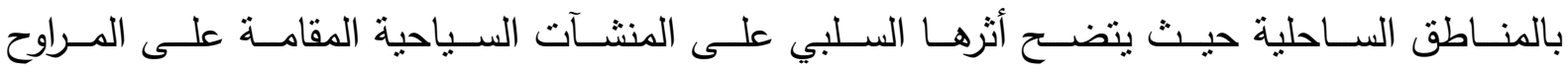

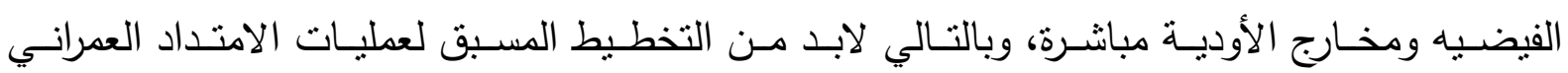
والصناعي والسكاني، وذلك لتفادى أخطار السيول بمنطقة الدراسة .

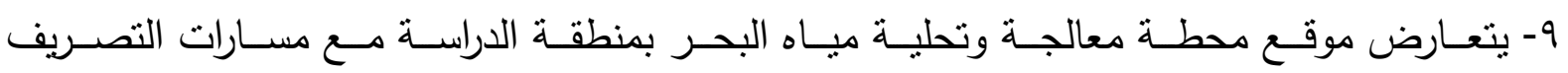

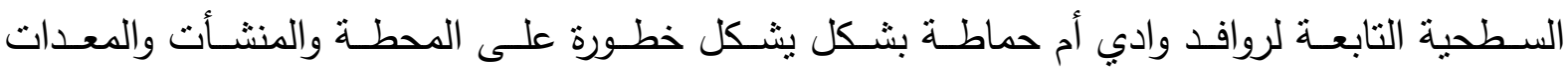
الاخلية بها في حالة التعرض لخطر السيول بنلك المنطقة .

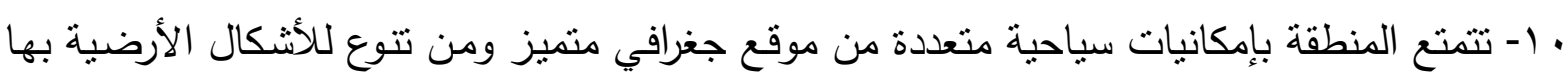

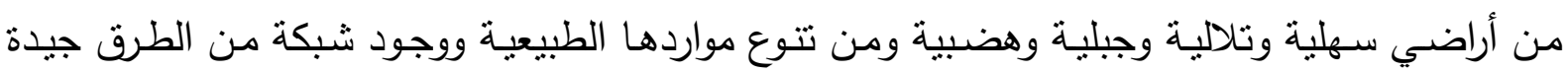

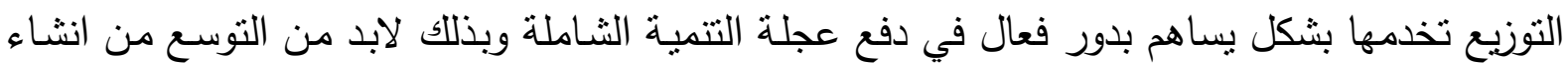

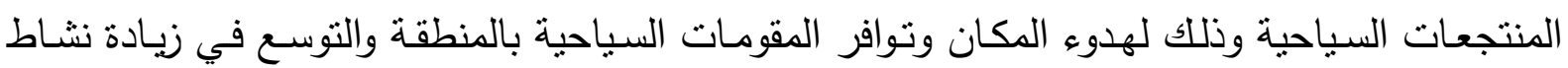
سياحة المعارض والمؤتمرات بمنطقة الدراسة خلال فترات ركود حركة السياحة . قائمة المراجع

أولاً: المراجع باللغة العربية.

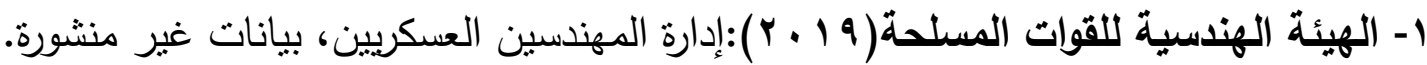

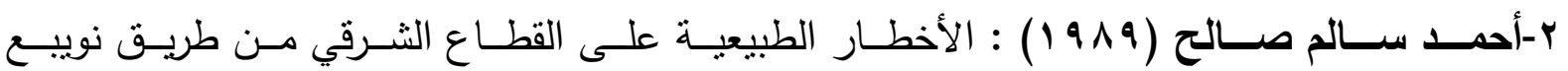

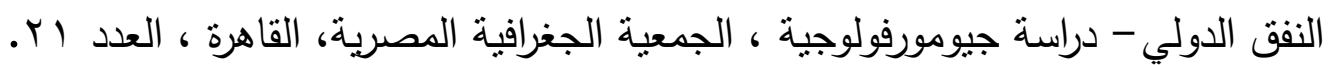

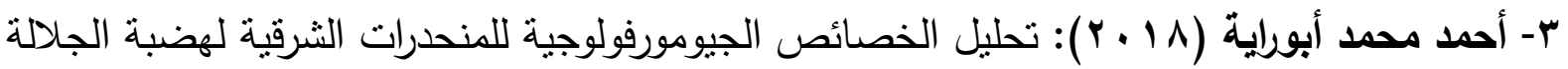

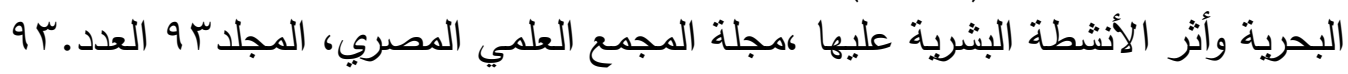

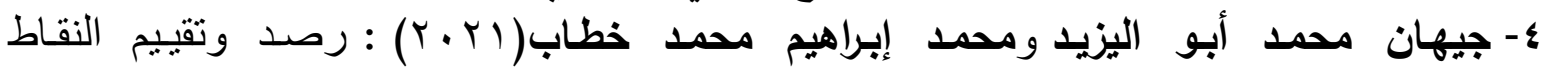

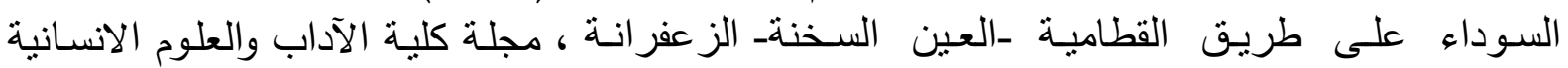

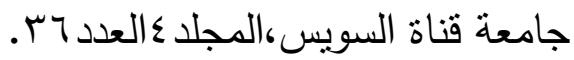

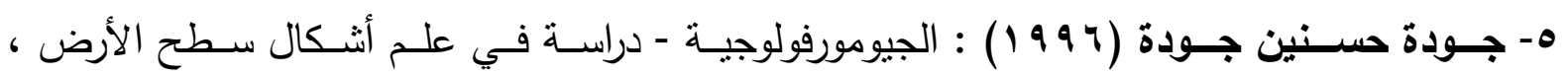

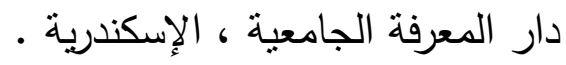

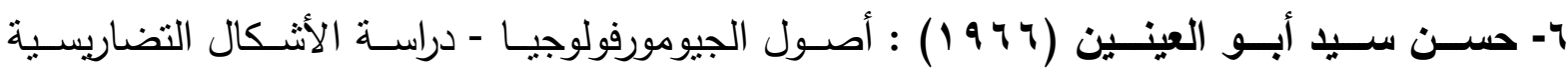
لسطح الأرض ، الطبعة العاشرة ، مؤسسة الثقافة الجامعية ، الإسكندرية. 


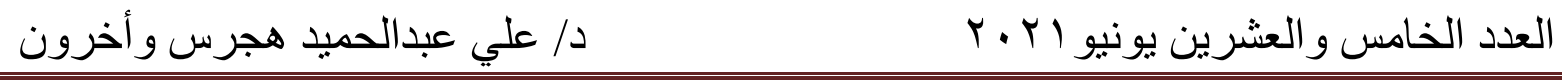

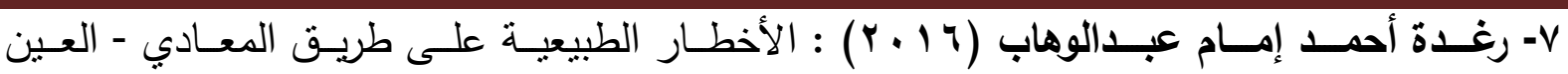

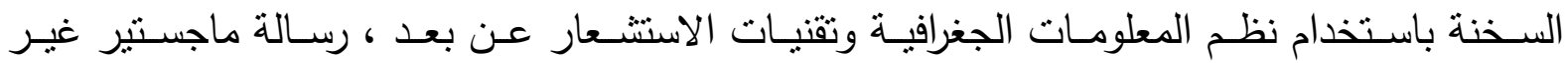

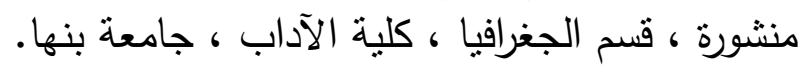

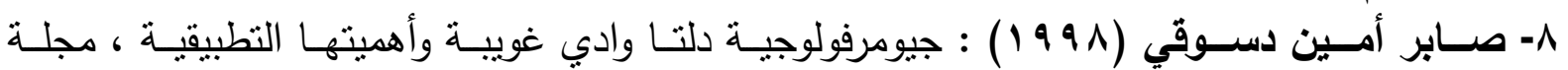

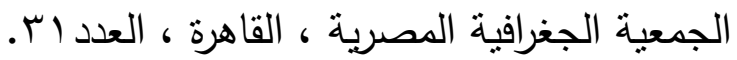

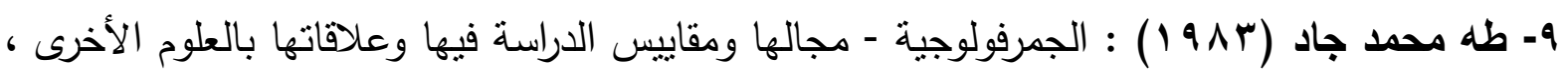

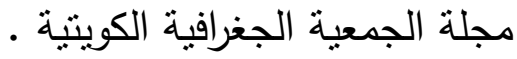

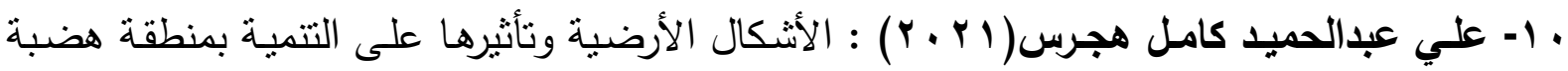

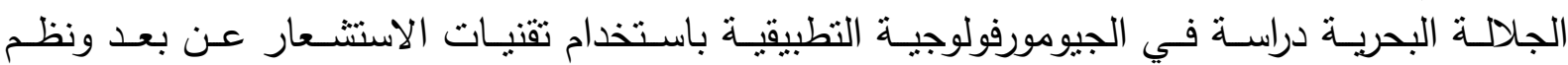
المعلومات الجغرافية ، رسالة دكتوراه غير منشورة ، كلية الآداب ، جامعة الإسكندرية الإنية.

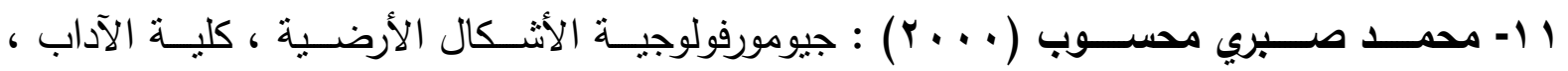

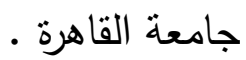

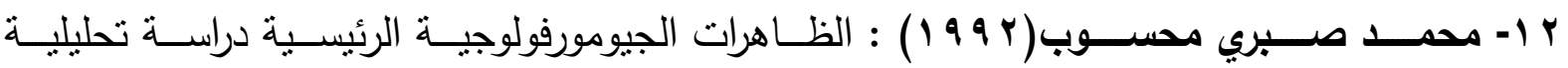

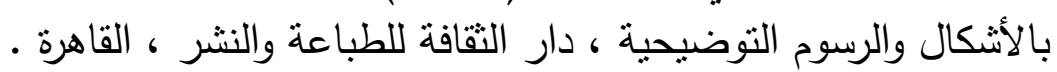

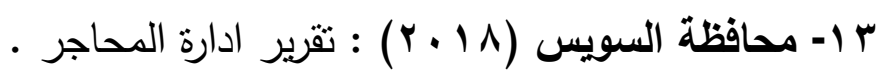

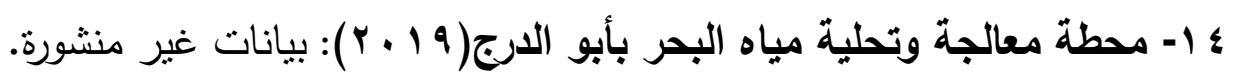
ثانياً: المراجع باللفة غير العربية.

10 Abdallah, A., and EI Adindany, A.,(1963): Stratigraphy of Upper Paleozoic Rocks, Western Side of Gulf of suez, Geol Survey, Egypt.

2- Abdallah A.M.A., (1993) : Structure Geology of the area between El Galala El Baharya and Gable Okheider, Ph.D. Faculty of Science , Ain Shams University

3LEI Nakkady, S.E., (1958): Stratigraphy and Petroleum Geology of Egypt , University of Assuit, Monography, Series, No.1.

4पEL $\square$ Rakaiby M.,(1980): Photo geological interpretation and Radio Activity of the Environs of Northern and southern Galala ,Eastern desert, Egypt , for Ph.D., Faculty of science, Mansoura University.

5 Leet, D. and Judson, S.,(1965) : Physical Geology, Prentice Hall, New Jersey .

6ロ Sadek, H., (1926): The Geography and Geology of the district Between Gabel Ataqa and Northern Galala, Gulf of Suez, Egypt, Cairo, Geol .Surv. Vol. IIV,G.S.E.

70 Said. R.,(1962) :the geology of Egypt . Elsevier ,Amsterdam and New York.

8[Shurmann, H.M.E.,(1955) :The Precambrian history of Suez Area ,Bull. Soc. Geog. Egypt.

9[Strahler ,A,N., (1957): Quantitative analysis of watershed geomorphology. Trans Am Geophys Union 38:913-920.

10[Young , A., (1972) : Slope Profile Analysis, Zeit. Fur. Geomorph. Vol. 7. 